UNIVERSIDADE DE SÃO PAULO

FACULDADE DE ODONTOLOGIA DE RIBEIRÃO PRETO

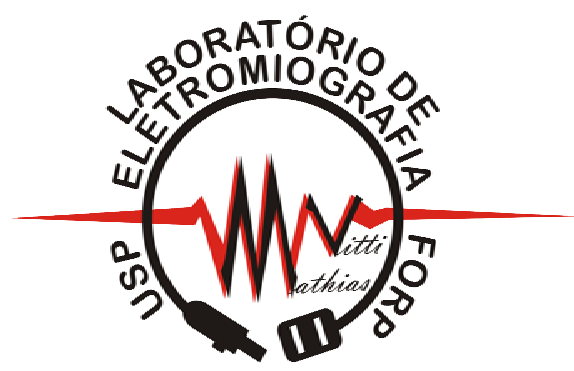

ANÁlise Eletromiográfica dos MúsCulos MASSETer e

TEMPORAL, ForÇA de MoRdida E EFICIÊNCIA MASTIGATÓRIA EM

INDIVÍDUOS COM ESQUIZOFRENIA E COM TRANSTORNOS DO

Humor, Medicados, Comparados com Indivíduos Sadios e NÃO MEDICADOS

RI CHARD HONORATO DE OLI VEI RA 


\section{ANÁliSe ElETROMiOgráFICA dos MúsCulos MASSETER E \\ TEMPORAL, ForÇA DE MordidA E EFICIÊNCIA MASTIGATÓRIA EM \\ INDIVÍDUOS COM ESQUIZOFRENIA E COM TRANSTORNOS DO}

Humor, Medicados, Comparados com Indivíduos Sadios E

NÃo Medicados

Dissertação de Mestrado apresentada à Faculdade de Odontologia de Ribeirão Preto da Universidade de São Paulo, como parte dos requisitos para obtenção do grau de Mestre em Biologia Oral.

Orientadora: Profa. Dra. Simone Cecilio Hallak Regalo 
Fi cha Catalográfica

Oliveira, Richard Honorato de

Análise eletromiográfica dos músculos masseter e temporal, força de mordida e eficiência mastigatória em indivíduos com esquizofrenia, e com transtornos do humor, medicados, comparados com indivíduos sadios e não medicados. Ribeirão Preto, 2010.

113 p.; $30 \mathrm{~cm}$

Dissertação de mestrado, apresentada à Faculdade de Odontologia de Ribeirão Preto/USP - Área de concentração: Biologia Oral.

Orientadora: Regalo, Simone Cecilio Hallak.

1. Eletromiografia. 2. Esquizofrenia. 3. Transtornos do humor. 4. Músculos masseter e temporal. 
Richard Honorato de Oliveira

Análise eletromiográfica dos músculos masseter e temporal, força de mordida e eficiência mastigatória em indivíduos com esquizofrenia e com transtornos do humor, medicados, comparados com indivíduos sadios e não medicados.

A comissão julgadora dos trabalhos de defesa da dissertação de Mestrado, Faculdade de Odontologia de Ribeirão Preto (USP) - área de concentração Biologia Oral, em sessão pública realizada a ................./2010 considerou 0 candidato.

\section{BANCA EXAMI NADORA}

1. Prof. Dr. Instituição:

Julgamento: Assinatura:

2. Prof. Dr. Instituição:

Julgamento: Assinatura:

3. Prof. Dr. Instituição:

Julgamento: Assinatura: 
'Todos os ateus que passaram por este mundo amaram a liberdade de pensar e de expressar suas ideias, inclusive a de que Deus não existe. Se essas ideias estivessem corretas, com a morte eles perderiam o que mais amavam - a liberdade de pensar - , pois sua memória seria destruída e não haveria Deus para resgatá-la."

“Ora, sem fé é impossível agradar a Deus; porque é necessário que aquele que se aproxima de Deus creia que ele existe, e que é galardoador dos que o buscam." 


\section{DEDI CATÓRI A}

\section{Ao meu pai Levi Honorato de Oliveira}

Uma vez, disse ao meu pai que ele era meu exemplo de homem íntegro, estudioso, trabalhador e observador da Palavra de Deus e ele me respondeu: "tenha Jesus como seu exemplo". Suas palavras sábias, sejam em momentos de júbilo ou, difíceis, me enchem de orgulho e gratidão a Deus por ter o privilégio de chamá-lo de meu amado

Papai!

\section{À minha mãe Eunice das Graças Oliveira}

Mulher forte, honesta, trabalhadora, criativa, amorosa, gentil, cheia de energia e cuja vida pertence a Deus. É capaz de dar a própria vida pelos filhos. Sabe exatamente o que significa viver, suas tristezas e alegrias. E o melhor, que vale a pena viver e ter o amor de uma família! Meus olhos se enchem de lágrimas, de emoção, em tê-la como minha amada mãezinha, te amo Mamãe!

\section{Ao meu irmão Davis Honorato de Oliveira}

Jovem que desde muito cedo mostrava ser um garoto especial, dotado de muita inteligência. Além de dedicar este trabalho a você gostaria que soubesse o quanto o amo. Sua existência me mostra que tenho mais que um companheiro pra trilhar essa oportunidade única que temos, que é a vida! 


\section{AGRADECI MENTOS ESPECIAIS}

A Deus, por tudo que sou e que tenho pois, nada ocorre sem a permissão dEle!

À Profa. Dra. Simone Cecilio Hallak Regalo, minha querida orientadora, que sempre me recebeu com um sorriso no rosto. Sempre me encorajou e, me confiou desafios. Obrigado por acreditar e confiar em mim!

Ao Prof. Dr. Jaime Eduardo Cecílio Hallak, pela amizade e por abrir as portas da ala psiquiátrica para que este estudo científico fosse realizado.

Ao amigo e mestre Luiz Gustavo de Souza (Gustavo), pelo companheirismo em cada exame realizado. Por me ensinar a dissecar peças anatômicas e por dissecarmos juntos as alegrias e as mazelas humanas dentro e fora do hospital.

À Profa. Dra. Marisa Semprini, minha co-orientadora que, me privilegiou com sua amizade e oportunidades, como a construção do Museu Virtual da FORPUSP. Seu dinamismo e alto-astral são dignos não só de uma pesquisadora, mas também de uma pessoa admirável onde se convergem conhecimento e simpatia.

À Profa. Dra. Selma Siéssere, minha amiga que sempre torceu pelo meu sucesso, me apoiou em minha carreira universitária, me permitiu ajudar em suas pesquisas e apresentar trabalhos. Juntamente, com o Gustavo e o Daniel me acolheram como família nesta magnífica cidade.

Ao Prof. Dr. Mathias Vitti, pelo privilégio em conhecê-lo, por fazer parte de sua equipe e pela satisfação em fazer a logomarca do laboratório de eletromiografia que leva seu nome. 


\section{AGRADECI MENTOS}

Ao meu colega de mestrado Fernando José Dias, pela amizade e companheirismo. Por ter me ajudado tantas vezes a me orientar no enorme campus da USP de Ribeirão Preto.

Ao meu colega de mestrado Marcelo Palinkas, pela amizade e por ter me ajudado em vários momentos, seja em avisos ou, participações em congressos. Seja por compartilhar comigo as alegrias e obstáculos da vida.

À minha colega de mestrado Flávia Argentato Cecilio, pela amizade e, por alegrarmos e sofrermos juntos. Valeu à pena!

Ao meu colega de mestrado Paulo Batista de Vasconcelos, pela amizade, pelas longas conversas e, pelas guloseimas e receitas mineiras.

À Clélia Aparecida Celino pela amizade, paciência e simpatia. Por sempre me ajudar com um largo sorriso no rosto.

A todos os professores do meu curso de mestrado que adicionaram um pouco mais de conhecimento à minha vida.

Aos meus colegas da Reabilitação Oral e de outros cursos que participaram de várias aulas comigo.

Às secretárias Isabel Cristina Galino Sola, Regiane Cristina Moi Sacilotto e Regiane de Cássia Tirado Damasceno pela amizade e ótimo atendimendo sempre.

À J uliana Alves Peres pelo carinho e apoio no início de meu mestrado.

Ao Prof. Dr. César Bataglion e família pela amizade sincera e pelas oportunidades de crescimento como pessoa e na carreira universitária. 
Aos colegas e professores - César Bataglion, Takami Hirono Hotta, Elaine Angélica de Souza Coronatto, Maria Cristina Candelas Zuccolotto, Ângela Bataglion e Ana Cláudia Silveira - do Curso de Oclusão, Disfunção Temporomandibular e Dor Orofacial em Pacientes com Necessidades Especiais da USP.

Aos colegas e professores, Profa. Solange Aparecida Nogueira Bataglion e Prof. Dr. Ademar Menezes Júnior, dos Cursos de Acupuntura e Fitoterapia respectivamente $(A P C D)$ e, do curso de Fotografia da USP em nome do querido Prof. Carlos de Araújo Arantes.

À Odinê Maria Rego Bechara pela amizade e troca de conhecimentos, seja na acupuntura ou em outros cursos.

À Ira Cristina Uekama, jovem repleta de alegria e bom humor, pela amizade verdadeira, pelo apoio não só nos momentos de alegria, mas também nas dificuldades.

Aos colegas da organização dos I, II e III Cursos de Verão em Odontologia da FORP e aos professores engajados.

Aos funcionários (limpeza, técnicos e biotério) pelo acolhimento e boa amizade, em especial à Elizabete Camilo Pereira ("Bete") pelo sorriso espontâneo e por sempre me acudir ao abrir a porta do laboratório quando eu esquecia minha chave. E, ao técnico do Laboratório de Anatomia Túlio Roberto Vasconcelos de Paula Lopes pela amizade.

Ao Sandoval Mateus da Silva, Maria Amélia Sallum, Bruno e Fernanda Sallum, família amada, adotada de coração, a qual está ao meu lado tanto nos momentos de alegria quanto nos difíceis. 
À USP e a FORP, pela magnífica infra-estrutura física e intelectual que me permitiu aperfeiçoar vários aspectos de minha vida acadêmica e pessoal.

À FAPESP, pela bolsa Mestrado e pelo auxílio financeiro, imprescindível para execução deste projeto. 


\section{ÍNDICE}

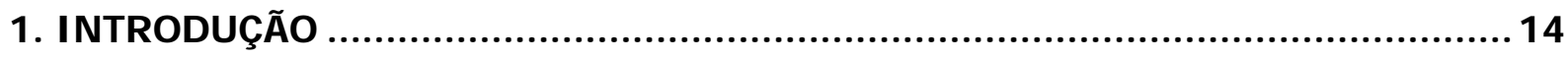

2. REVI SÃO DA LITERATURA............................................................................. 19

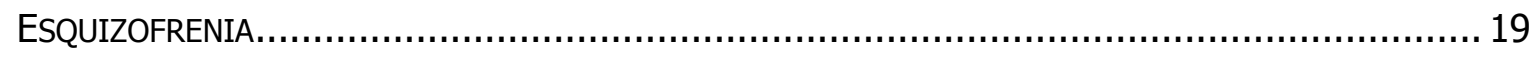

TRANSTORNOS DO HUMOR ........................................................................ 27

Farmacoterapia para o transtorno depressivo maior .......................................... 30

Farmacoterapia para o transtorno bipolar I .............................................. 33

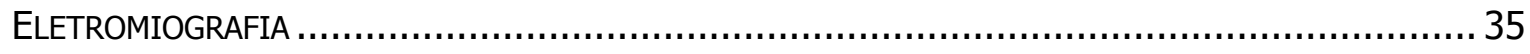

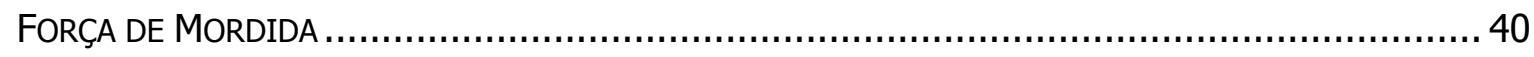

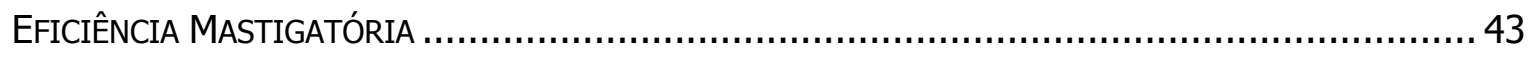

3. PROPOSI ÇÃO............................................................................................ 52

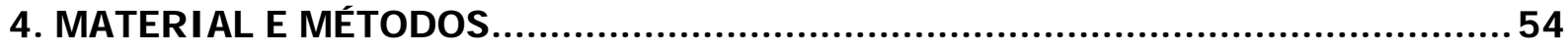

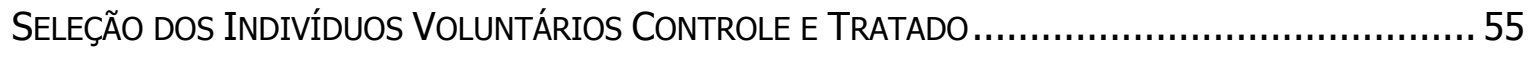

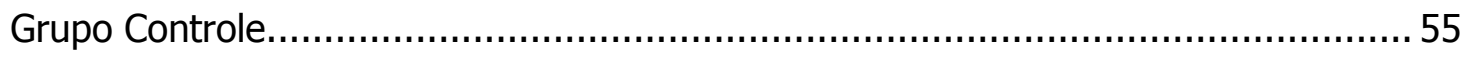

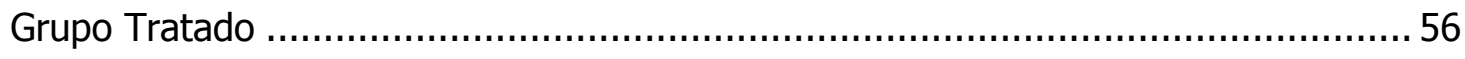

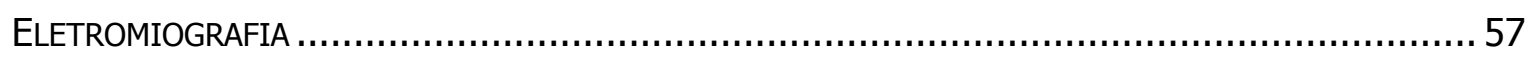

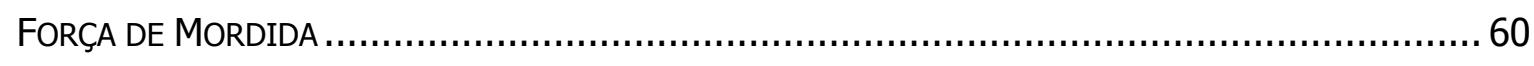

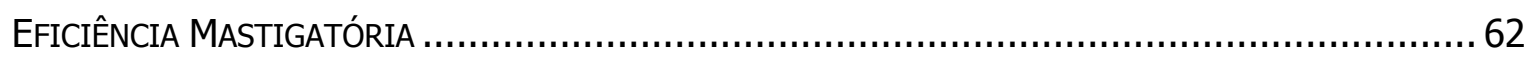

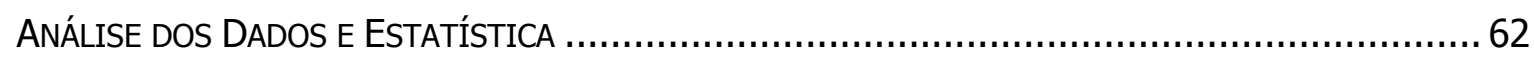

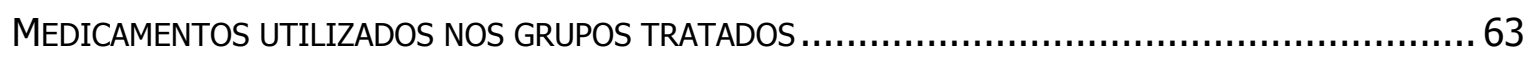

5. RESULTADOS

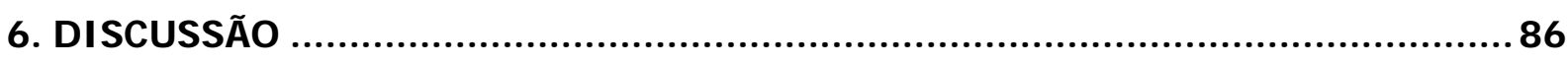

7. CONCLUSÕES........................................................................................... 97

REFERÊNCI AS BI BLI OGRÁFI CAS ..................................................................99 


\section{RESUMO}

OLIVEIRA, R. H. Análise eletromiográfica dos músculos masseter e temporal, força de mordida e eficiência mastigatória em indivíduos com esquizofrenia e, com transtornos do humor, medicados, comparados com indivíduos sadios e não medicados. 2010. 113 f. Dissertação (Mestrado) - Faculdade de Odontologia de Ribeirão Preto, Universidade de São Paulo, Ribeirão Preto, 2010.

$\mathrm{Na}$ literatura encontramos trabalhos que revelam que em indivíduos tratados com antipsicóticos e antidepressivos há um aumento de cáries, gengivite, periodontite e estomatites. No entanto, além dessas propriedades anticolinérgicas, sabidamente as drogas antipsicóticas e, em menor intensidade, as drogas antidepressivas provocam ações no sistema muscular como um todo. O uso de drogas antipsicóticas é reconhecidamente associado com efeitos colaterais motores agudos e crônicos, como parkinsonismo, acatisia e discinesia tardia. Medicações antidepressivas, tanto as clássicas tricíclicas, quanto as de nova geração, como os inibidores seletivos de recapitulação de serotonina têm sido apontadas como causadoras de efeitos musculares colaterais semelhantes aos antipsicóticos. Tendo em vista o exposto, o objetivo deste trabalho foi analisar eletromiograficamente os músculos masseter e temporal, a força de mordida e a eficiência mastigatória em indivíduos tratados com antipsicóticos e antidepressivos, mais precisamente, pacientes com esquizofrenia e transtornos do humor, e comparar com o grupo controle, dada a importância destas funções dentro das ações do sistema estomatognático.

Palavras-Chave: Eletromiografia, esquizofrenia, transtornos do humor, músculos masseter e temporal. 


\begin{abstract}
OLIVEIRA, R. H. Electromyographic analysis of masseter and temporal muscles, bite force and masticatory efficiency in patients with schizophrenia and mood disorders with drug therapy, compared with healthy subjects and unmedicated. 2010. 113 p. Dissertation (Master) - Faculty of Dentistry of Ribeirão Preto, University of São Paulo, Ribeirão Preto, 2010.

In the literature we found studies showing that individuals treated with antipsychotics and antidepressants are an increase of caries, gingivitis, periodontitis and stomatitis. However, besides these anticholinergic properties, known antipsychotic drugs, and less intensity, antidepressant drugs cause muscle actions in the system as a whole. The use of antipsychotic drugs is known to be associated with side effects engines acute and chronic conditions such as parkinsonism, akathisia and tardive dyskinesia. Antidepressant medications, tricyclic both classical, as the new generation, such as selective inhibitors of recapitulation of serotonin have been identified as causing muscle side effects similar to antipsychotics. Given the above, the objective was to analyze the electromyographically masseter and temporal muscles, bite force and masticatory efficiency in patients treated with antipsychotics and antidepressants, specifically, patients with esquizofrina and mood disorders, and compare with the group control, given the importance of these functions within the actions of the stomatognathic system.
\end{abstract}

Keywords: Electromyography, schizophrenia, mood disorders, masseter and temporal muscles. 
“... a maior vingança contra um inimigo é perdoá-lo. Se compreendê-lo, você o perdoa. Se o perdoa, ele morre dentro de você e renasce não mais como inimigo. Caso contrário, ele dormirá com você, roubará seu sono, comerá com você e destruirá seu apetite."

Augusto Cury em $\boldsymbol{O}$ Mestre do Amor 


\section{I NTRODUÇÃO}

É reconhecido há longo tempo que indivíduos portadores de transtornos psiquiátricos crônicos apresentam alterações no seu estado de saúde geral (Sjögren, Nordström, 2000). Estudos realizados em indivíduos portadores de esquizofrenia e depressão demonstraram que tais indivíduos apresentam deficiências em seus cuidados de higiene e manutenção do bom estado de sua saúde bucal e que tanto os transtornos psiquiátricos per si, quanto o uso crônico de medicações podem influenciar na ocorrência de alterações no sistema estomatognático (Elter et al., 2002; Thomas et al., 1996; Friedlander, Birch, 1990).

Quanto às medicações, têm sido descrito que o fato de provocarem xerostomia, pelas suas propriedades anticolinérgicas, aumentaria em indivíduos dentados a incidência de cáries, gengivite, periodontite e estomatites (Sjögren, Nordström, 2000). No entanto, além dessas propriedades anticolinérgicas, sabidamente as drogas antipsicóticas e, em menor intensidade, as drogas antidepressivas possuem ações no sistema muscular como um todo.

O uso de drogas antipsicóticas, particularmente os antipsicóticos tradicionais, é reconhecidamente associado a efeitos colaterais motores agudos e crônicos, incluindo parkinsonismo, acatisia e discinesia tardia (Marchese et al., 2002). A discinesia tardia, por sua vez, é um efeito colateral sério, por vezes incapacitante e irreversível, caracterizado por movimentos involuntários na região bucofacial, que se desenvolve em torno de $20 \%$ dos pacientes tratados com antipsicóticos tradicionais (típicos) e, em com menor freqüência, com antipsicóticos atípicos (Marchese et al., 2002).

Em indivíduos que fazem uso de medicações antidepressivas, tanto as clássicas tricílicas, quanto às de nova geração, assim como de inibidores seletivos de recaptação de serotonina, estão sujeitos a efeitos colaterais em músculos, semelhantes aos efeitos colaterais clínicos encontrados em indivíduos que utilizam antipsicóticos (Kaplan et al., 2007a;b). 
Sabe-se que a musculatura da cabeça e pescoço é de fundamental importância para o desempenho das atividades do homem relacionadas à mastigação, deglutição, assim como da própria fala. A eletromiografia (EMG) tem sido utilizada como método importante nas pesquisas clínicas de várias especialidades contribuindo para elucidar o desempenho desta musculatura e, assim constituindo-se em um importante instrumento para a investigação das bases fisiopatológicas das alterações que acometem a musculatura do aparelho estomatognático.

A eletromiografia se constitui em um dispositivo de pesquisa empregada como procedimento de avaliação, envolvendo a deteç̧ão e registro dos potenciais elétricos das fibras musculares esqueléticas (Sullivan, Schmitz, 1993). Com a EMG há a possibilidade de sabermos quando e como um músculo é ativado e ainda determinar como se estabelece a coordenação de diferentes músculos envolvidos no movimento (Regalo et al., 2003).

Na psiquiatria, a EMG tem sido utilizada para avaliar alterações neuro-musculares próprias dos transtornos psiquiátricos, como na esquizofrenia; a influência de medicações em técnicas terapêuticas como a estimulação magnética transcraniana; a intensidade da resposta emocional facial em indivíduos em remissão de episódios agudos e como marcadores de resposta terapêutica e remissão de quadros depressivos.

Flyckt et al. (2000a;b) demonstraram com seu estudo maior freqüência de alterações neuro-musculares e psicomotoras aferidas com EMG na musculatura tibial e biópsia muscular em indivíduos portadores de esquizofrenia, bem como em parentes em primeiro grau dos mesmos, quando comparados com indivíduos normais.

Davey et al. (1997) apontaram que as respostas motoras à estimulação magnética transcraniana poderão ser utilizadas como marcadores de resposta às medicações antidopaminérgicas, como os antipsicóticos.

Mattes et al. (1995) descreveram que indivíduos portadores de esquizofrenia apresentaram resposta emocional inapropriada durante interação social e que esta resposta pôde ser aferida por meio de EMG. Os resultados desta pesquisa revelaram redução da 
atividade EMG no músculo zigomático durante a apresentação de uma entrevista e de um vídeo que, por sua vez, deveriam promover resposta de felicidade ou sorriso, sugerindo assim diminuição na capacidade de tais indivíduos de expressarem felicidade.

Greden et al. (1984) e Carney et al. (1981) descreveram em seus trabalhos que níveis aumentados da atividade EMG nos músculos corrugador do supercílio e zigomático seriam preditivos de uma melhor resposta terapêutica quando da introdução da terapia apropriada. Além disso, a EMG tem sido utilizada tanto em modelos animais, quanto em humanos, para a avaliação da rigidez muscular provocada por drogas antipsicóticas e antidopaminérgicas (Crocker, Hemsley, 2001; Hemsley, Crocker, 1999; Scelsa et al., 1996; Cunningham et al., 1996, Lorenc-Koci et al., 2003).

Estudos relacionando atividade EMG, medicações psicotrópicas e alterações odontológicas realizado por Micheli et al. (1993) revelam que em oito casos analisados os indivíduos apresentavam bruxismo diurno desencadeado por medicações antidopaminérgicas tendo em vista que tais indivíduos não apresentavam outras possíveis causas odontológicas. Nesses oito casos foram identificados dois padrões distintos de contrações musculares: um com contrações forçadas rítmicas e breves e outro com contrações prolongadas sustentadas. Tais contrações eram ausentes durante o sono e não apresentavam remissão na vigência de tratamento sintomático. Dois outros estudos realizados por Raigrodski et al. (2001) e Mohamed et al. (1997) avaliaram a eficácia de uma droga antidepressiva (amitriptilina) no tratamento do bruxismo do sono (atividade massetérica noturna) e concluíram que não existiam evidências suficientes que dêem suporte para se indicar o uso de tal medicamento no tratamento dessa patologia. Mohamed et al. (1997) apontam ainda que a amitriptilina provocava de maneira imprevisível tanto a diminuição, quanto o aumento das contrações musculares massetéricas.

Pesquisas atuais se preocupam em determinar a força de mordida dos seres humanos saudáveis e com diversas alterações, procurando avaliar e compreender a funcionalidade do sistema mastigatório (Helkimo et al., 1975; Kiliaridis, 1995; Kogawa et al, 2006; Santos CM, 
2009; Palinkas M, 2010). Outros trabalhos (Pröschel et al., 2001) relataram a importância do conhecimento da força da mastigação, a qual é essencial para a avaliação funcional da ação das cargas oclusais em restaurações, tecidos alveolares, implantes e na articulação temporomandibular. E ainda outros (Zivko-Babic et al., 2002) descreveram a força de mordida como a expressão e medida da função mastigatória. Alguns autores citam a força de mordida como a melhor medida para analisar a eficiência mastigatória de um indivíduo (Carapito, 2004).

Estudos anteriores se concentraram em determinar a força da mordida em seres humanos, na tentativa de avaliar e compreender a função do sistema mastigatório, considerando que a força da mordida é um componente da função mastigatória, a qual é exercida pelos músculos levantadores da mandíbula e, regulada pelos sistemas nervoso, muscular, esquelético e condições dentais (Piancino et al., 2005; Kogawa et al., 2006). A força oclusal máxima pode fornecer informações essenciais que poderiam ajudar em um diagnóstico apropriado a respeito da função mastigatória (Okiyama, 2003).

No entanto, trabalhos de pesquisa que possam demonstrar e justificar a ação de medicações antipsicóticas e antidepressivas sobre a musculatura dos indivíduos que a utilizam, incluindo-se nesta avaliação a mastigatória e facial, que por sua vez pode promover resultados que indiquem distúrbios severos e particularmente restritivos para a região da face e da cabeça são ausentes na literatura. Sendo assim, considerando a ausência de estudos específicos quanto ao impacto que essa ação muscular acarreta sobre a fisiologia e patologia bucal de funções relacionadas a mastigação e deglutição é que este trabalho propôs analisar esta musculatura em indivíduos com esquizofrenia e com transtornos de humor que estão medicados e estabelecer parâmetros de comparação com indivíduos sadios visando contribuir com informações novas que poderá auxiliar o cirurgião dentista a elaborar diagnósticos, estabelecer prognósticos permitindo ao indivíduo melhoria na sua qualidade de vida, principalmente com relação aos efeitos colaterais da medicação na atuação do sistema estomatognático. 
2. REVI SÃo dA LITERATURA 


\section{REVI SÃO DA LITERATURA}

\section{ESQUI ZOFRENI A}

Benedict Morel (1809-1873), psiquiatra francês, usou o termo démence précoce para definir indivíduos deteriorados mentalmente onde a doença havia se iniciado na adolescência. Emil Kraepelin (1893) traduziu a démence precoce definida por Morel como dementia precox, termo que enfatiza o processo cognitivo distinto (dementia) e o início precoce (precox) do transtorno psiquiátrico. Em (1924) Eugen Bleuler criou o termo esquizofrenia, em substituição a dementia precox descrita na literatura médica e, assim, o termo foi escolhida para expressar a presença de cisões entre comportamento, emoção e pensamento e, enfatizou-se que, ao contrário do conceito de Kraepelin, a esquizofrenia não necessitava ter curso deteriorante (Stone, 1999). Com esta definição distingue-se esta patologia de outras tais como a dupla personalidade (Kaplan et al., 2007a). De acordo com a revisão de texto do quarto Manual Diagnóstico e Estatístico de Transtornos Mentais (DSM-IVTR/ julho de 2000) a dupla personalidade é agora denominada transtorno dissociativo de identidade, sendo caracterizada como transtorno dissociativo e, portanto, difere totalmente da esquizofrenia.

De acordo com a DSM-IV-TR, esquizofrenia é a doença mental que se caracteriza pela desorganização abrangente dos processos mentais, apresentando-se como síndrome, ou seja, sinais e sintomas que englobam os pensamentos, percepções e emoções, podendo causar vários prejuízos nas relações sociais e familiares. O indivíduo chega à situação clínica de não saber distinguir as experiências imaginárias da realidade. Ocorrem períodos de crises agudas onde os sintomas são intensos e esses são intercalados por períodos onde os sintomas são brandos. Geralmente, acomete o indivíduo no final da adolescência ou no início da idade adulta, antes dos 40 anos, com tendência ao longo dos anos que haja deterioração da personalidade do indivíduo (Cancro, Lehman, 2000; Carone et al., 1991). 
A esquizofrenia é de etiologia desconhecida, porém sugere-se que haja combinação de fatores biológicos, genéticos e ambientais que podem contribuir de diferentes maneiras no aparecimento, desenvolvimento e gravidade desta patologia (Sweeney et al., 2000; Bogerst et al., 1993; Kane, 1996; Harrison, 1995).

Os estudos de prevalência em diferentes países realizados nos últimos anos sugerem uma prevalência aproximada de esquizofrenia na ordem de $1 \%$ e as diferentes estimativas de incidência da esquizofrenia sugerem a ocorrência de aproximadamente quatro casos novos por ano para uma população de 10.000 habitantes. A incidência real deve estar entre 1 e 7 casos novos para 10.000 habitantes por ano, dependendo do critério diagnóstico adotado na estimativa. Esses dados são compatíveis aos estudos epidemiológicos realizados no Brasil (Mari, Leitão, 2000). Segundo o DSM-IV-TR, a incidência da esquizofrenia é mais alta entre pessoas nascidas em áreas urbanas de países industrializados.

Não há consistência de possíveis diferenças na prevalência da esquizofrenia entre sexos, independentemente da metodologia empregada nos diferentes levantamentos epidemiológicos, no entanto, o início da doença é mais precoce no homem do que na mulher. Entretanto, na presença de história familiar positiva para distúrbios psicóticos, a idade de início é mais precoce para homens e para mulheres (Mari, Leitão, 2000; DSM-IVTR, 2000).

Antes dos 25 anos de idade, dois terços daqueles que dão entrada num hospital psiquiátrico são homens e apenas um terço são mulheres. Os homens apresentam faixa de idade entre 10 e 25 anos como sendo idade de pico do início da doença, no entanto, as mulheres, apresentam duas faixas de pico, ou seja, entre os 25 e 35 anos e a outra ocorre na meia-idade. Noventa por cento dos indivíduos em tratamento tem entre 15 e 55 anos de idade e é extremamente raro ter o início da doença antes dos 10 anos ou após os 60 anos. Quando o início da esquizofrenia ocorre após os 45 anos de idade o transtorno é chamado de Esquizofrenia de Início Tardio (Moldin, 2000). 
Dados de estudos multicêntricos sugerem que os pacientes de países menos desenvolvidos apresentam prognóstico melhor na esquizofrenia (Mari, Leitão, 2000).

Indivíduos esquizofrênicos apresentam taxa de mortalidade mais alta que a população em geral seja por acidentes e causas naturais. O suicídio é uma das principais causas de mortalidade entre os indivíduos, podendo chegar à proporção de até quinze por cento se analisarmos todos os indivíduos que morrem por suicídio. Porém, em alguns fatores como gênero masculino, raça branca e isolamento social, a taxa de suicídio é semelhante a indivíduos em geral (Kendler, Diehl, 1993; Addington, Addington, 1992).

O custo financeiro da esquizofrenia nos Estados Unidos é estimado excedendo o de todos os cânceres juntos. Os esquizofrênicos ocupam cerca de cinqüenta por cento de todos os leitos de hospitais psiquiátricos e respondem por dezesseis por cento de toda a população psiquiátrica em tratamento (Kaplan et al., 2007a). Um único trabalho desenvolvido sobre este tema no Brasil (Leitão et al., 2006), revela que aproximadamente oitenta e dois por cento dos indivíduos esquizofrênicos no Estado de São Paulo estão sob cobertura do SUS. Destes, cerca de quatro por cento estão em internações temporárias, dois e meio por cento em internações de caráter permanente, vinte e três por cento em tratamento ambulatorial e setenta e um por cento sem tratamento regular. Assim, o custo direto total da esquizofrenia para o setor público, no Estado de São Paulo, no ano de 1998, foi de duzentos e vinte e dois milhões (quase dois e meio por cento do total de gastos em saúde do Estado).

O diagnóstico da esquizofrenia é baseado em critérios diagnósticos propostos pelo DSM-IV-TR que classifica esta patologia em cinco subtipos (Paranóide, Desorganizado, Catatônico, Indiferenciado e Residual). Dentre as características encontradas para o diagnóstico desta patologia encontramos alterações relacionadas com atividade muscular, mas nenhuma menção sobre a musculatura da mastigação especificamente.

A década de 50 é um marco na história da psicofarmacoterapia tendo em vista período quem que foi possível a síntese e a descoberta da propriedade antipsicótica da 
clorpromazina (neuroléptico ou antipsicótico), quanto à classificação destes medicamentos de acordo com a estrutura química e os efeitos clínicos; quanto a sua atividade antipsicótica; quanto à ação (prolongada ou rápida), quanto à dose única diária ("drug holidays") e eficácia terapêutica. Faz, também, recomendações sobre o emprego no primeiro episódio e no tratamento de manutenção. Os antipsicóticos trouxeram benefícios consideráveis, proporcionando remissão completa em cerca de vinte e cinco por cento dos casos, reduzindo ao máximo as internações, com possibilidade de reintegração do doente à família, à sociedade e ao trabalho. Os antipsicóticos de nova geração ainda não demonstraram capacidade de modificar essa tendência (Bechelli, 2000).

Pesquisas constataram que intervenções psicossociais, incluindo a psicoterapia, favorecem a melhoria clínica, porém os antipsicóticos constituem o principal agente no tratamento. Vale ressaltar que, grande parte dos esquizofrênicos são melhor beneficiados pela combinação de antipsicóticos com tratamentos psicossociais que qualquer um dos tratamentos isoladamente (American Psychiatric Association, 2000; Gabbard, 1994; Kurumaji, Okubo, 2000; Kane, 1996).

Os fármacos antipsicóticos, lançados no início da década de 1950, revolucionaram o tratamento da esquizofrenia, já que o número de indivíduos com recaídas tratadas com placebo é de duas a quatro vezes maior se comparado ao número tratados com antipsicóticos. Porém, esses fármacos não curam a esquizofrenia, apenas tratam seus sintomas (American Psychiatric Association, 2000).

Os antipsicóticos podem ser divididos em duas classes principais: os antagonistas do receptor de dopamina (p.ex.: clorpromazina e haloperidol) e os antagonistas da serotoninadopamina (p.ex.: risperidona e clozapina).

São ditos antipsicóticos-padrão e são eficazes no tratamento dos sintomas positivos da esquizofrenia (p.ex.: delírios), porém, possuem duas deficiências relevantes: poucos indivíduos têm seu funcionamento mental razoavelmente normalizado; geram muitos efeitos 
adversos graves e incômodos como a acatisia, sintomas semelhantes aos do parkinsonismo, como rigidez e tremor, discinesia tardia e síndrome neuroléptica maligna (Kapur; Remington, 1996).

São denominados antipsicóticos atípicos e, em relação aos antipsicóticos-padrão interagem com subtipos diferentes de receptores da dopamina e afetam receptores serotonérgicos e glutamatérgicos. Produzem menos efeitos adversos neurológicos e endócrinos além de serem eficazes no tratamento de sintomas negativos da esquizofrenia (p.ex.: retraimento) e, dos positivos. Causam, também, poucos sintomas extrapiramidais. Tornaram-se a primeira escolha no tratamento da esquizofrenia e fazem parte desses fármacos a clozapina, a risperidona, a olanzapina, o sertindol, a quetiapina e a ziprasidona (Kinon; Lieberman, 1996; Kurumaji; Okubo, 2000; George et al., 2002; Gaertner et al., 2001; Goff et al., 1992; Limpert; Amador, 2001; Prikhojan; Davis, 2001).

Clozapina: é o mais útil para indivíduos refratários e para aqueles com discinesia tardia. Tem pouca atividade antagonista do receptor $D_{2}$ e parece reduzir os sintomas da discinesia tardia sem piorar a condição. Seu uso deve ser com cautela, pois pode gerar fortes efeitos adversos como a agranulocitose potencialmente fatal em 1 a $2 \%$ dos indivíduos, requerendo um monitoramento semanal da contagem de neutrófilos. Apresenta alto risco de convulsões e efeitos anticolinérgicos significativos.

Risperidona: possui efeitos adversos leves e em doses habituais não está associada a sintomas extrapiramidais. Causa menos sedação e efeitos anticolinérgicos que os antagonistas do receptor de dopamina. São indicados para indivíduos com doença leve a moderada no seu primeiro episódio ou para aqueles com doença grave e refratária ao tratamento.

Olanzapina: possui efeitos adversos leves e diferentes da risperidona. Causa menos efeitos extrapiramidais, porém a probabilidade de causar sedação, ganho de peso, hipotensão ortostática e constipação é maior. 
Sertindol: além dos seus efeitos adversos serem leves, são em sua maioria transitórios. Pode causar hipotensão ortostática se não titulado lentamente, taquicardia sinusal, congestão nasal e diminuição do volume ejaculatório. Além de não causar sintomas anticolinérgicos causa pouco ganho de peso. É ideal para indivíduos com baixa adesão, pois sua meia-vida é de três dias.

Quetiapina: não aumenta o risco de sintomas extrapiramidais e pode causar sedação, taquicardia, ganho de peso e agitação. Deve ser titulado lentamente pra evitar hipotensão ortostática e síncope.

Ziprasidona: possui benefícios adicionais para indivíduos com sintomas afetivos, pois bloqueia a recaptação da serotonina e da noradrenalina, e para indivíduos com ansiedade já que é antagonista para receptores $5-\mathrm{HT}_{1 \mathrm{~A}}$. Apesar de não causar ganho de peso pode produzir sedação, náusea e tontura.

De acordo com Kaplan et al., 2007a, o uso de medicamentos antipsicóticos deve seguir cinco princípios no tratamento dos sintomas da esquizofrenia: definir os sintomasalvo; um antipsicótico que funcionou no passado deve ser usado novamente; quando uma reação inicial negativa grave (sentimento subjetivo negativo peculiar, excesso de sedação ou reação distônica aguda) é observada, os clínicos devem levar em consideração a troca por outro agente em menos de quatro semanas; deve-se evitar o uso de mais de um medicamento antipsicótico ao mesmo tempo, porém, a combinação com outros agentes pode ser indicada; deve-se manter, após o episódio psicótico, uma dosagem efetiva o mais baixa possível do antipsicótico.

Outros medicamentos podem ser utilizados e os adjuvantes mais utilizados são o lítio, anticonvulsivantes (p.ex.: carbamazepina e valproato) e os benzodiazepínicos.

Lítio: em associação a um antipsicótico pode reduzir em até $50 \%$ dos indivíduos os sintomas psicóticos. É empregado, também, em indivíduos que não podem tomar nenhum antipsicótico e é benéfico naqueles indivíduos com oscilações de humor. 
Anticonvulsivantes: geralmente a carbamazepina ou o valproato são utilizados em combinação com o lítio ou, um antipsicótico. Além dos efeitos anticonvulsivantes, sugere-se que podem reduzir episódios de violência em alguns indivíduos. Agem sobre enzimas hepáticas o que diminui os níveis sangüíneos dos antipsicóticos.

Benzodiazepínicos: são empregados em pacientes que não respondem bem ao uso exclusivo de antipsicóticos. Possuem efeitos depressores sobre o sistema nervoso central. São utilizados no tratamento da ansiedade, insônia, convulsões e espasmos musculares. Como exemplos têm-se o alprazolam, o diazepam e o lorazepam. Altas dosagens de diazepam podem produzir efeitos benéficos em pacientes esquizofrênicos. O lorazepam é preferível ao diazepam por ter menos potencial de abuso e por ter ação mais curta. Observase também, que a gravidade da psicose pode ser exarcebada com a retirada do benzodiazepínico. O diazepam pode provocar sonolência, ataxia, vertigem, tremores, perda de equilibrio, perda de peso, esquecimento de fatos recentes e coordenação anormal; O lorazepam, sonolência, ataxia, hipotensão, depressão respiratória, fadiga, cefaléia e tonturas; O clonazepam, sonolência, movimentos anormais dos olhos, perda da voz, movimentos involuntários dos braços e pernas, coma, visão dupla, dificuldade para falar, aparência de "olho-vítreo", dor de cabeça, fraqueza muscular, depressão respiratória, fala mal articulada, tremor, vertigem, perda de equilíbrio, coordenação anormal, sensação de "cabeça-leve", letargia, formigamento e alteração da sensibilidade das extremidades; 0 clobazam, sonolência, descoordenação motora, alterações gastro-intestinais, diarréia, vômitos, alterações do apetite, alterações visuais, irregularidades cardiovasculares, alteração da memória, confusão, depressão e vertigem.

Vale ressaltar, que de acordo com vários autores outras terapias podem e devem ser associadas ao uso de fármacos, pois quando associadas aos antipsicóticos e outros agentes, produzem resultados muito melhores se comparados aos casos onde se utiliza apenas as medicações. Dentre as diversas terapias, temos a eletroconvulsoterapia (ECT), a lobotomia 
frontal (experimental), terapias psicossociais, treinamentos de habilidades sociais, terapias de orientação familiar, manejo de caso, tratamento comunitário assertivo, terapia de grupo, terapia cognitivo-comportamental, psicoterapia individual e a terapia vocacional, já que muitas pessoas esquizofrênicas são capazes de realizar trabalhos de alta qualidade sendo que algumas chegam a apresentar habilidades excepcionais e até mesmo brilhantismo em um campo limitado como conseqüência de algum aspecto idiossincrático do seu transtorno (Kaplan et al., 2007a, Breier et al., 1991; Carone et al, 1991; Kane, 1996; Lysaker et al, 2002; Penn et al., 2002).

Antipsicóticos, em especial, os típicos podem causar parkinsonismo, o que exige a utilização de medicamentos que combatam esse efeito adverso como o biperideno. Sendo que, o biperideno pode causar agitação, confusão mental, secura da boca, midríase, taquicardia, retenção urinária, constipação, distúrbios psíquicos, dentre outros (Kaplan et al., 2007a). 


\section{TRANSTORNOS DO HUMOR}

De acordo com Kaplan et al. 2007b, edições prévias do DSM classificava os transtornos do humor como transtornos afetivos porém, o termo transtornos do humor é preferível pois se refere a estados emocionais persistentes, e não simplesmente à expressão externa (afetiva) de um estado emocional transitório. Os transtornos do humor são considerados síndromes, ou seja, são um conjunto de sinais e sintomas persistentes por semanas ou meses e que representam um desvio acentuado do desempenho habitual da pessoa e que tendem a recorrer de forma periódica ou cíclica. O estado de humor pode apresentar-se deprimido, normal ou elevado, ou seja, os transtornos se referem a alternâncias do estado de humor onde haja sensação de perda do controle e, uma experiência subjetiva de muito sofrimento.

Segundo o DSM-IV-TR, os transtornos do humor são classificados em: transtorno depressivo maior (também conhecido como depressão unipolar), transtorno bipolar, transtorno distímico, transtorno ciclotímico, transtorno depressivo menor, transtorno depressivo breve recorrente, transtorno do humor devido a uma condição médica geral e transtorno do humor induzido por substâncias, transtorno bipolar sem outra especificação, transtorno depressivo sem outra especificação e transtorno do humor sem outra especificação.

O presente trabalho se ateve, para a divisão dos grupos, somente há dois sub-tipos de transtornos do humor: o transtorno depressivo maior (depressão unipolar) e o transtorno bipolar do tipo I.

A depressão unipolar ocorre sem história de episódios maníacos, mistos ou hipomaníacos. Cada episódio de depressão deve durar no mínimo duas semanas, e geralmente o indivíduo pode experimentar mudanças no apetite e no peso, alterações no sono e no nível de atividade, falta de energia, sentimentos de culpa, dificuldade para pensar e tomar decisões, além de pensamentos recorrentes de morte e suicídio. Episódio maníaco é 
um período distinto de estado de humor anormal e persistentemente elevado, expansivo ou irritável, durando pelo menos uma semana ou um menor período, no caso do indivíduo necessitar internação hospitalar. Um episódio hipomaníaco dura pelo menos quatro dias e é semelhante ao episódio maníaco, exceto por não ser grave o suficiente para causar comprometimento do desempenho social e ocupacional. Deve-se lembrar que, tanto a mania quanto a hipomania é associado ao aumento da auto-estima, redução da necessidade de sono, presença de distratibilidade, grande atividade física e mental e envolvimento excessivo em comportamento prazeroso (Kaplan et al. 2007b).

Quanto ao transtorno bipolar, o DSM-IV-TR o divide em transtorno bipolar I e II, sendo que o transtorno bipolar I é caracterizado por um curso clínico com um ou vários episódios maníacos e, às vezes, episódios depressivos maiores. O transtorno bipolar II é definido por episódios de depressão maior e de hipomania, em vez de mania.

Os episódios de depressão são caracterizados pelo humor depressivo e pela perda de interesses ou de prazer. Os indivíduos relatam que se sentem desesperançados, tristes ou desvalorizados. Eles descrevem a depressão como uma dor emocional tipo agonia e muitas vezes se queixam de serem incapazes de chorar, um sintoma que desaparece quando melhoram (Akiskal, 2000; Coryell et al., 1992a). Ainda, quase todos os indivíduos com depressão reclamam de perda de energia, dificuldade de terminar suas tarefas, mau desempenho na escola e no trabalho e se sentem menos motivados a desenvolver novos projetos. Cerca de $80 \%$ se queixam de dificuldades com o sono, despertar precoce na madrugada e despertares múltiplos durante a noite, onde ruminam sobre seus problemas. Pode ocorrer tanto diminuição do apetite e perda de peso quanto o contrário também (Coryell et al., 1992b; Johnson et al., 2000).

Em episódios depressivos a lentificação psicomotora generalizada é o sintoma mais comum, embora possa ocorrer especialmente em idosos uma agitação psicomotora. A agitação normalmente é representada pelo torcer das mãos e por arrancar cabelos. 
Normalmente, os indivíduos deprimidos apresentam postura encurvada, sem movimentos espontâneos e com o olhar desviado para baixo. Buscam reclusão social e reduzem de maneira generalizada suas atividades. Muitos exibem redução da taxa e do volume da fala, além de demorarem muito a responder a perguntas, demonstrando desinteresse e falta de energia (Rice et al.,1992).

Até $90 \%$ dos indivíduos sofrem com a ansiedade. Condições médicas pré-existentes como diabete, hipertensão, doença pulmonar obstrutiva crônica e doença cardíaca podem ser agravadas pelas diversas modificações na ingestão de alimentos e no repouso desses indivíduos (Gotlib; Nolan, 2000).

Os episódios maníacos são caracterizados por um estado de humor elevado, expansivo ou irritável. O estado de humor eufórico pode contagiar as pessoas e até causar a impressão de que inexiste o problema. Diversas vezes o estado de euforia passa a ser de irritação quando os planos ambiciosos do indivíduo são contrariados, ou seja, o humor desses indivíduos geralmente oscila entre euforia no início da doença para irritabilidade excessiva posterior, principalmente quando se sentem frustrados. São tagarelas, desorganizados, às vezes divertidos e muitas vezes hiperativos (Rice et al., 1992; Akiskal, 2000).

Quando hospitalizados, os maníacos tendem a criar conflitos entre os membros da equipe que estão cuidando deles, pela exploração das fraquezas de cada membro. Quando não hospitalizados, tendem a consumir excessivamente bebidas alcoólicas. Sua desinibição se reflete muitas vezes em usar o telefone demasiadamente e nas primeiras horas da manhã. Possuem tendência em despir em lugares públicos, usar roupas e jóias extravagantes, agem por impulsividade, e cometem falta de atenção a pormenores como se esquecer de voltar o telefone no gancho. É comum preocuparem com idéias religiosas, financeiras, sexuais, políticas ou de perseguição que podem evoluir para sistemas delirantes 
complexos. Em alguns casos, podem brincar com urina e fezes e sofrer regressão (Sands; Harrow, 2000; MacKinnon et al., 2002).

Delírios são comuns em $75 \%$ dos indivíduos maníacos, principalmente relacionados a idéias de grandeza, autoconfiança, riqueza e capacidades extraordinárias, além de alucinações bizarras. A grande maioria possui características de serem ameaçadores e agressivos. A mentira e o disfarce são comuns na mania (Akiskal, 2000).

O tratamento do transtorno do humor, atualmente, utiliza-se da farmacoterapia associada a diferentes terapias tais como: psicossocial, cognitiva, comportamental, de orientação psicanalítica e familiar, onde se obtém excelentes resultados desde que os indivíduos e a família estejam cientes de que os transtornos do humor são crônicos e que necessitam de estratégias futuras de tratamento. É importante esclarecer ao portador da patologia e a seus familiares que recaídas podem ocorrer principalmente devido a acontecimentos estressantes da vida. Então, faz parte do tratamento reduzir o número e intensidade dos agentes estressores. Cada episódio, para um bom prognóstico, deve ser encarado com otimismo tanto pelo indivíduo quanto pela família, mesmo que o tratamento inicial não seja promissor (Sachs; Thase, 2000).

\section{Farmacoterapia para o transtorno depressivo maior}

Há 40 anos existem os medicamentos tricíclicos que se mostram específicos e eficientes para o tratamento do transtorno depressivo maior. O uso da medicação quase dobra a chance do indivíduo em depressão melhorar, porém, alguns não respondem bem ao primeiro tratamento (Kaplan et al., 2007b).

Antes do surgimento dos Inibidores Selectivos da Recaptação da Serotonina (ISRSs), todos os antidepressivos eram tóxicos em doses elevadas e apresentavam muitos efeitos adversos. Compreendem os ISRSs a fluoxetina, a paroxetina, a sertralina, a bupropiona, a venlafaxina, a nefazodona e a mirtazapina que são igualmente eficientes, mais seguros e 
apresentam melhor tolerância que os antidepressivos anteriores (Sheldon et al., 2004; Beasley et al., 2007).

A principal indicação dos antidepressivos é o episódio depressivo maior, sendo que, os primeiros sintomas a melhorarem são os distúrbios no sono e no apetite, posteriormente são atenuados os problemas de agitação, ansiedade, falta de esperança, falta de energia, dificuldade de concentração, sentimento de impotência e redução da libido.

Os ISRSs podem causar agitação, mal-estar gastrintestinal ou náuseas antes de reduzirem a depressão, porém esses efeitos adversos passam com o tempo. Uma grande preocupação quanto aos antidepressivos é sua letalidade quando ingeridos em doses excessivas (Sheldon et al., 2004).

Utilizados no tratamento da depressão, os tricíclicos, tetracíclicos, a trazodona, alprazolan e a mirtazapina podem causar sedação. Os Inibidores da Monoamina Oxidase (IMAOs) não são muito escolhidos, pois exigem restrição alimentar de tiramina, do contrário causa crise hipertensiva (Beasley et al., 2007).

Os IMAOs são utilizados quando o paciente não responde ao tratamento com outros antidepressivos. Fazem parte do grupo dos IMAOs a fenelzina, a iproniazida, a isocarboxazida, a harmalina, a nialamida, a pargilina, a selegilina, a toloxatona e a tranilcipromina, podendo causar os seguintes efeitos adversos: obstipação, confusão, perda da coordenação motora precisa, retenção urinária, excitação, convulsões, ganho de peso, hipotensão postural, boca seca, sedação e tremores.

A combinação com álcool e outras drogas potencializa a letalidade dos antidepressivos quando em doses elevadas (Kaplan et al., 2007b).

Lítio: é acrescido a um antidepressivo quando o mesmo se torna não-responsivo pra que o mesmo se torne responsivo. O mecanismo de ação do lítio é desconhecido e sabe-se que ele potencializa o sistema serotonérgico neuronal (Baldessarini; Tondo, 2000; Keck et al., 1996). 
Liotironina: também é acrescido a um antidepressivo para que o mesmo se torne responsivo. Seus efeitos adversos incluem cefaléias e sensações de calor (Brunello et al., 1999).

L-triptofano: é um aminiácido precursor da serotonina e tem sido utilizado associado a um antidepressivo ou isoladamente. Quando empregado sozinho tem ação antidepressiva e hipnótica. Pode causar a síndrome de eosinofilia-mialgia que é caracterizada por fadiga, mialgia, dispnéia, exantemas e tumefação das extremidades (Brunello et al., 1999).

A combinação de medicamentos tricíclicos ou tetracíclicos com um IMAO também pode ser utilizada em pacientes que não respondem a diversos outros tratamentos. Porém, evita-se devido aos altos índices de efeitos adversos, tais como inquietação, tonturas, abalos musculares, sudorese, convulsões, hiperpirexia e até a morte (Baldwin, 2000; De Lima et al., 1999).

Antidepressivos tricíclicos: são utilizados no tratamento da depressão crônica ou profunda, e das fases depressivas na doença bipolar. São exemplos de tricíclicos a amitriptilina, a clomipramina, a desipramina, a imipramina, a nortriptilina e a doxepina. Podem causar os seguintes efeitos adversos: mania, obstipação, xerostomia, visão com acuidade diminuída, retenção urinária, dificuldade de concentração e aprendizagem, hipotensão postural e aumento do risco de morte súbita cardíaca (Kaplan et al., 2007a).

Alguns antidepressivos podem causar convulsões, devido a esse efeito adverso utilizam-se anticonvulsivantes como a fenitoína ou o fenobarbital. Sendo que a fenitoína pode provocar efeitos adversos tais como, nistagmo, hirsutismo, hiperplasia gengival, ataxia, sedação e anemia. E, o fenobarbital pode provocar sonolência, dificuldade em acordar e para falar, problemas de coordenação e equilíbrio, vertigem com cefaléia, reações alérgicas cutâneas, artralgia, distúrbios do humor, anemia megaloblástica, osteomalácia e raquitismo. 


\section{Farmacoterapia para o transtorno bipolar I}

Além da carbamazepina, o lítio, o divalproato e a olanzapina são tratamentos ditos padrão para a fase maníaca do transtorno bipolar. Quando os pacientes são intolerantes ao tratamento padrão pode-se optar pelo uso da gabapentina ou da lamotrigina, apesar de sua eficácia ainda não estar totalmente definida. O topiramato além de ser um anticonvulsivante também apresenta benefícios em pacientes bipolares, porém pode causar fadiga, embotamento cognitivo e perda de peso (Kaplan et al., 2007a).

Antipisicóticos típicos podem ser utilizados, porém os pacientes bipolares são particularmente sensíveis aos seus efeitos adversos. Já os antipscicóticos atípicos, como a olanzapina, são úteis no controle de curto prazo, como monoterapia, por possuir propriedades antimaníacas intrínsecas.

Pacientes que não respondem bem ao uso de um estabilizador de humor podem se dar bem com o tratamento combinado de medicamentos, como por exemplo: lítio e ácido valpróico, lítio e carbamazepina e ácido valpróico, porém essas combinações devem ser monitoradas já que trazem o risco de neurotoxicidade e toxicidade hepática respectivamente.

Lítio: é o tratamento padrão para o transtorno bipolar I. Seus substitutos são a carbamazepina ou o valproato quanto os efeitos adversos indicam a necessidade de troca do medicamento. Como efeitos colaterais têm-se: efeitos renais (sede, poliúria, e efeitos mais graves como compromentimento da função tubular), efeitos sobre a tireóide (bócio, mixedema), efeitos sobre o sistema nervoso central (perda de memória e tremor), efeitos dermatológicos (acne, psoríase), efeitos metabólicos (aumento de peso), efeitos gastrintestinais (diarréia). Normalmente o uso do lítio não é efetivo em casos graves, quando da presençca de transtorno esquizoafetivo, de sintomas mistos maníacos e depressivos, sintomas somáticos, abuso de álcool e uso de drogas, ciclagem rápida e quando não há histórico familiar para o transtorno bipolar I. 
Valproato: é considerado, também, um medicamento de primeira escolha, além do fato de ser melhor tolerado por alguns pacientes que o líto e a carbamazepina. Também chamado de ácido valpróico, o valproato pode aprensentar os seguintes efeitos adversos: trombocitopenia, alopécia, tremor, aumento de peso, sedação e mal-estar gastrintestinal.

Carbamazepina: interações medicamentosas indesejáveis torna a escolha da carbamazepina como uma segunda opção, já que é uma potente indutora de enzimas e pode baixar os níveis de outros medicamentos como o haloperidol, além de ser auto-indutora, ou seja, induz seu próprio metabolismo. Incluem em seus efeitos adversos náuseas, sedação, ataxia, toxicidade hepática, hiponatremia e supressão da medula óssea.

Outros medicamentos utilizados no tratamento de pacientes bipolares incluem os benzodiazepínicos, geralmente empregados como tranqüilizantes, nestes incluem o lorazepam, clonazepam, clobazam, dentre outros. 


\section{EleTromi OGRAFIA}

Moyers, em 1949, utilizou a eletromiografia (EMG) pela primeria vez na Odontologia, sendo que ela se apresenta como uma importante metodologia para a análise e diagnóstico da função muscular. A EMG se baseia na determinação de presença e registro da atividade elétrica do tecido muscular esquelético, o que permite identificar e descrever a função das unidades motoras por meio dos modelos de ativação muscular, a amplitude elétrica de ativação e as freqüências que constituem o registro eletromiográfico. A eletromiografia cinesiológica, para análise da função muscular, tem aplicação em muitas áreas da saúde, tais como a Odontologia, Medicina, Fisioterapia e Fonoaudiologia, que podem incluir o exame eletromiográfico de superfície como exame complementar para facilitar diagnósticos e estabelecer prognósticos mais precisos.

Schimidt, em 1979, afirmou que o homem só pode produzir trabalho ou atuar sobre o meio ambiente por meio de seus músculos, válido para todo trabalho físico, inclusive para as chamadas "atividades intelectuais", que seriam o falar e o escrever exigindo a ação apurada de determinados grupos musculares. A contração muscular ocorre por meio das muitas fibras musculares estimuladas de maneira não simultânea pela fibra nervosa motora, onde esse conjunto, forma o que se denomina unidade motora. O eletromiógrafo registra o estímulo propagado nas unidades motoras, que demarca uma derivação celular do potencial do músculo e pode ser usado como meio de auxílio diagnóstico de doenças musculares, tais como miastenia (debilidade muscular), miotonia (espasmos musculares tônicos) e paralisias.

Jankelson, em 1990, verificou que o nível da atividade muscular no repouso, registrado por eletromiógrafo, é um método valioso para examinar a posição fisiológica do sistema estomatognático. Gibbs, et al. (1984) afirmou que a atividade eletromiográfica máxima do músculo masseter ocorre durante a posição de intercuspidação máxima e em oclusão cêntrica. Relatou também, que a melhor escolha para monitoramento da atividade geral, no músculo temporal e no músculo masseter, é o eletrodo de superfície, já que há 
uma predominância de tipos mistos de fibras com distribuição variada nas diversas partes dos músculos levantadores da mandíbula. Altmann (1990) afirmou que o tônus muscular tem profunda relação com posturas bucais incorretas, podendo encontrar-se nessas situações hipotonia para músculos levantadores da mandíbula, língua, lábios e bochechas.

Mioche et al. (1999) avaliaram 36 voluntários jovens que mastigaram cinco tipos de alimentos e, relataram que tanto a atividade eletromiográfica do músculo masseter como a do temporal aumentaram em função da textura dos alimentos. Foi verificado que o músculo temporal foi mais suscetível à variação da textura dos alimentos que o músculo masseter. 0 que significa dizer que a eletromiografia também é capaz de captar diferenças na atividade da musculatura da mastigação em função da variação da textura dos alimentos.

Ferrario et al. (2002) na tentativa de correlacionar a oclusão e a atividade eletromiográfica, avaliaram a atividade eletromiográfica dos músculos da mastigação com o número de contatos oclusais em indivíduos jovens. Observaram que alterações na superfície oclusal podem alterar o desempenho dos músculos da mastigação, pela fato de que nos indivíduos com poucos contatos oclusais houve menor atividade eletromiográfica.

Lous et al. (1970) foram os primeiros a documentar o uso da eletromiografia como uma ferramenta para avaliar a atividade dos músculos da mastigação em portadores de disfunção temporomandibular (DTM), demonstrando que na posição de repouso mandíbular, a atividade dos músculos temporal e masseter foi significativamente maior nesses indivíduos quando comparada com o grupo controle.

Pedroni (2003) relatou que atualmente a eletromiografia continua sendo aplicada em estudos sobre pacientes com DTM com dor miofascial, descrevendo principalmente a atividade elétrica na posição de repouso mandibular, ou seja, a hiperatividade ou hipoatividade dos músculos nessa situação, o equilíbrio muscular na mastigação, no apertamento dental e na atividade parafuncional. 
Alajbeg et al. (2003) avaliaram por meio da EMG a simetria da atividade dos músculos masseter, temporal e supra-hióides e o efeito de placa oclusal sobre essa assimetria em pacientes com DTM e em sujeitos saudáveis. Sendo que, as maiores assimetrias foram observadas nos músculos temporais. Após o tratamento, o nível de simetria do músculo temporal durante apertamento máximo aumentou significativamente. Os autores concluíram que a eletromiografia é um método valioso no registro da melhora de simetria de atividade dos músculos da mastigação após a aplicação de placa oclusal em pacientes com DTM.

Santos et al. (2003) avaliaram, em indivíduos desdentados, a atividade eletromiográfica do músculo orbicular da boca, antes e após receberem próteses totais, e detectaram que ocorreu hiperatividade muscular quando do uso de próteses totais, o que demonstra que a eletromiografia é um método científico capaz de auxiliar os cirurgiõesdentistas no diagnóstico e acompanhamento de diversas condições de saúde bucal.

Contudo, sabe-se que eletromiografia de superfície ainda é uma técnica que necessita ser aprimorada e adaptada para ser difundida para o uso clínico. A mesma dificuldade encontrada em relação ao diagnóstico das disfunções musculares e articulares foi experimentada pelos pesquisadores em eletromiografia. A comparação entre estudos sempre foi prejudicada pela falta de padronização da metodologia. Apesar de ser uma técnica que permite o acesso a processos bioquímicos e fisiológicos dos músculos esqueléticos sem procedimentos invasivos, ela ainda apresenta limitações que comprometem o sucesso de sua utilização em qualquer um dos campos de aplicação (Acierno et al., 1995; De Luca, 1997; Klasser; Okeson, 2006).

Em 1999 o projeto SENIAM (Surface ElectroMyoGraphy for the Non-Invasive Assessment of Muscles) estabeleceu regras para a utilização da eletromiografia de superfície para a pesquisa internacional. A padronização permitiu aos pesquisadores comparar diferentes trabalhos e trocar informações, pois estabeleceu o tipo de eletrodo, seu tamanho 
e material, as configurações, os locais de captação do sinal, as formas de processamento, o tipo de filtro, entre outros cuidados (Merletti, 1999; Hermens et al., 1999).

A impedância da pele, o momento do dia, a variabilidade entre os indivíduos e o posicionamento dos eletrodos são alguns dos fatores que podem interferir na captação da atividade eletromiográfica (Merletti, 1999; Hermens et al., 1999; Klasser; Okeson, 2006). Ruf et al. (1997) relataram que nem todos os voluntários avaliados apresentaram o mesmo padrão de comportamento eletromiográfico, mesmo existindo significância estatística para a comparação entre os dados. Alguns voluntários tiveram comportamento eletromiográfico inverso ao da maioria do grupo testado. Os autores atribuiram esse acontecimento ao fato de existir uma variabilidade grande entre os indivíduos.

Todavia, "é importante salientar que o uso da eletromiografia de superfície com o propósito de pesquisa tem o seu mérito cientifico" afirmaram Klasser e Okeson (2006). Os autores também salientaram que o controle adequado das condições dos exames eletromiográficos e o conhecimento dos pesquisadores permitirão o uso da EMG para contribuir para o diagnóstico e o tratamento das disfunções musculares e articulares.

Atualmente, a eletromiografia de superfície tem sido muito mais que um exame complementar para o estudo anatômico, fisiológico e neurofisiológico do sistema músculoesquelético, e desenvolveu-se cada vez mais para possuir um caráter diagnóstico, de fácil aplicação, não produzir desconforto ao indivíduo, além de não interferir na fisiologia local da musculatura. Grande parte das pesquisas consideradas nesse trabalho tem como base a análise comparativa entre voluntários dentados completos e voluntários com alterações de oclusão ou reabilitação bucal, o que evidencia o fato da eletromiografia tornar possível o estudo científico das alterações na atividade muscular de acordo com fatores de variação como: tipo de reabilitação, alimentação, classificação da oclusão, hábitos de vida, entre outros fatores como o uso de medicamentos. 
Desta forma, o uso da eletromiografia pode ter um papel imprescindível para o estudo de doentes psiquiátricos sob tratamento farmacológico. Acredita-se que o estudo desses indivíduos possa contribuir para o avanço do conhecimento funcional dos músculos mastigatórios a fim de esclarecer o quanto os mesmos são afetados pela medicação administrada. 


\section{FORÇA DE MORDI DA}

A força de mordida é obtida pela ação dos músculos levantadores da mandíbula e regulada por outros músculos do sistema muscular, assim como pelos sistemas neurológico, esquelético e dental (Linderholm; Wennström, 1970; Sheikholeslam et al., 1980; Ow et al., 1989; Piancino et al., 2005; Kogawa et al., 2006; Sonnesen; Bakke, 2007), podendo ser mensurada por métodos diretos, como o dinamômetro, e indiretos, como imagens ultrassonográficas ou registros eletromiográficos ou mesmo associando os métodos indiretos (Shiau; Wang, 1993).

Watt (1958) avaliou a força de mordida em voluntários com dentes naturais hígidos e encontrou forças que variaram entre 3 a $64 \mathrm{Kg}$ em todos os dentes que ocluíam, não encontrando correlação entre a força de mordida, altura e peso dos indivíduos adultos.

Helkimo et al. (1977) pesquisaram a relação entre a força de mordida máxima de dentes incisivos e primeiros- molares em relação ao gênero e a idade, concluindo que a força de mordida foi maior no homem, diminuindo com a idade, principalmente nas mulheres.

Ono et al. (1992) concluiu que a força da musculatura mastigatória demonstra a quantidade adequada de força que uma pessoa possa ter para triturar e cortar alimentos, e influencia a habilidade do sistema mastigatório.

Tsuga et al. (1998) avaliaram indivíduos de 80 anos de idade e concluíram que a força de mordida é importante para a função e a saúde do sistema mastigatório.

Sonnesen e Bakke (2007) encontraram que a amplitude da força de mordida aumenta com a idade, e é maior nos homens quando comparados às mulheres (Regalo et al., 2008).

Hatch et al. (2001) avaliaram 631 indivíduos dentados entre 37 e 80 anos de idade e concluíram que a maior massa muscular dos músculos da mastigação está presente nos indivíduos do gênero masculino. 
Rentes et al. (2002) e Bonjardim et al. (2005) relatam que a força de mordida varia de acordo com a morfologia facial, com a estrutura física geral, com o gênero do indivíduo, com o estado da dentição e com a idade.

Para Pereira et al. (2006) a força de mordida e o número de dentes funcionais são determinantes no desempenho mastigatório. E que, a força de mordida não é afetada pela disfunção temporomandibular, mas encontraram uma correlação entre a força de mordida máxima e o peso e a altura nos indivíduos com disfunção temporomandibular.

Regalo et al. (2008) estudaram a força de mordida máxima na região de primeiros molares e de incisivos, em 41 índios brancos do Xingu e 41 indivíduos brasileiros, entre 18 e 28 anos de idade, e concluíram que a força de mordida máxima foi maior na população indígena em ambas as regiões analisadas e bilateralmente e que, os índios tem uma maior força de mordida que as índias.

Roldán et al. (2009) pesquisaram a força de mordida máxima nas regiões de molares e, incisiva variando-se a idade e medições dentro de uma mesma sessão e entre sessões distintas para averiguar a confiabilidade do teste e encontraram que a confiabilidade dentro da mesma sessão era substancialmente superior à confiabilidade entre sessões, que por sua vez foi superior à confiabilidade total em todas as regiões de mordida. A confiabilidade foi maior na região de mordida de incisivos.

Pereira et al. (2009) investigaram a força de mordida em pacientes com desordem temporomandibular(DTM) subaguda antes e após o tratamento e constataram que a força de mordida molar máxima melhorou significantemente após o tratamento da DTM.

Thongudomporn et al. (2009) testaram o quanto a força de mordida máxima contribui para os parâmetros da morfologia do osso alveolar, espessura alveolar, ou seja, forma e largura do arco. E, concluíram que a força máxima de mordida teve uma influência seletiva sobre a espessura alveolar e na forma, mas não na largura do arco. 
Koc et al. (2010) revisando a literatura revelaram que fatores tais como, a presença de dor e disfunção temporomandibular, sexo, idade, morfologia craniofacial, fatores oclusais, dispositivos de gravação e as técnicas são fatores importantes na determinação da força de mordida. Portanto, deve-se ter cuidado quando se compara os valores de força de mordida relatados em pesquisas.

Yousefzadeh et al. (2010) pesquisaram a força de mordida máxima entre negros do leste africano e brancos e não encontraram diferença estatisticamente significante.

Jofré et al. (2010) verificaram a relação entre força de mordida molar máxima e a perda de osso marginal, mas não encontraram nenhuma relação entre elas. 


\section{EfI CI ÊNCIA MASTI GATÓRI A}

Kurth (1942) salientou que conhecer os parâmetros relacionados com os ciclos mastigatórios é de grande importância para a Odontologia.

Segundo Brown (1975) o estudo dos movimentos mandibulares tem importantes aplicações em muitos campos da Odontologia, onde os padrões de movimentação deveriam ser considerados em conjunto com a articulação mandibular, com o sistema de articulações sinoviais, com os músculos e com as estruturas associadas, quando houvesse uma suspensão dos movimentos normais da mandíbula.

Bates et al. (1976) descreveram a forma do ciclo mastigatório, tanto na dentição natural quanto em indivíduos usuários de próteses dentais, após a mastigação de vários tipos de alimentos. O padrão do ciclo mastigatório apresentou poucas variações num mesmo indivíduo, porém variou bastante entre indivíduos, sendo influenciado pela oclusão e pela consistência, tipo, tamanho e textura do bolo alimentar. Os autores verificaram que os indivíduos mastigam pelo lado no qual ocorre o maior número de contatos dentais sendo que, se estes forem iguais dos dois lados, a mastigação será bilateral alternada e o bolo alimentar movido de um lado para o outro de forma consistente e regular.

O padrão mastigatório normal foi estudado por Wickwire et al. (1981) em crianças com dentição decídua, mista e permanente. Estes pesquisadores relataram que o padrão dos ciclos mastigatórios é bem estabelecido em crianças com dentição decídua, caracterizado por grandes excursões laterais durante o movimento de abertura bucal, sendo maior que a excursão lateral de fechamento. Por volta dos doze ou quatorze anos, o padrão típico muda completamente e, se caracteriza por um padrão de abertura sagital e fechamento lateral.

Gibbs et al. (1982) também estudaram o padrão mastigatório típico comparando-o entre crianças com dentição decídua, mista e permanente, e adultos. Os registros foram realizados durante a mastigação orientada de alimentos de consistências macia e dura. Os resultados demonstraram que a mastigação em adultos e crianças com oclusão normal 
caracterizava-se pelo contato dental, pausa na posição de intercuspidação máxima e amplos movimentos laterais. O padrão mastigatório em crianças com dentição decídua caracterizavase por amplos movimentos laterais na abertura (maior que o de fechamento). Com o aumento da idade, o padrão se alterava, caracterizado pela abertura medial e amplo movimento lateral de fechamento bucal. Estes autores também verificaram que os alimentos mais duros provocam excursões laterais mais amplas nos adultos e mais mediais nas crianças.

Para Ramfjord e Ash (1984), a oclusão adequada possibilita a mastigação bilateral, alternada e multidirecional, o que proporciona a distribuição homogênea do alimento sobre a superfície dos dentes tanto do lado direito quanto do lado esquerdo, com distribuição uniforme das forças mastigatórias nos tecidos de suporte dos dentes, o que facilita a estabilidade dos tecidos periodontais e da própria oclusão. Na mastigação bilateral alternada a atividade muscular é bilateralmente sincrônica. Para estes pesquisadores, a mastigação realizada com movimentos unilaterais não é ideal.

Ao estudar a eficiência mastigatória em 1984, Carlsson concluiu que a idade relacionada ao estado da oclusão explicava a maioria dos casos de diminuição na eficiência e que a idade por si só pouco influenciava. Em seu estudo, verificou que a eficiência mastigatória era muito menor em pacientes portadores de próteses totais quando comparada com a eficiência mastigatória dos indivíduos com dentes naturais, com próteses fixas sobre os dentes naturais ou com implantes osteointegrados. Para este autor, a melhor garantia de uma boa eficiência mastigatória com o passar da idade, era manutenção de uma quantidade razoável de dentes naturais e saudáveis na cavidade da boca.

van der Bilt et al. (1993) compararam a eficiência mastigatória de um grupo de indivíduos com perda, em média, de seis dentes posteriores e, de um grupo controle com dentição completa. Verificaram que o número de ciclos mastigatórios para preparar o alimento para deglutição era significativamente maior para os participantes do grupo 
experimental do que para o grupo controle, mas não encontraram correlação entre a eficiência mastigatória e o número de ciclos mastigatórios dentro dos grupos estudados.

Enlow (1993) afirmou que ao contrário da sucção, que é um comportamento instintivo, a mastigação é um comportamento adquirido, onde o bebê descobre o processo mastigatório. Com o início do uso do sistema mastigatório, ocorrem alterações estruturais e funcionais subsequentes no esqueleto facial. Dentro de um sistema estímulo - respostas, observam-se mudanças específicas do sistema músculo - esqueleto associado à função mastigatória.

Felício (1994) afirmou que a mastigação é o estímulo para a continuidade e manutenção da saúde muscular, articular e periodontal do sistema estomatognático e que algumas maloclusões poderiam ser oriundas de mastigação insuficiente, maus hábitos e má postura alimentar.

Vários trabalhos utilizaram a eletromiografia para avaliar a ativação dos músculos mastigatórios durante a mastigação (Kashiwagi et al., 1995; Blanksma; Van Eijden, 1995; Hermens et al., 1999; Bazzotti, 1999; Buzinelli; Bérzin, 2001; González et al., 2002; Tomiyama et al., 2004).

O sinal eletromiográfico obtido em situações dinâmicas como a mastigação é considerado importante fonte de informações clínica e cinesiológica (Bazzotti, 1999; Sgobbi de Faria; Bérzin, 1998; Rilo et al., 1997; Michelotti et al., 1997).

Kiliaridis (1995) também estudou o efeito do treino mastigatório em relação à força e resistência dos músculos mastigatórios. O grupo experimental mastigou uma goma dura especial, por uma hora diária, durante vinte e oito dias. Registrou-se a máxima força e a duração de mordida. Houve aumento significativo no grupo experimental, em relação à máxima força de mordida. O autor concluiu que exercícios mastigatórios sistemáticos produzem aumento significativo da força mastigatória, especialmente em músculos fracos. 


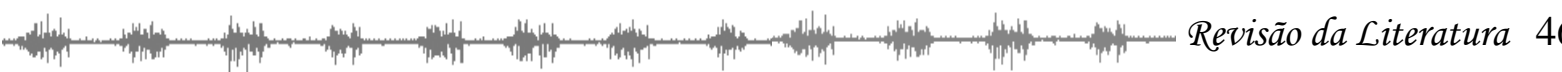

A mastigação é o primeiro passo do processo digestório e é considerada uma das funções mais importantes do sistema estomatognático, estando diretamente relacionados com a manutenção dos arcos dentais, com a estabilidade da oclusão e com o estímulo funcional, principalmente sobre o periodonto, músculos e articulações (Karkazis; Kossioni, 1997).

De Luca (1997) afirmou que é por meio da integral da envoltória do sinal eletromiográfico que é feita a análise da eficiência e do desempenho do ciclo mastigatório.

Karkazis e Kossioni (1997) avaliaram em seus estudos o efeito da consistência de alimento duro e macio (cenoura e chiclete) sobre a atividade eletromiográfica do músculo masseter durante a mastigação em indivíduos jovens (vinte e dois a trinta e dois anos), Classe I de Angle, sem disfunções. Consideraram a média da atividade eletromiográfica integrada durante a mastigação, a velocidade mastigatória (número de ciclos em dez segundos), a duração do ato mastigatório e a duração do ciclo mastigatório. Verificaram que para o alimento duro, a média dos valores da atividade eletromiográfica integrada e a velocidade mastigatória foi significantemente maior e para o chiclete somente o ciclo mastigatório foi maior. Não houve diferenças quanto a duração do ato mastigatório considerando os dois alimentos.

Youssef et al. (1997) buscou determinar as diferenças entre sexos durante a mastigação, por meio da análise da atividade eletromiográfica dos músculos masseter e temporal. Os resultados mostraram que os homens apresentaram ciclos mastigatórios mais curtos, maior velocidade e maior força mastigatória, quando comparados às mulheres.

Henrikson et al. (1998) avaliaram a eficiência e a habilidade mastigatória de jovens do sexo feminino, com oclusão normal e maloclusão de classe II, dessa forma, associando eficiência e habilidade mastigatória com sinais e sintomas de disfunções temporomandibulares. Os autores concluíram que a eficiência e a habilidade mastigatória 
eram, parcialmente, dependentes da oclusão e que, os sintomas de disfunção temporomandibular influenciaram a eficiência e a habilidade.

Yamashita et al. (1999) ao revisarem a literatura, concluíram não haver um padrão mastigatório ideal que pudesse ser usado clinicamente ou em pesquisas para garantir a saúde do sistema mastigatório e nem predizer a eficiência mastigatória. A parte mais importante do ciclo mastigatório está próxima da máxima intercuspidação onde os contatos deslizantes ocorrem.

Papargyriou et al. (2000) também verificaram que o padrão dos movimentos mandibulares durante a mastigação é influenciado por vários fatores centrais e periféricos. Num estudo longitudinal em crianças com duração de seis anos, ficou evidente que o padrão dos ciclos mastigatórios varia durante o crescimento, sendo possivelmente decorrentes das modificações anatômicas, maturação do sistema nervoso e alteração das demandas funcionais.

A função mastigatória, por meio da dinâmica mandibular fisiológica, propicia estímulos mecânicos adequados à cabeça da mandíbula e ligamento periodontal, principais meios de adaptação para o crescimento e desenvolvimento facial, assim como para a manutenção dos processos adaptativos, presentes por toda a vida (McNeill, 2000).

A função mastigatória (definida como o desempenho mastigatório) tem sido muitas vezes medida pela determinação da capacidade de um indivíduo de moer ou triturar determinado alimento e muitos fatores influenciam o desempenho do sistema mastigatório, tais como a perda dos dentes, restaurações nos dentes posteriores, a força de mordida, idade e sexo, contatos oclusais e função motora (van der Bilt, 2002).

Mizumori et al. (2003) avaliaram a influência da textura do alimento na lateralidade do movimento mastigatório em dez sujeitos saudáveis entre vinte e quatro e vinte e oito anos de idade, de ambos os sexos, sem sinais de disfunção temporomandibular. Diferenças 
significativas foram verificadas entre os alimentos mais duros e os mais moles. Os alimentos mais duros provocam maior lateralidade mandibular

Peyron et al. (2004) estudaram a influência da idade na habilidade dos indivíduos adaptarem o sistema mastigatório à dureza dos alimentos, concluindo que: com o aumento da idade o número de ciclos mastigatórios aumentou para o mesmo alimento ser triturado, porém a capacidade de adaptação do sistema estomatognático é grande e as funções se mantêm.

Piancino et al. (2005a) estudaram a coordenação neuromuscular dos músculos masseter e temporais durante a mastigação, em mulheres de 24 anos, com oclusão normal. A análise eletromiográfica durante os ciclos mastigatórios mostrou que a atividade eletromiográfica era mais elevada no músculo do masseter homolateral ao lado de mastigação do que no músculo contralateral, enquanto que os músculos temporais apresentavam atividades eletromiográficas similares. Na comparação da mastigação de um bolo alimentar duro versus um bolo alimentar macio, a atividade durante a mastigação do bolo alimentar duro foi maior no músculo masseter contralateral que a do músculo masseter homolateral, indicando o equilíbrio neuromuscular do sistema estomatognático e a sua capacidade de se adaptar a diferentes cargas mastigatórias.

Oliveira et al. (2006) analisando a amplitude eletromiográfica dos ciclos mastigatórios em indivíduos surdos (controles) concluíram que os valores de RMS (raiz quadrada média) obtidos da seleção de janelas de $250 \mathrm{~ms}$, em períodos relativamente estáveis do sinal eletromiográfico de ciclos mastigatórios não sofreram mudanças relativas ao tempo de coleta, em ambos os grupos estudados.

Segundo Regalo et al. (2006a) a eletromiografia tem se constituído em um importante instrumento para a investigação das bases fisiopatológicas das alterações que acometem o desempenho da musculatura facial durante a mastigação. 
Peyron e Woda (2006) descreveram que a idade exercia um papel importante nos indivíduos mais idosos a percepção era diminuída e, consequentemente levavam mais tempo para reagir. Se suas dentições estavam relativamente completas e saudáveis, precisavam simplesmente de aumentar o número de ciclos mastigatórios para uma determinada quantidade de alimento. $\mathrm{E}$, naturalmente, a textura dos alimentos também influenciava, pois quanto mais duro era o alimento maior era o número de ciclos mastigatórios.

Mishellany-Dutour et al. (2008) avaliaram o impacto da idade e da dentição na função mastigatória. O grupo 1 era constituído de indivíduos completamente dentados (idade 35,6 + / - 10,6 anos), o grupo 2 era constituído por indivíduos idosos completamente dentados (idade $68,8+/-7,0$ anos) e o grupo 3 era constituído por indivíduos idosos usuários de prótese total (idade 68,1 + / - 7,2 anos). Indivíduos idosos dentados utilizavam maior número de ciclos mastigatórios para chegar ao limiar de deglutição dos alimentos do que os indivíduos mais jovens, com o tamanho das partículas de alimento menores, sequências mastigatórias mais longas, e maior atividade eletromiográfica tanto para amendoins quanto para cenouras. Além disso, os indivíduos usuários de próteses totais utilizavam maior número de ciclos mastigatórios do que os indivíduos idosos dentados para chegar ao limiar de deglutição de amendoins, com partículas de alimento maiores, apesar do maior número de ciclos mastigatórios, maior tempo de duração da seqüência mastigatória e maior atividade eletromiográfica. A função mastigatória foi, portanto, adaptada ao envelhecimento, mas foi prejudicada nos usuários de próteses totais, onde os seus aparelhos protéticos não se adaptavam perfeitamente ao aparelho mastigatório deficiente.

Vianna-Lara et al. (2009) compararam a eletromiografia de superfície dos músculos masseter e temporal nos diferentes padrões faciais, concluindo que os diferentes tipos de padrão facial vertical não determinam padrões distintos na atividade eletromiográfica, durante o repouso e mastigação bilateral. Ap Biasotto-Gonzalez et al. (2010) compararam pela eletromiografia a atividade dos músculos masseter, temporal e suprahióideos, a 
mastigação de diferentes materiais em indivíduos com oclusão normal, sem história de desordem temporomandibular, mostrando que o parafilme e o rolete de algodão apresentaram menor coeficiente de variação, sendo considerados como melhores materiais para serem utilizados nos estudos eletromiográficos na condição clínica de mastigação. 
3. ProposiçÃo 


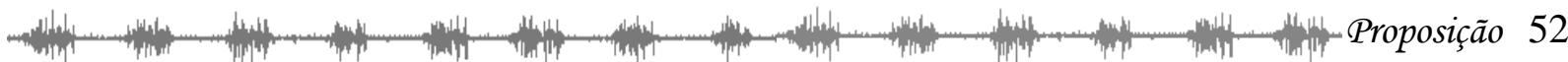

\section{Proposição}

O objetivo deste trabalho foi analisar comparativamente:

1) A atividade eletromiográfica dos músculos masseter e temporal na condição de repouso e nas condições clínicas posturais da mandíbula (lateralidade direita e esquerda, protrusão e contração voluntária máxima),

2) A força de mordida molar máxima direita e esquerda e

3) A eficiência mastigatória de indivíduos que apresentavam esquizofrenia e transtornos do humor que faziam uso de medicamentos (grupos tratados) com indivíduos que não apresentavam patologias e que não faziam uso de medicamentos (grupo controle). 
4. MATeRi al e Métodos 


\section{MAteri al e Métodos}

O presente trabalho foi realizado no Laboratório de Eletromiografia "Prof. Dr. Mathias Vitti" do Departamento de Morfologia, Estomatologia e Fisiologia da Faculdade de Odontologia de Ribeirão Preto da Universidade de São Paulo - USP (Figura 1), sob responsabilidade da Profa. Dra. Simone Cecilio Hallak Regalo e colaboração do Prof. Dr. Jaime Eduardo Cecilio Hallak, Chefe do Setor de Psiquiatria e responsável pelo do Laboratório de Neuropsiquiatria Clínica da Faculdade de Medicina de Ribeirão Preto da Universidade de São Paulo. A coleta dos dados realizada nos voluntários do grupo tratado e controle ocorreram respectivamente: em uma sala adaptada na ala psiquiátrica ( $3^{\circ}$ andar) do Hospital das Clínicas e no Laboratório de Eletromiografia da Faculdade de Odontologia ambos localizados no Campus Universitário de Ribeirão Preto - USP.

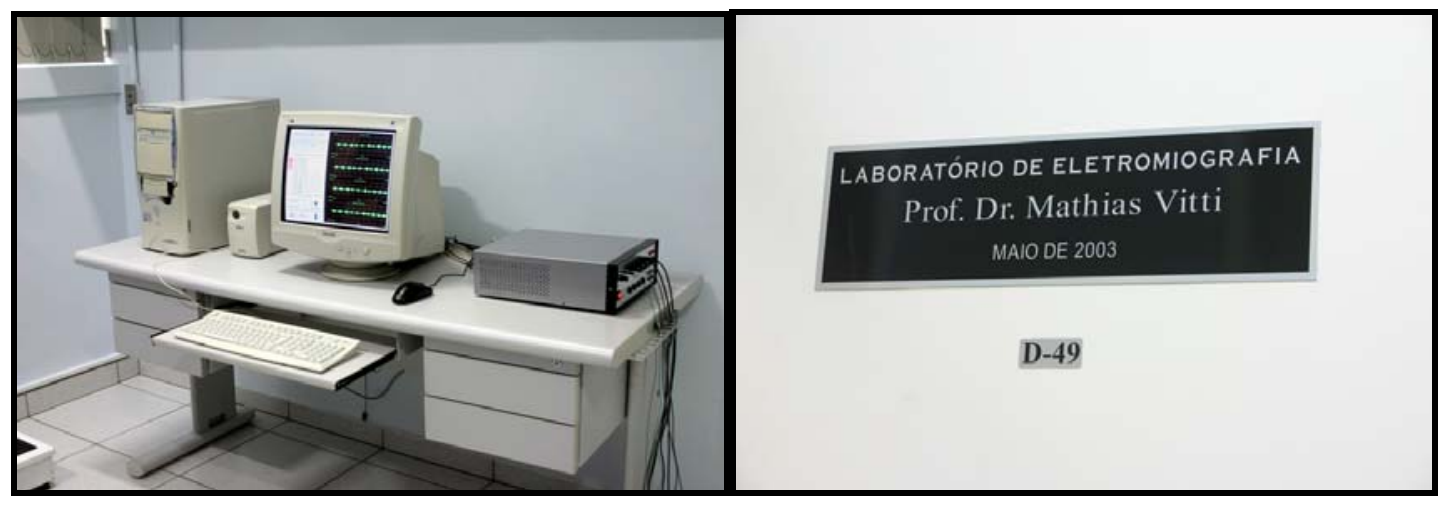

Figura 1. Eletromiógrafo no laboratório de Eletromiografia "Prof. Dr. Mathias Vitti" do Departamento de Morfologia, Estomatologia e Fisiologia da Faculdade de Odontologia de Ribeirão Preto da Universidade de São Paulo

Os participantes do estudo foram devidamente esclarecidos sobre as condições do presente estudo e assinaram o "Termo de Consentimento Livre e Esclarecido". A presente pesquisa foi aprovada pelo Comitê de Ética em Pesquisa da Faculdade de Odontologia de Ribeirão Preto da Universidade de São Paulo, de acordo com o processo $\mathrm{n}^{\circ}$ 
Foram analisados eletromiograficamente os músculos masseter e temporal em diversas situações clínicas, obtidas as forças de mordida molar máxima direita e esquerda e a eficiência mastigatória em 80 indivíduos, com idade média de 35 anos ( \pm 6anos) de ambos os sexos, assim distribuídos:

\begin{tabular}{|c|c|c|c|}
\hline Grupo & $\begin{array}{c}\mathbf{n}^{\circ} \text { de } \\
\text { indivíduos }\end{array}$ & Patologia & Tratamento básico \\
\hline $1=$ & 20 & Esquizofrênicos & Antipsicóticos diversos \\
tratado & & Transtornos do Humor & Antidepressivos e \\
\hline $2=$ & 20 & Bipolar tipo I) & Estabilizadores do Humor \\
tratado & & Sem patologias & Não medicados \\
\hline $3=$ & 40 & & \\
\hline controle* & & & \\
\hline
\end{tabular}

*os indivíduos controle foram pareados sujeito a sujeito

\section{SELEÇÃo dos I ndi ví duOS VoluntáRI OS CONTROLE E TRATAdo}

\section{Grupo Controle}

Para a seleção da amostra foram determinados critérios de inclusão e exclusão por meio de anamnese e exames clínicos. Na anamnese foram obtidas informações referentes aos dados pessoais, histórico médico, histórico dental, presença de hábitos parafuncionais, possíveis sinais e sintomas clínicos de disfunção temporomandibular. Dentre os critérios de inclusão odontológicos foram selecionados indivíduos que não relatavam qualquer sinal ou sintoma doloroso na face, incluindo a articulação temporomandibular, e que possuía na arcada dental a presença de, pelo menos, de incisivos até primeiros molares, tanto superiores quanto inferiores, 
estando restaurados, direta ou indiretamente, e/ou hígidos. Não foram selecionados indivíduos que faziam uso de aparelhos ortodônticos.

\section{Grupo Tratado}

A seleção dos pacientes voluntários para os Grupos 1 e 2 foi realizada pelos médicos residentes do setor de psiquiatria, Dr. Joel Porfirio Pinto e Dr. João Paulo Maia de Oliveira, supervisionados pelo Prof. Dr. Jaime Eduardo Cecilio Hallak. Os critérios para determinação da doença, seja ela esquizofrenia ou transtorno do humor foram estritamente médicos, levando em consideração o DSM-IV-TR e a décima Classificação Estatística Internacional de Doenças e Problemas Relacionados com a Saúde (CID-10). A participação da equipe odontológica no trabalho se restringiu apenas a avaliação proposta na metodologia deste estudo.

A abordagem inicial aos pacientes tratados para conhecimento sobre os objetivos e desenvolvimento da pesquisa foi realizada primeiramente pelo médico. Pacientes portadores das patologias em crise aguda de sua doença, imobilizados em macas ou cadeiras, não foram abordados. Somente após o aceite de participação voluntária dos pacientes, os mesmos eram encaminhados para que tomassem conhecimento da metodologia que seria utilizada; posteriormente eram submetidos ao exame clínico da cavidade da boca e estando de acordo com os critérios de inclusão propostos pelo estudo, o Termo de Consentimento Livre e Esclarecido era lido e assinado pelo voluntário.

Os voluntários do Grupo 3 foram estudantes e/ou funcionários de várias Unidades do Campus de Ribeirão Preto da Universidade de São Paulo.

Os grupos tratados e controle foram pareados sujeito a sujeito (gênero, idade, peso, altura). 


\section{EleTromi OGRAFIA}

Para o registro eletromiográfico foram utilizados cinco canais do sistema Myosystem BR1 - DataHominis Ltda (Uberlândia, MG, Brasil) (Figura 2), com aquisição simultânea, aterramento comum a todos canais, filtros de baixa passagem de $10 \mathrm{~Hz}$ a $5 \mathrm{KHz}$; impedância de entrada dos canais de $10 \mathrm{G} \Omega$ em modo diferencial, 12 bites de faixa de resolução dinâmica, faixa de amplitude $-10 \mathrm{~V}$ a $+10 \mathrm{~V}$ e freqüência de amostragem por canal de $2 \mathrm{KHz}$. Para visualização e processamento dos sinais foi utilizado o programa Myosystem I versão 3.5 (Uberlândia, MG, Brasil) que também permitiu, após a digitalização, que os sinais fossem analogicamente amplificados com um ganho de 1000x, filtrados por um filtro passa-banda de 0,01-1,5kHz e amostrados por uma placa conversora A/D de 12 bites com freqüência de aquisição de $2 \mathrm{kHz}$.

Eletrodos ativos diferenciais de superfície (duas barras de cloreto de prata, de $10 \mathrm{~mm}$ de comprimento por $2 \mathrm{~mm}$ de largura, afastadas em 10mm, com impedância de entrada de $10 \mathrm{G} \Omega$ e taxa de rejeição do modo comum de $130 \mathrm{~dB}$ a $60 \mathrm{~Hz}$ ) (Figura 3), foram usados neste estudo. A pele da região de colocação dos eletrodos recebeu limpeza com álcool e tricotomia quando necessária. Os eletrodos ativos diferenciais foram posicionados sobre a pele na região do ventre de ambos os masseteres direito e esquerdo, e sobre a pele na região da porção anterior do músculo temporal direito e esquerdo. A posição dos eletrodos foi determinada seguindo as recomendações de Cram et al. (1998) que preconizam o teste de função muscular, e foram fixados por esparadrapos adesivos com a maior extensão das barras em sentido perpendicular à direção das fibras musculares. Um eletrodo circular de aço inoxidável (três centímetros de diâmetro) também foi usado como eletrodo de referência (eletrodo terra) (Figura 4), fixado sobre a pele da região do dorso do punho. 


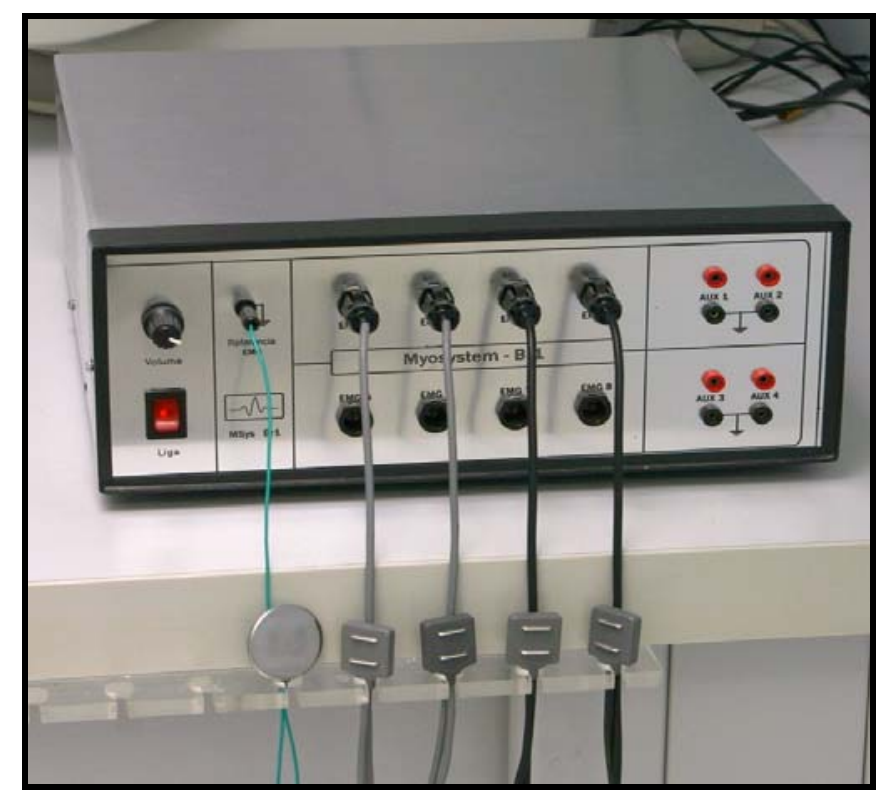

Figura 2. Myosystem - BR1 - DataHominis Tecnologia Ltda.

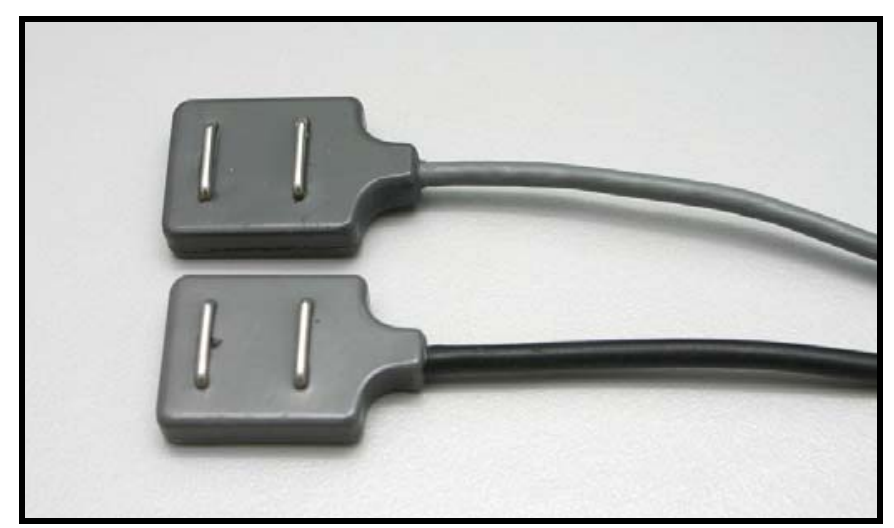

Figura 3. Eletrodos ativos de superfície.

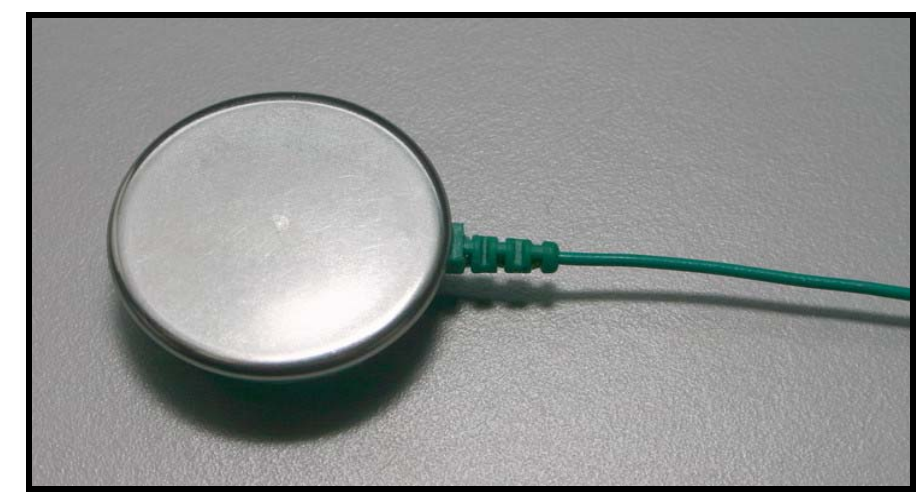

Figura 4. Eletrodo circular de aço inoxidável (eletrodo de referência). 
Previamente à realização de cada experimento, foram dadas as instruções e explicações necessárias, solicitando sempre aos voluntários que permanecessem o mais calmo possível, respirando lenta e pausadamente. Os voluntários foram orientados e treinados para que realizassem previamente todos os movimentos mandibulares que seriam avaliados durante os exames para assegurar a confiabilidade nos procedimentos.

Os sinais eletromiográficos foram coletados pelo tempo de cinco segundos durante o repouso e em diferentes condições clínicas, como protrusão, lateralidade direita e esquerda e, por tempo de quatro segundos nas condições de contração voluntária máxima (fator normalizante) e apertamento dental com parafilme. A coleta foi realizada também durante os movimentos de mastigação habitual com amendoim e uva-passa e mastigação não-habitual, com o uso de parafilme.

O parafilme é um material inerte que se constitui em uma folha de parafina (Parafilm $\mathrm{M}^{\circledR}$ ) que foi dobrada ( $18 \times 17 \times 4 \mathrm{~mm}$, peso $245 \mathrm{mg}$ ) e colocada em ambos os lados da arcada dental durante o apertamento dental e durante a mastigação não-habitual (Figura 5).

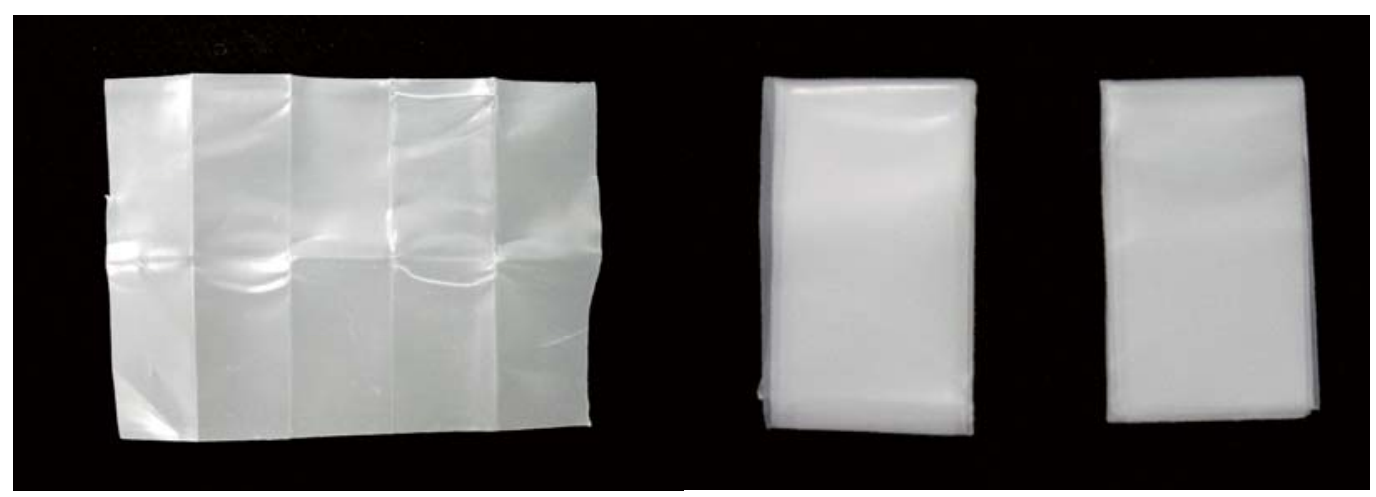

Figura 5. Parafilme - folha de parafina (Parafilm $M^{\circledR}$ ) que foi dobrada $(18 \times 17 \times 4 \mathrm{~mm}$, peso 245mg)

O registro das atividades musculares durante mastigação habitual foi executada durante dez segundos com os indivíduos mastigando 5 amendoins e depois mastigando 6 uvas passas (cinco gramas de cada um). O registro das atividades musculares durante a mastigação não habitual também ocorreu durante dez segundos. Nesta mastigação, um 


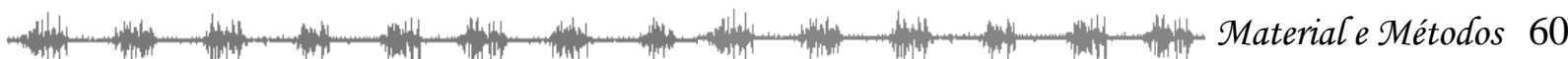

movimento de curta excursão de abertura e fechamento, do tipo charneira, foi solicitado para reduzir os efeitos da mudança de comprimento $x$ tensão do músculo, típico em registros dinâmicos (De Luca, 1997).

Durante a coleta dos dados eletromiográficos, os voluntários permaneceram sentados confortavelmente em uma cadeira (tipo escritório), com os braços junto ao corpo e as mãos apoiadas sobre as coxas. Foram analisados os músculos masseter direito (MD), masseter esquerdo (ME), temporal direito (TD) e temporal esquerdo (TE).

\section{FORÇA DE MORDI DA}

Os registros da força de mordida foram realizados após os exames eletromiográficos. O aparelho usado para a determinação da força de mordida foi um dinamômetro digital, modelo IDDK (Kratos, Cotia, SP, Brasil), com capacidade até 100Kgf, adaptado às condições bucais, pertencente ao Departamento de Morfologia, Estomatologia e Fisiologia da Faculdade de Odontologia de Ribeirão Preto - Universidade de São Paulo. O aparelho possui escala em Kgf ou N, uma tecla "set-zero" que permite o controle exato dos valores obtidos e também registro de "pico", que facilita a leitura da força máxima durante a obtenção dos valores. É provido de duas hastes que contém nas extremidades discos de teflon, sobre os quais é aplicada a força a se registrar. Sua célula de carga de precisão elevada e circuito eletrônico para indicar a força fornecem medidas precisas e de fácil leitura no seu visor digital (Figura 6). 


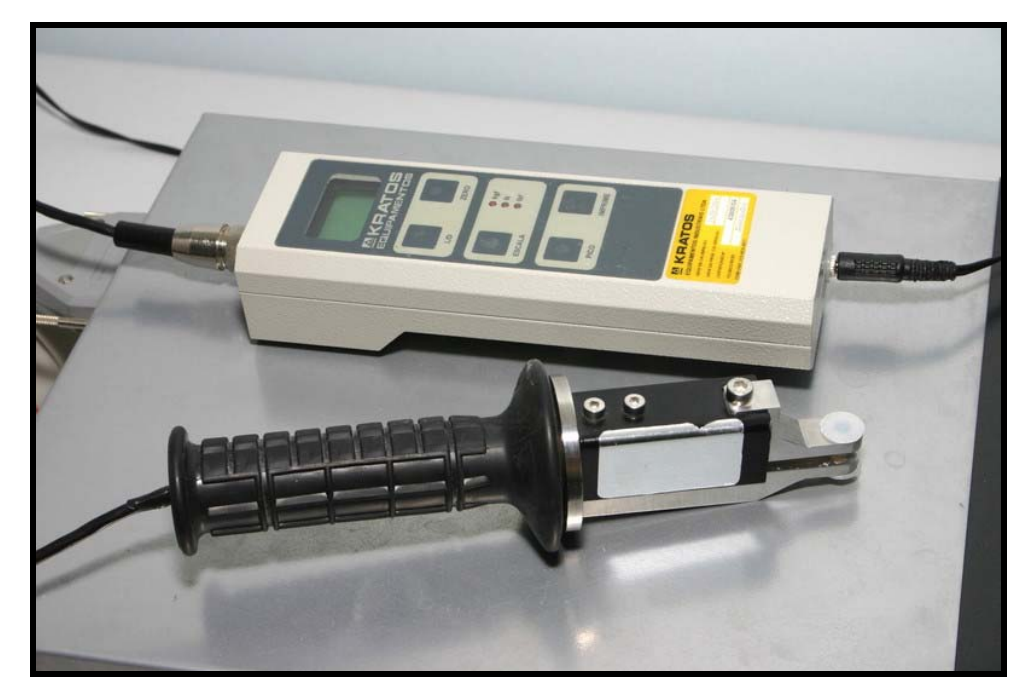

Figura 6. Dinamômetro IDDK Kratos

As medidas foram realizadas na região do primeiro molar permanente direito e esquerdo, por ser a região onde desenvolvemos a maior força de mordida (Regalo et al., 2008). As medidas da força de mordida foram coletadas com os voluntários sentados numa cadeira de escritório com os braços estendidos ao longo do corpo e as mãos estendidas sobre as coxas. O dinamômetro, a cada troca de voluntário, era limpo com álcool e protegido com dedeiras de látex descartáveis (Wariper-SP), posicionadas nas hastes de mordida do aparelho como medida de biossegurança. Os indivíduos eram orientados e treinados para realizar o teste de morder as hastes, para assegurar a confiabilidade no procedimento.

Foram obtidas três medidas de cada lado (tomadas em Kgf), alternando o lado direito e esquerdo, com intervalo de dois minutos entre cada mordida. A força de mordida foi obtida pela média das três medidas para cada lado (Sonnesen et al., 2001; Kogawa et al., 2006). 


\section{EfI CI ÊNCI A MASTI GATÓRI A}

A eficiência do ciclo mastigatório dos voluntários dos grupos estudados foi verificada por meio da integral da envoltória do sinal eletromiográfico, sendo este valor em microvolts/segundo, durante a unidade de tempo. Nos sinais eletromiográficos colhidos durante a mastigação, os valores foram obtidos dos ciclos mastigatórios da coleta do sinal durante 10 segundos. Os dados foram normalizados pela integral da envoltória do sinal coletado durante a contração voluntária máxima.

\section{ANÁli SE dOS DADOS E Estatística}

Os sinais eletromiográficos foram processados no programa Myosystem - $\mathrm{Br} 1$ versão 3.5. Após a digitalização, os sinais foram analogicamente amplificados (com um ganho de 1000x), filtrados (filtro passa-banda de $0,01-1,5 \mathrm{kHz}$ ) e amostrados por uma placa conversora A/D de 12 bites com freqüência de aquisição de $2 \mathrm{KHz}$. O sinal eletromiográfico bruto foi utilizado para derivar valores de amplitude eletromiográfica, obtidos pelo cálculo da raiz quadrada da média (RMS). Os valores da RMS obtidos durante a CVM foram utilizados para a normalização dos valores nas demais situações clínicas. Os dados eletromiográficos foram normalizados e submetidos à análise estatística utilizando o software SPSS versão 17.0 (SPSS Inc.; Chicago, IL, USA). Para a eficiência mastigatória, foram utilizados os valores da integral da envoltória nas mastigações habitual e não habitual, normalizados pelo valor da integral da envoltória do sinal eletromiográfico durante a contração voluntária máxima (CVM), colhido por quatro segundos.

Foi realizada a análise descritiva (médias, desvios padrão, valor máximo e valor mínimo), para cada variável. Os valores obtidos foram comparados pela ANOVA. 


\section{MEDI CAMENTOS UTI LI ZADOS NOS GRUPOS TRATADOS}

Foram registrados a utilização dos seguintes medicamentos nos grupos tratados (Tabelas 1 a 5):

Tabela 1: Antipsicóticos e as dosagens utilizadas no tratamento dos pacientes do grupo com esquizofrenia.

\begin{tabular}{|l|l|l|}
\hline \multicolumn{1}{|c|}{ ANTI PSI CóTI CO } & \multicolumn{1}{c|}{ CLASSI FI CAÇÃO } & \multicolumn{1}{c|}{ DOSAGENS } \\
\hline Olanzapina & Atípico & $10,15,20$ e $30 \mathrm{mg} / \mathrm{dia}$ \\
\hline Clozapina & Atípico & 150,200 e $750 \mathrm{mg} / \mathrm{dia}$ \\
\hline Risperidona & Atípico & $5 \mathrm{mg} / \mathrm{dia}$ \\
\hline Haloperidol & Típico & 2,5 e $7,5 \mathrm{mg} / \mathrm{dia}$ \\
\hline Quetiapina & Atípico & 150 e $600 \mathrm{mg} / \mathrm{dia}$ \\
\hline
\end{tabular}

Tabela 2: Outros medicamentos utilizados no tratamento dos pacientes do grupo com Esquizofrenia.

\begin{tabular}{|l|l|l|}
\hline \multicolumn{1}{|c|}{ MEDI CAMENTO } & \multicolumn{1}{c|}{ DOSAGENS } & \multicolumn{1}{c|}{ FI NALI DADE } \\
\hline Diazepam & $10 \mathrm{mg} / \mathrm{dia}$ & $\begin{array}{l}\text { Tratar ansiedade e causa } \\
\text { relaxamento muscular }\end{array}$ \\
\hline Biperideno & $4 \mathrm{mg} / \mathrm{dia}$ & Antiparkinsoniano \\
\hline Ácido Valpróico & $1 \mathrm{~g} / \mathrm{dia}$ & $\begin{array}{l}\text { Anticonvulsivante } \mathrm{e} \\
\text { estabilizador de humor }\end{array}$ \\
\hline
\end{tabular}


Tabela 3: Medicamentos e suas finalidades terapêuticas no tratamento dos pacientes do grupo com Transtorno Bipolar.

\begin{tabular}{|l|l|l|}
\hline \multicolumn{1}{|c|}{ MEDI CAMENTO } & \multicolumn{1}{|c|}{ DOSAGENS } & \multicolumn{1}{c|}{ FI NALI DADE } \\
\hline Risperidona & $4 \mathrm{mg} / \mathrm{dia}$ & Antipsicótico atípico \\
\hline Olanzapina & 15 e $20 \mathrm{mg} / \mathrm{dia}$ & Antipsicótico atípico \\
\hline Aripiprazol & $15 \mathrm{mg} / \mathrm{dia}$ & Antipsicótico atípico \\
\hline Carbonato de Lítio & $\begin{array}{l}900,1050 \text { e } 1500 \\
\mathrm{mg} / \mathrm{dia}\end{array}$ & Estabilizador de humor \\
\hline Ácido Valpróico & 1250 e $1500 \mathrm{mg} / \mathrm{dia}$ & $\begin{array}{l}\text { Anticonvulsivante e } \\
\text { estabilizador de humor }\end{array}$ \\
\hline Carbamazepina & $1200 \mathrm{mg} / \mathrm{dia}$ & $\begin{array}{l}\text { Anticonvulsivante } \mathrm{e} \\
\text { estabilizador de humor }\end{array}$ \\
\hline Topiramato & $50 \mathrm{mg} / \mathrm{dia}$ & Anticonvulsivante \\
\hline Lorazepam & 2,4 e $8 \mathrm{mg} /$ dia & Tranquilizante \\
\hline Clonazepam & $2 \mathrm{mg} / \mathrm{dia}$ & Tranquilizante \\
\hline Clobazam & $20 \mathrm{mg} / \mathrm{dia}$ & Tranquilizante \\
\hline Bupropiona & $150 \mathrm{e} 300 \mathrm{mg} /$ dia & Antidepressivo atípico \\
\hline Biperideno & $2 \mathrm{mg} / \mathrm{dia}$ & Antiparkinsoniano \\
\hline
\end{tabular}

Tabela 4: Antidepressivos, e suas dosagens, utilizados no tratamento dos pacientes do grupo com Depressão.

\begin{tabular}{|l|l|l|}
\hline \multicolumn{1}{|c|}{ ANTI DEPRESSI VO } & \multicolumn{1}{c|}{ CLASSI FI CAÇÃO } & \multicolumn{1}{c|}{ DOSAGENS } \\
\hline Imipramina & Antidepressivo tricíclico & $75 \mathrm{mg} / \mathrm{dia}$ \\
\hline Tranilcipromina & IMAO & $30 \mathrm{mg} / \mathrm{dia}$ \\
\hline Fluoxetina & ISRS & $20 \mathrm{e} 40 \mathrm{mg} / \mathrm{dia}$ \\
\hline Paroxetina & ISRS & $20 \mathrm{mg} / \mathrm{dia}$ \\
\hline Clomipramina & Antidepressivo trić́clico & $175 \mathrm{mg} / \mathrm{dia}$ \\
\hline Mirtazapina & ISRS & $30 \mathrm{mg} / \mathrm{dia}$ \\
\hline
\end{tabular}


Tabela 5: Outros medicamentos utilizados no tratamento dos pacientes do grupo com Depressão.

\begin{tabular}{|l|l|l|}
\hline \multicolumn{1}{|c|}{ MEDI CAMENTO } & \multicolumn{1}{c|}{ DOSAGENS } & \multicolumn{1}{c|}{ FI NALI DADE } \\
\hline Clonazepam & 1,2 e $6 \mathrm{mg} / \mathrm{dia}$ & Tranqüilizante \\
\hline Quetiapina & 50 e $800 \mathrm{mg} / \mathrm{dia}$ & Antipsicótico atípico \\
\hline Risperidona & $2 \mathrm{mg} / \mathrm{dia}$ & Antipsicótico atípico \\
\hline Fenitoína & & Anticonvulsivante \\
\hline Fenobarbital & & Anticonvulsivante \\
\hline
\end{tabular}


5. Resultados 


\section{Resultados}

\section{Dados Eletromiográficos}

Como descrito na metodologia, os exames eletromiográficos foram realizados durante o desenvolvimento de atividades posturais como repouso, protrusão, lateralidade direita e lateralidade esquerda e contração voluntária máxima; e atividades dinâmicas como mastigação habitual de amendoim e uvas passas, e mastigação não habitual, de parafilme.

Os exames avaliaram a atividade dos músculos masseter direito, masseter esquerdo, temporal direito e temporal esquerdo. Os dados de atividade eletromiográfica foram normalizados, tabelados e verificou-se que eles se distribuíram de maneira normal. Os resultados das atividades posturais e das dinâmicas foram analisados de forma independente, principalmente porque os valores das atividades posturais derivaram da RMS e os valores das mastigações, derivaram da integral da envoltória, sendo assim, estão apresentados abaixo de forma separada. 


\section{Atividades Posturais}

\section{REPOUSO}

Durante o repouso, notou-se maior atividade eletromiográfica nos voluntários com esquizofrenia (Grupo 1) e com transtornos do humor (Grupo 2) quando comparada com a atividade do grupo controle (Grupo 3), com diferenças estatísticas significantes. A atividade eletromiográfica do grupo com transtornos do humor foi maior em relação ao grupo com esquizofrenia para todos os músculos analisados exceto para o músculo temporal esquerdo, onde a atividade foi maior no grupo com esquizofrenia (Figura 7 e Tabela 6).

\section{Repouso}

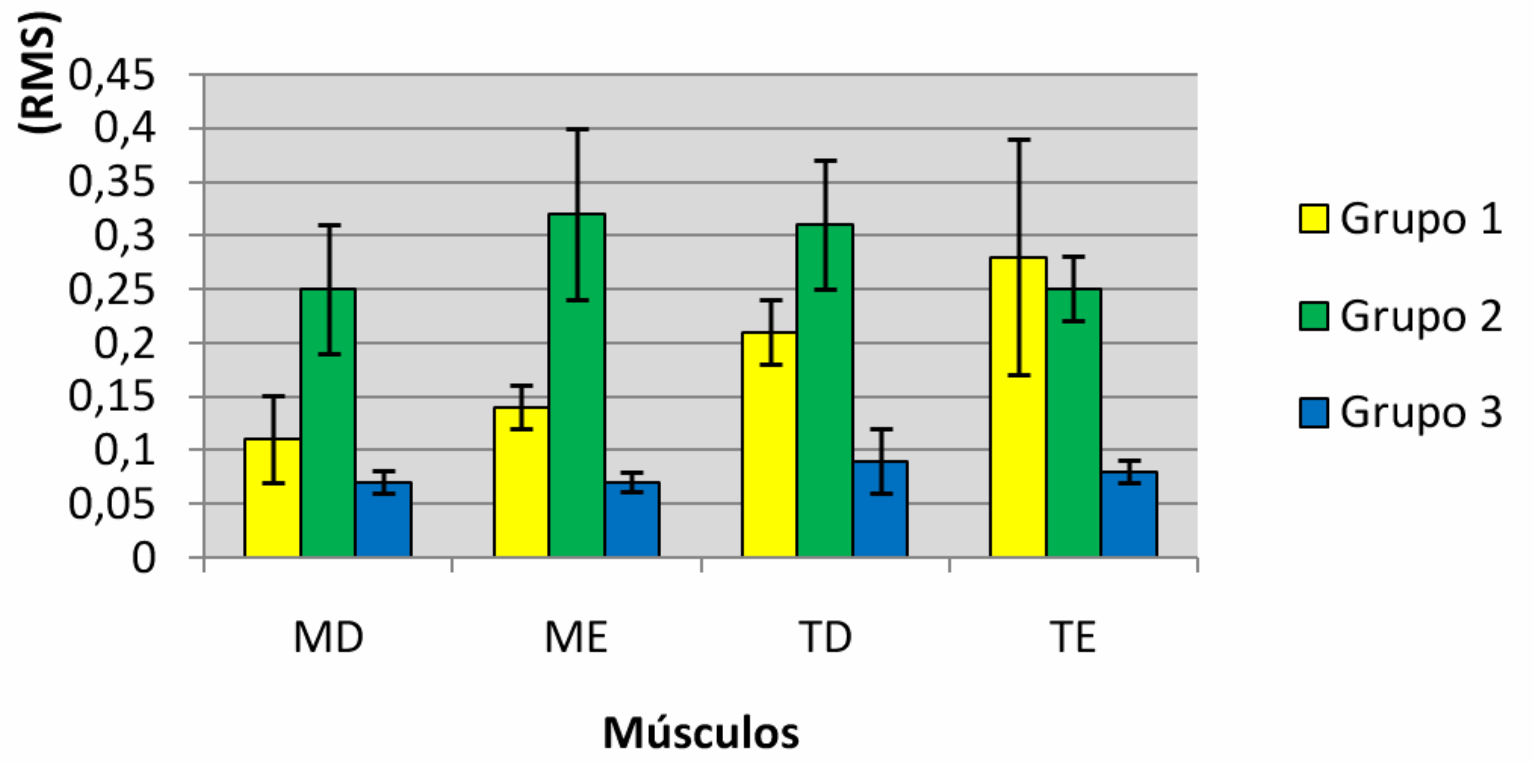

Figura 7. Valores médios eletromiográficos normalizados dos músculos masseter direito (MD) e esquerdo (ME), temporal direito (TD) e esquerdo (TE) nos três grupos analisados, para a condição clínica de repouso. 
Tabela 6. Médias eletromiográficas normalizadas (RMS) e erro-padrão dos músculos masseter direito (MD), masseter esquerdo (ME), temporal direito (TD) e temporal esquerdo (TE) dos três grupos durante a condição clínica de repouso.

\begin{tabular}{cccccc}
\hline Regiões & $\begin{array}{c}\text { Grupos de } \\
\text { Indivíduos }\end{array}$ & No & Média & Erro Padrão & Sig. \\
\hline \multirow{3}{*}{ Masseter Direito } & Grupo 1 & 20 & 0,11 & $\pm 0,04$ & \\
& Grupo 2 & 20 & 0,25 & $\pm 0,06$ & $* *$ \\
& Grupo 3 & 40 & 0,07 & $\pm 0,01$ & \\
\hline \multirow{3}{*}{ Masseter Esquerdo } & Grupo 1 & 20 & 0,14 & $\pm 0,02$ & $*$ \\
& Grupo 2 & 20 & 0,32 & $\pm 0,08$ & $*$ \\
& Grupo 3 & 40 & 0,07 & $\pm 0,009$ & \\
\hline \multirow{3}{*}{ Temporal Direito } & Grupo 1 & 20 & 0,21 & $\pm 0,03$ & \\
& Grupo 2 & 20 & 0,31 & $\pm 0,06$ & \\
& Grupo 3 & 40 & 0,09 & $\pm 0,03$ & \\
\hline \multirow{3}{*}{ Temporal Esquerdo } & Grupo 1 & 20 & 0,28 & $\pm 0,11$ & \\
& Grupo 2 & 20 & 0,25 & $\pm 0,03$ & \\
& Grupo 3 & 40 & 0,08 & $\pm 0,01$ & \\
\hline
\end{tabular}

*Significativo para $\mathrm{p}<0,05$

$* *$ Significativo para $\mathrm{p}<0,01$ 


\section{LATERALI DADE DI REITA}

Durante a análise dos dados gerados pela manutenção da posição lateralidade direita, os grupos com esquizofrenia e transtornos do humor revelaram um padrão de contração eletromiográfica maior que o grupo controle para todos os músculos. A atividade eletromiográfica nos voluntários com esquizofrenia apresentou um equilíbrio entre os lados direito e esquerdo para os músculos masseter e temporal. A atividade eletromiográfica nos voluntários com transtornos do humor foi muito maior para todos os músculos e grupos com exceção do músculo temporal esquerdo, onde a atividade foi maior no grupo com esquizofrenia (Figura 8 e Tabela 7).

\section{Lateralidade Direita}

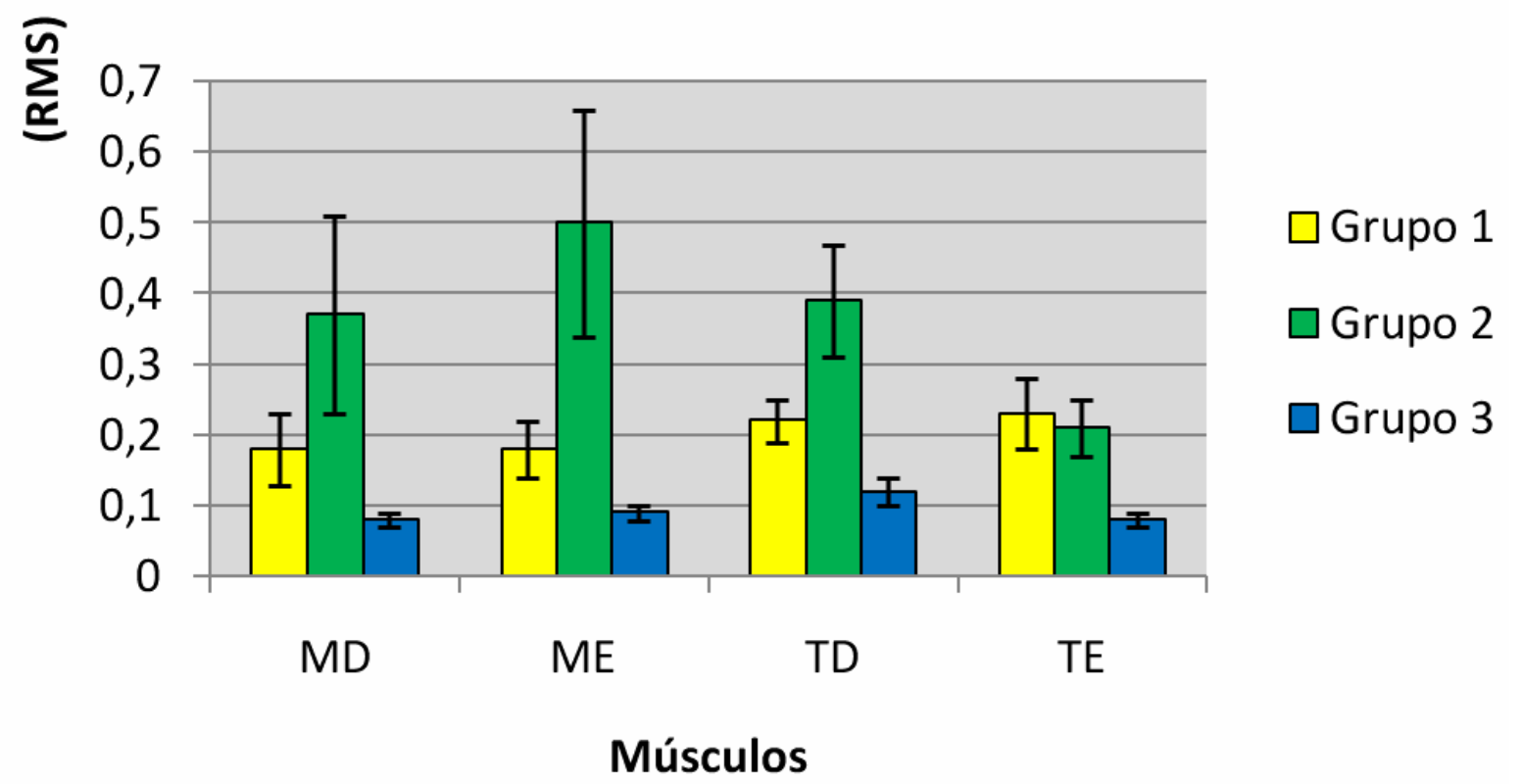

Figura 8. Valores médios eletromiográficos normalizados dos músculos masseter direito (MD) e esquerdo (ME), temporal direito (TD) e esquerdo (TE) nos três grupos analisados, para a condição clínica de lateralidade direita. 
Tabela 7. Médias eletromiográficas normalizadas (RMS) e erro-padrão dos músculos masseter direito (MD), masseter esquerdo (ME), temporal direito (TD) e temporal esquerdo (TE) dos três grupos durante a condição clínica de lateralidade direita.

\begin{tabular}{cccccc}
\hline Regióes & $\begin{array}{c}\text { Grupos de } \\
\text { Indivíduos }\end{array}$ & No & Média & Erro Padrão & Sig. \\
\hline \multirow{3}{*}{ Masseter Direito } & Grupo 1 & 20 & 0,18 & $\pm 0,05$ & \\
& Grupo 2 & 20 & 0,37 & $\pm 0,14$ & $*$ \\
& Grupo 3 & 40 & 0,08 & $\pm 0,01$ & \\
\hline \multirow{3}{*}{ Masseter Esquerdo } & Grupo 1 & 20 & 0,18 & $\pm 0,04$ & $*$ \\
& Grupo 2 & 20 & 0,5 & $\pm 0,16$ & $*$ \\
& Grupo 3 & 40 & 0,09 & $\pm 0,01$ & \\
Temporal Direito & Grupo 1 & 20 & 0,22 & $\pm 0,03$ & \\
& Grupo 2 & 20 & 0,39 & $\pm 0,08$ & $*$ \\
& Grupo 3 & 40 & 0,12 & $\pm 0,02$ & \\
\hline \multirow{3}{*}{ Temporal Esquerdo } & Grupo 1 & 20 & 0,23 & $\pm 0,05$ & \\
& Grupo 2 & 20 & 0,21 & $\pm 0,04$ & \\
& Grupo 3 & 40 & 0,08 & $\pm 0,01$ & \\
\hline
\end{tabular}

*Significativo para $p<0,05$

$* *$ Significativo para $\mathrm{p}<0,01$ 


\section{LATERALI DADE ESQUERDA}

Quando se analisou a manutenção da posição de lateralidade esquerda verificou-se novamente uma hiperativação de todos os músculos analisados para o grupo com transtorno de humor. Houve diferença estatisticamente significante para a comparação entre todos os grupos e músculos. (Figura 9 e Tabela 8).

\section{Lateralidade Esquerda}

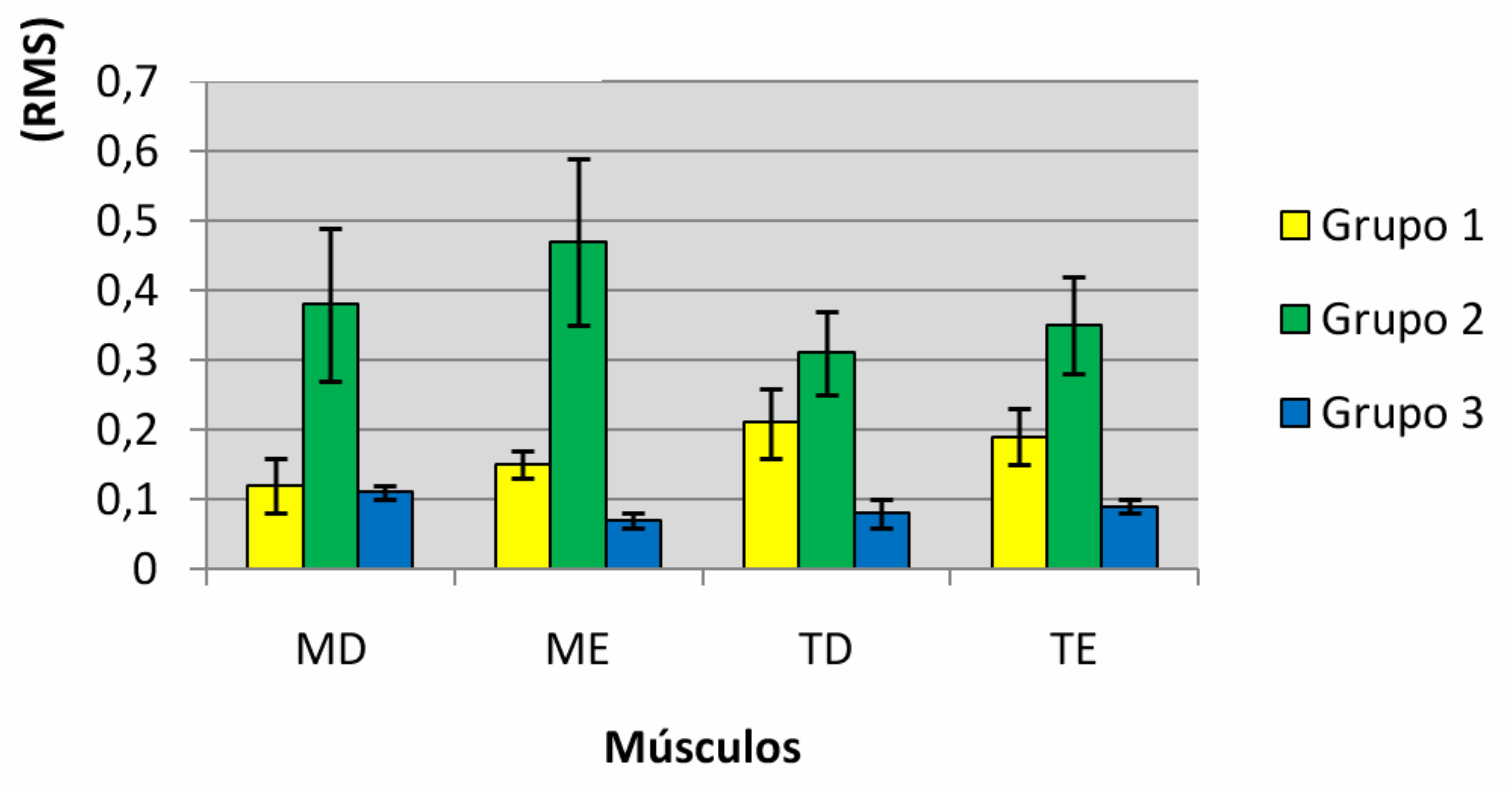

Figura 9. Valores médios eletromiográficos normalizados dos músculos masseter direito (MD) e esquerdo (ME), temporal direito (TD) e esquerdo (TE) nos três grupos analisados, para a condição clínica de lateralidade esquerda. 
Tabela 8. Médias eletromiográficas normalizadas (RMS) e erro-padrão dos músculos masseter direito (MD), masseter esquerdo (ME), temporal direito (TD) e temporal esquerdo (TE) dos três grupos durante a condição clínica de lateralidade esquerda.

\begin{tabular}{cccccc}
\hline Regióes & $\begin{array}{c}\text { Grupos de } \\
\text { Indivíduos }\end{array}$ & No & Média & Erro Padrão & Sig. \\
\hline \multirow{3}{*}{ Masseter Direito } & Grupo 1 & 20 & 0,12 & $\pm 0,04$ & \\
& Grupo 2 & 20 & 0,38 & $\pm 0,11$ & $* *$ \\
& Grupo 3 & 40 & 0,11 & $\pm 0,01$ & \\
\hline \multirow{3}{*}{ Masseter Esquerdo } & Grupo 1 & 20 & 0,15 & $\pm 0,02$ & \\
& Grupo 2 & 20 & 0,47 & $\pm 0,12$ & $* *$ \\
& Grupo 3 & 40 & 0,07 & $\pm 0,01$ & \\
\hline \multirow{3}{*}{ Temporal Direito } & Grupo 1 & 20 & 0,21 & $\pm 0,05$ & $*$ \\
& Grupo 2 & 20 & 0,31 & $\pm 0,06$ & $*$ \\
& Grupo 3 & 40 & 0,08 & $\pm 0,02$ & \\
\hline \multirow{2}{*}{ Temporal Esquerdo } & Grupo 1 & 20 & 0,19 & $\pm 0,04$ & \\
& Grupo 2 & 20 & 0,35 & $\pm 0,07$ & $*$ \\
& Grupo 3 & 40 & 0,09 & $\pm 0,01$ & \\
\hline
\end{tabular}

*Significativo para $\mathrm{p}<0,05$

$* *$ Significativo para $\mathrm{p}<0,01$ 


\section{PROTRUSÃO}

Durante a manutenção da posição de protrusão, a atividade eletromiográfica nos voluntários com transtorno de humor foi maior para todos os músculos analisados exceto para o temporal direito. Houve diferença estatisticamente significante entre todos os grupos (Figura 10 e Tabela 9).

\section{Protrusão}

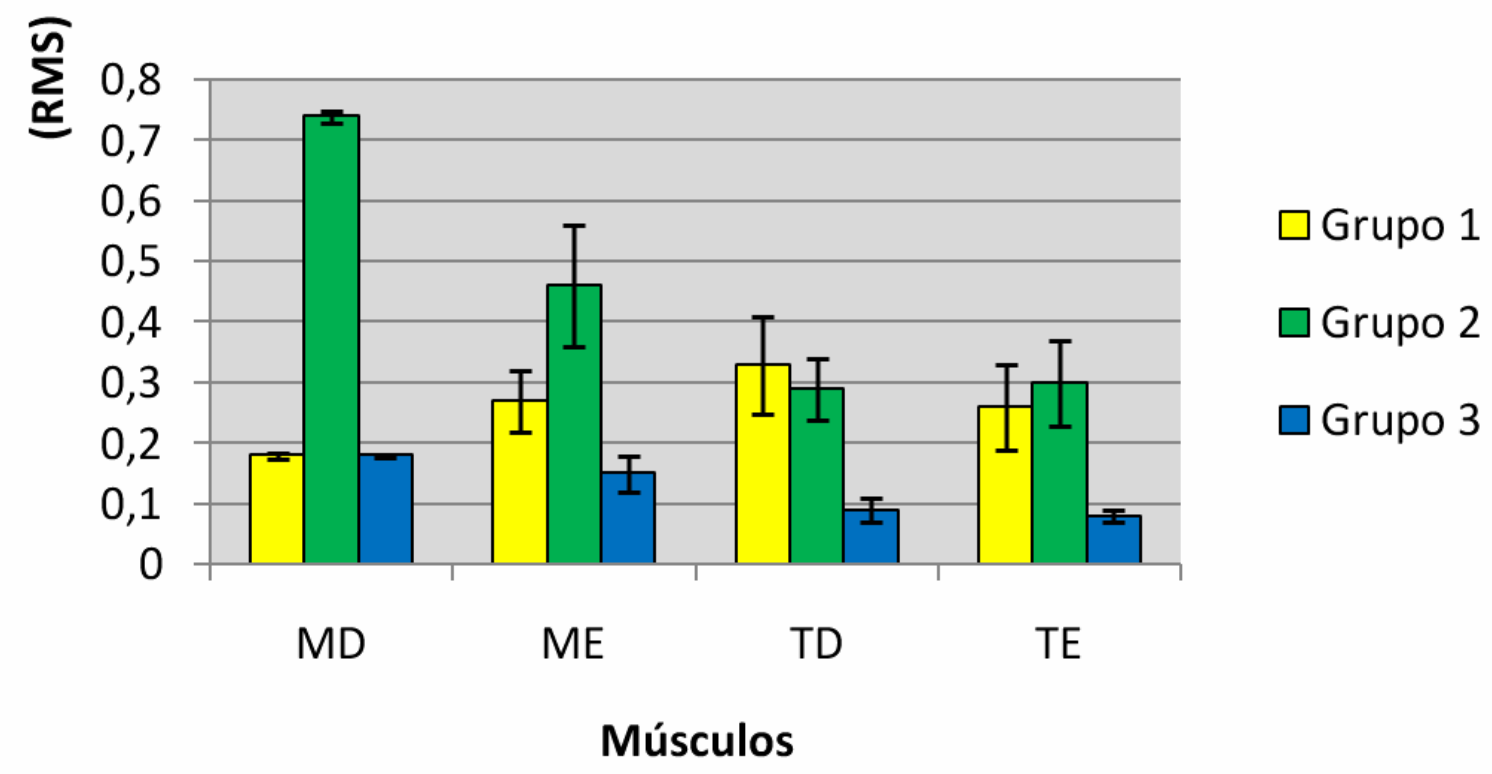

Figura 10. Valores médios eletromiográficos normalizados dos músculos masseter direito (MD) e esquerdo (ME), temporal direito (TD) e esquerdo (TE) nos três grupos analisados, para a condição clínica de protrusão. 
Tabela 9. Médias eletromiográficas normalizadas (RMS) e erro-padrão dos músculos masseter direito (MD), masseter esquerdo (ME), temporal direito (TD) e temporal esquerdo (TE) dos três grupos durante a condição clínica de protrusão.

\begin{tabular}{cccccc}
\hline Regióes & $\begin{array}{c}\text { Grupos de } \\
\text { Indivíduos }\end{array}$ & No & Média & $\begin{array}{c}\text { Erro } \\
\text { Padrão }\end{array}$ & Sig. \\
\hline \multirow{3}{*}{ Masseter Direito } & Grupo 1 & 20 & 0,18 & $\pm 0,005$ & \\
& Grupo 2 & 20 & 0,74 & $\pm 0,01$ & $* *$ \\
& Grupo 3 & 40 & 0,18 & $\pm 0,002$ & \\
\hline \multirow{3}{*}{ Masseter Esquerdo } & Grupo 1 & 20 & 0,27 & $\pm 0,05$ & $*$ \\
& Grupo 2 & 20 & 0,46 & $\pm 0,1$ & $* *$ \\
& Grupo 3 & 40 & 0,15 & $\pm 0,03$ & \\
Temporal Direito & Grupo 1 & 20 & 0,33 & $\pm 0,08$ & $*$ \\
& Grupo 2 & 20 & 0,29 & $\pm 0,05$ & $*$ \\
& Grupo 3 & 40 & 0,09 & $\pm 0,02$ & \\
\hline \multirow{3}{*}{ Temporal Esquerdo } & Grupo 1 & 20 & 0,26 & $\pm 0,07$ & \\
& Grupo 2 & 20 & 0,3 & $\pm 0,07$ & $*$ \\
& Grupo 3 & 40 & 0,08 & $\pm 0,01$ & \\
\hline
\end{tabular}

*Significativo para $\mathrm{p}<0,05$

$* *$ Significativo para $\mathrm{p}<0,01$ 


\section{APERTAMENTO DENTAL COM PARAFI LME}

Durante a manutenção da posição de apertamento dental com parafilme não houve diferença estatisticamente significante entre os grupos analisados (Figura 11 e Tabela 10).

\section{Apertamento Parafilme}

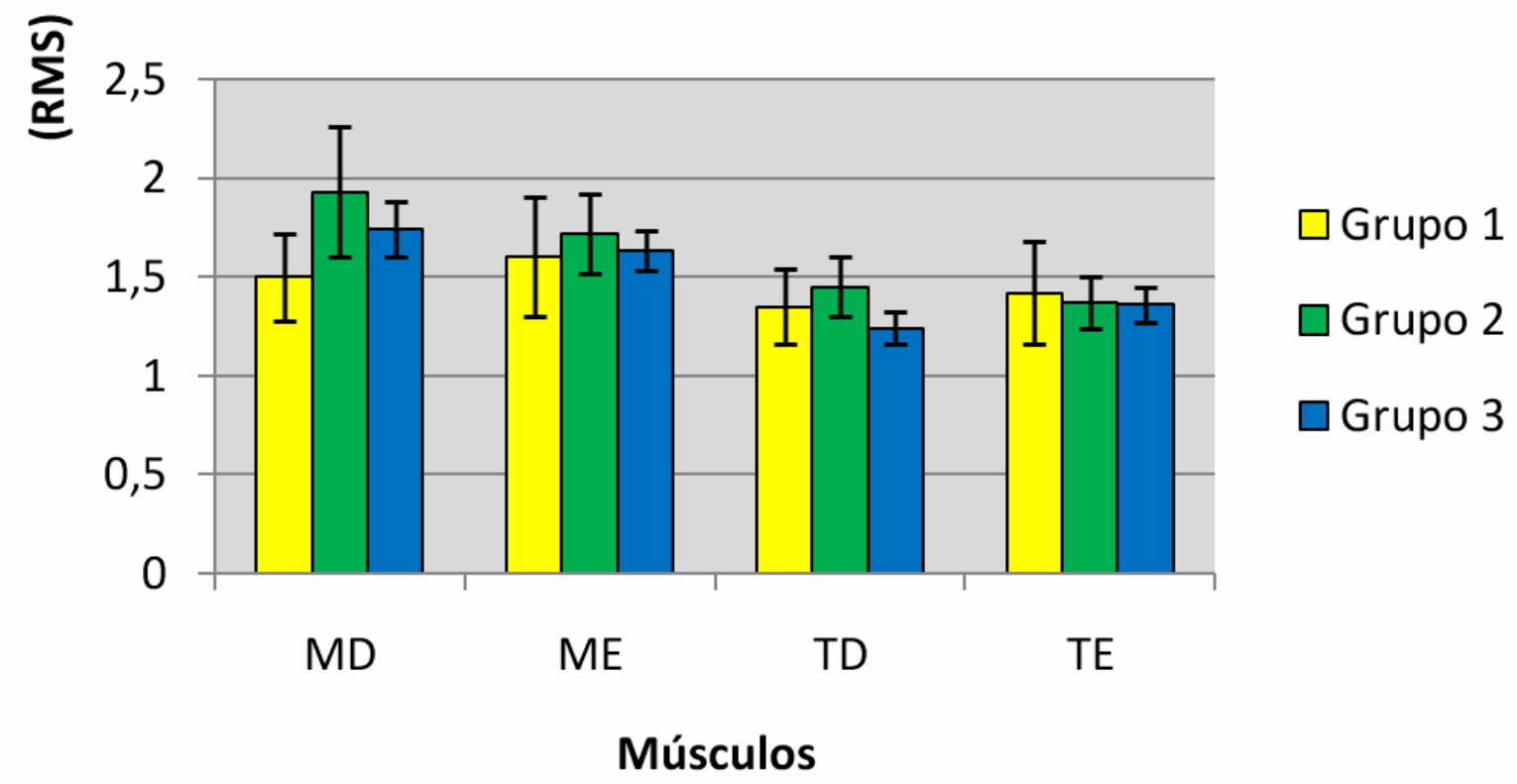

Figura 11. Valores médios eletromiográficos normalizados dos músculos masseter direito (MD) e esquerdo (ME), temporal direito (TD) e esquerdo (TE) nos três grupos analisados, para a condição clínica de apertamento dental com parafilme. 
Tabela 10. Médias eletromiográficas normalizadas (RMS) e erro-padrão dos músculos masseter direito (MD), masseter esquerdo (ME), temporal direito (TD) e temporal esquerdo (TE) dos três grupos durante a condição clínica de apertamento dental com parafilme.

\begin{tabular}{cccccc}
\hline Regióes & $\begin{array}{c}\text { Grupos de } \\
\text { Indivíduos }\end{array}$ & No & Média & Erro Padrão & Sig. \\
\hline \multirow{3}{*}{ Masseter Direito } & Grupo 1 & 20 & 1,5 & $\pm 0,22$ & \\
& Grupo 2 & 20 & 1,93 & $\pm 0,33$ & n.s. \\
& Grupo 3 & 40 & 1,74 & $\pm 0,14$ & \\
\hline \multirow{3}{*}{ Masseter Esquerdo } & Grupo 1 & 20 & 1,6 & $\pm 0,3$ & \\
& Grupo 2 & 20 & 1,72 & $\pm 0,2$ & n.s. \\
& Grupo 3 & 40 & 1,63 & $\pm 0,1$ & \\
\hline \multirow{3}{*}{ Temporal Direito } & Grupo 1 & 20 & 1,35 & $\pm 0,19$ & \\
& Grupo 2 & 20 & 1,45 & $\pm 0,15$ & n.s. \\
& Grupo 3 & 40 & 1,24 & $\pm 0,08$ & \\
\hline \multirow{3}{*}{ Temporal Esquerdo } & Grupo 1 & 20 & 1,42 & $\pm 0,26$ & \\
& Grupo 2 & 20 & 1,37 & $\pm 0,13$ & n.s. \\
& Grupo 3 & 40 & 1,36 & $\pm 0,09$ & \\
\hline
\end{tabular}

*Significativo para $\mathrm{p}<0,05$

$* *$ Significativo para $\mathrm{p}<0,01$

n.s. = diferença entre grupos não significante 


\section{ATI VIDADES DINÂMICAS: MASTIGAÇÃO HABITUAL DE AMENDOINS E UVAS PASSAS E MASTI GAÇÃO NÃO HABI TUAL DE PARAFI LME}

\section{MASTI GAÇÃO DE AMENDOI M}

A análise da mastigação de amendoim revelou que os voluntários tratados possuem maior atividade eletromiográfica para todos os músculos, exceto para o músculo temporal esquerdo para o grupo com esquizofrenia. O grupo com transtornos do humor apresentou maior atividade eletromiográfica para todos os músculos testados, maior que o grupo com esquizofrenia. Porém, essas diferenças não se mostraram estatisticamente significantes (Figura 12 e Tabela 11).

\section{Mastigação Amendoim}

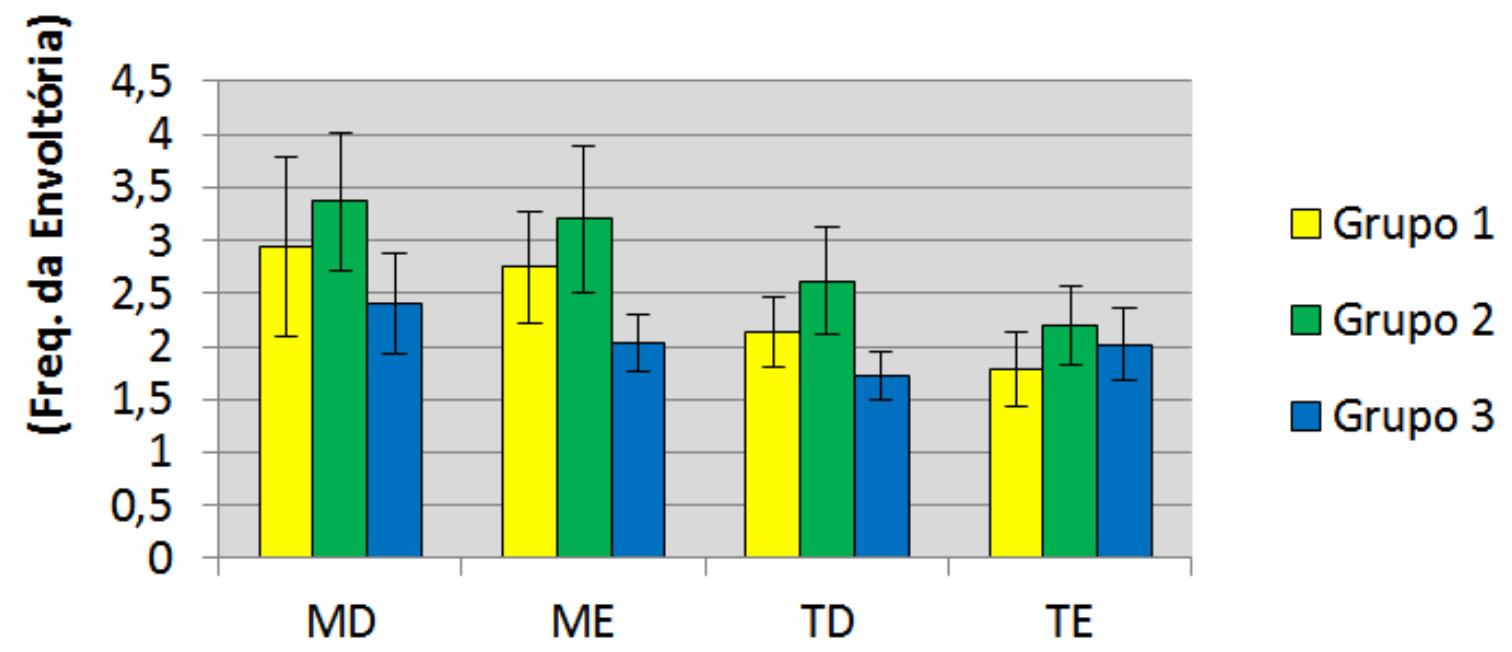

\section{Músculos}

Figura 12. Valores médios eletromiográficos normalizados dos músculos masseter direito (MD) e esquerdo (ME), temporal direito (TD) e esquerdo (TE) nos três grupos analisados, para a atividade dinâmica de mastigação habitual de amendoim. 
Tabela 11. Médias eletromiográficas normalizadas $(\delta)$ e erro-padrão dos músculos masseter direito (MD), masseter esquerdo (ME), temporal direito (TD) e temporal esquerdo (TE) dos três grupos durante a atividade dinâmica de mastigação habitual de amendoim.

\begin{tabular}{cccccc}
\hline Regióes & $\begin{array}{c}\text { Grupos de } \\
\text { Indivíduos }\end{array}$ & No & Média & Erro Padrão & Sig. \\
\hline \multirow{3}{*}{ Masseter Direito } & Grupo 1 & 20 & 2,94 & $\pm 0,85$ & \\
& Grupo 2 & 20 & 3,37 & $\pm 0,65$ & n.s. \\
& Grupo 3 & 40 & 2,40 & $\pm 0,47$ & \\
\hline \multirow{3}{*}{ Masseter Esquerdo } & Grupo 1 & 20 & 2,75 & $\pm 0,53$ & \\
& Grupo 2 & 20 & 3,20 & $\pm 0,70$ & n.s. \\
& Grupo 3 & 40 & 2,03 & $\pm 0,26$ & \\
\hline \multirow{3}{*}{ Temporal Direito } & Grupo 1 & 20 & 2,14 & $\pm 0,33$ & \\
& Grupo 2 & 20 & 2,62 & $\pm 0,50$ & n.s. \\
& Grupo 3 & 40 & 1,72 & $\pm 0,23$ & \\
\hline \multirow{2}{*}{ Temporal Esquerdo } & Grupo 1 & 20 & 1,78 & $\pm 0,35$ & \\
& Grupo 2 & 20 & 2,20 & $\pm 0,37$ & n.s. \\
& Grupo 3 & 40 & 2,02 & $\pm 0,35$ & \\
\hline
\end{tabular}

*Significativo para $p<0,05$

$* *$ Significativo para $\mathrm{p}<0,01$

n.s. = diferença entre grupos não significante 


\section{MASTI GAÇÃO DE UVAS PASSAS}

Durante a mastigação de uvas passas, notou-se que os voluntários tratados apresentaram atividade eletromiográfica maior para todos os músculos em relação ao grupo controle. Além disso, o grupo com esquizofrenia apresentou maior atividade nos músculos masseteres que o grupo com transtornos do humor, porém, nos músculos temporais a maior atividade ocorreu no grupo com transtornos do humor. Contudo, apenas para a análise da atividade eletromiográfica do músculo masseter esquerdo houve diferença estatísticamente significante entre os grupos (Figura 13 e Tabela 12).

\section{Mastigação Uva}

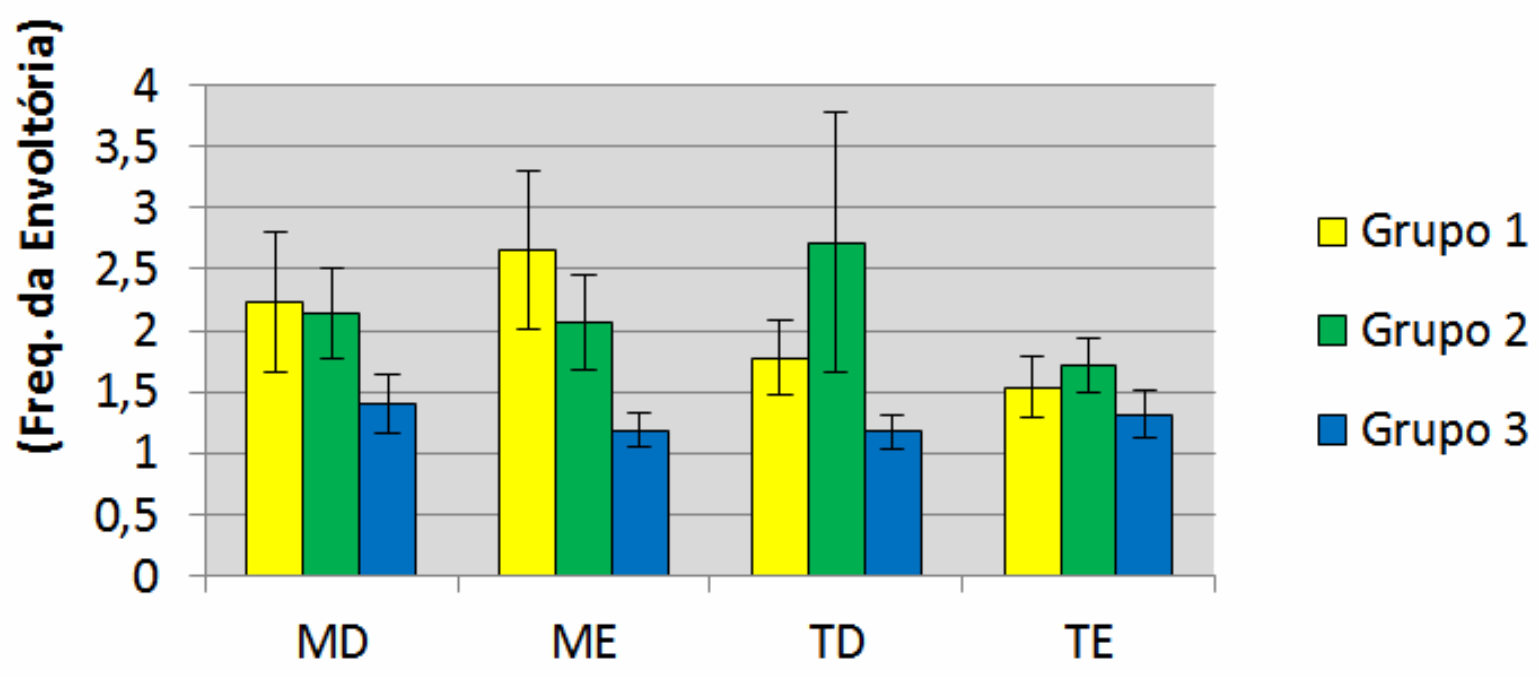

\section{Músculos}

Figura 13. Valores médios eletromiográficos normalizados dos músculos masseter direito (MD) e esquerdo (ME), temporal direito (TD) e esquerdo (TE) nos três grupos analisados, para a a atividade dinâmica de mastigação habitual de uvas passas. 
Tabela 12. Médias eletromiográficas normalizadas $(S)$ e erro-padrão dos músculos masseter direito (MD), masseter esquerdo (ME), temporal direito (TD) e temporal esquerdo (TE) dos três grupos durante a atividade dinâmica de mastigação habitual de uvas passas.

\begin{tabular}{cccccc}
\hline Regióes & $\begin{array}{c}\text { Grupos de } \\
\text { Indivíduos }\end{array}$ & No & Média & Erro Padrão & Sig. \\
\hline \multirow{3}{*}{ Masseter Direito } & Grupo 1 & 20 & 2,23 & $\pm 0,57$ & \\
& Grupo 2 & 20 & 2,14 & $\pm 0,37$ & n.s. \\
& Grupo 3 & 40 & 1,41 & $\pm 0,24$ & \\
\hline \multirow{3}{*}{ Masseter Esquerdo } & Grupo 1 & 20 & 2,66 & $\pm 0,64$ & \\
& Grupo 2 & 20 & 2,07 & $\pm 0,39$ & $*$ \\
& Grupo 3 & 40 & 1,19 & $\pm 0,14$ & \\
\hline \multirow{3}{*}{ Temporal Direito } & Grupo 1 & 20 & 1,78 & $\pm 0,30$ & \\
& Grupo 2 & 20 & 2,72 & $\pm 1,06$ & n.s. \\
& Grupo 3 & 40 & 1,18 & $\pm 0,14$ & \\
\hline \multirow{2}{*}{ Temporal Esquerdo } & Grupo 1 & 20 & 1,54 & $\pm 0,25$ & \\
& Grupo 2 & 20 & 1,71 & $\pm 0,22$ & n.s. \\
& Grupo 3 & 40 & 1,32 & $\pm 0,19$ & \\
\hline
\end{tabular}

*Significativo para $p<0,05$

$* *$ Significativo para $\mathrm{p}<0,01$

n.s. = diferença entre grupos não significante 


\section{MASTI GAÇÃO DE PARAFI LME}

Durante a mastigação de parafilme, houve maior atividade eletromiográfica de todos os músculos dos voluntários tratados quando comparados com o grupo controle. Houve maior atividade do grupo com transtornos do humor para todos os músculos, exceto para o temporal esquerdo, em relação ao grupo com esquizofrenia que se apresentou maior e, para o músculo masseter direito que apresentou a mesma atividade para os dois grupos. Porém, todas as diferenças não se apresentaram estatisticamente significantes (Figura 14 e Tabela 13).

\section{Mastigação Parafilme}

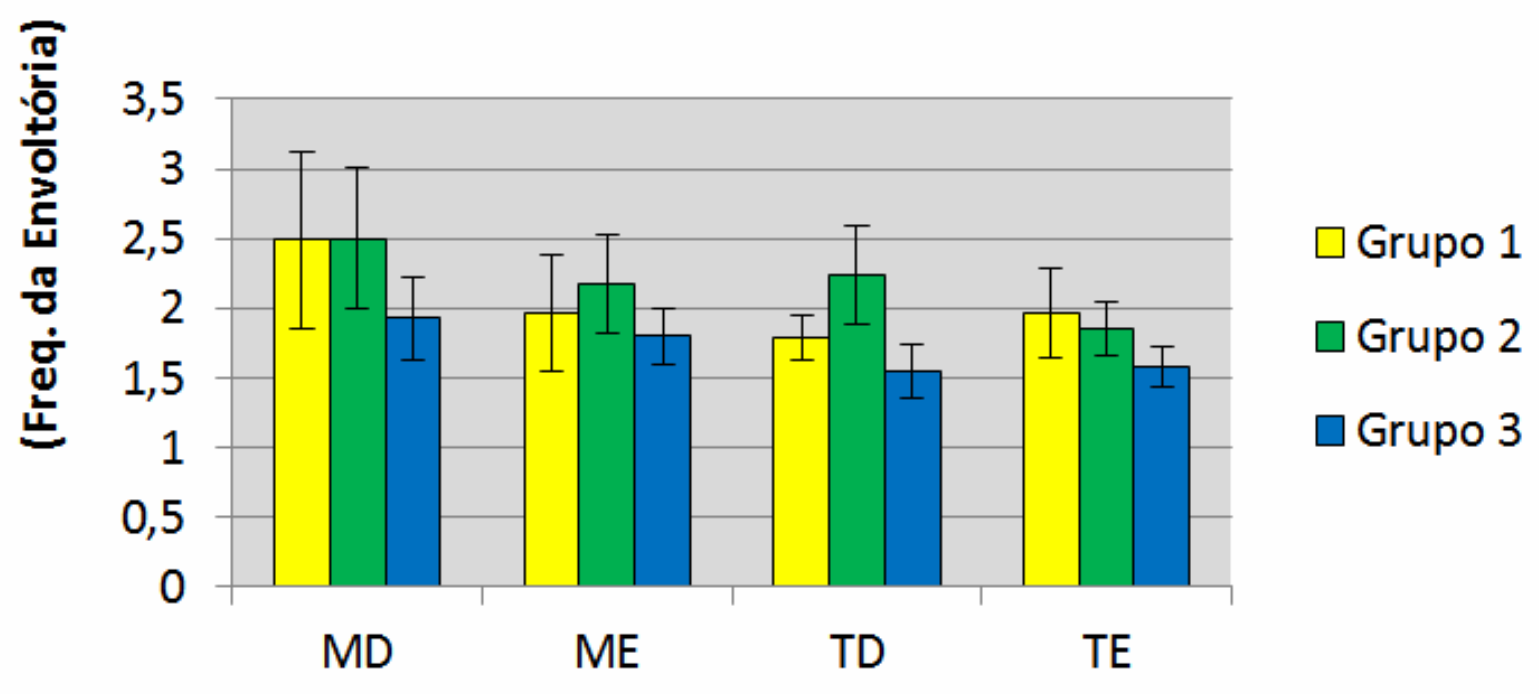

\section{Músculos}

Figura 14. Valores médios eletromiográficos normalizados dos músculos masseter direito (MD) e esquerdo (ME), temporal direito (TD) e esquerdo (TE) nos três grupos analisados, para a a atividade dinâmica de mastigação não habitual de parafilme. 
Tabela 13. Médias eletromiográficas normalizadas $(S)$ e erro-padrão dos músculos masseter direito (MD), masseter esquerdo (ME), temporal direito (TD) e temporal esquerdo (TE) dos três grupos durante a atividade dinâmica de mastigação não habitual de parafilme.

\begin{tabular}{cccccc}
\hline Regióes & $\begin{array}{c}\text { Grupos de } \\
\text { Indivíduos }\end{array}$ & No & Média & Erro Padrão & Sig. \\
\hline \multirow{3}{*}{ Masseter Direito } & Grupo 1 & 20 & 2,49 & $\pm 0,63$ & \\
& Grupo 2 & 20 & 2,50 & $\pm 0,51$ & n.s. \\
& Grupo 3 & 40 & 1,93 & $\pm 0,30$ & \\
\hline \multirow{3}{*}{ Masseter Esquerdo } & Grupo 1 & 20 & 1,97 & $\pm 0,42$ & \\
& Grupo 2 & 20 & 2,17 & $\pm 0,35$ & n.s. \\
& Grupo 3 & 40 & 1,80 & $\pm 0,20$ & \\
\hline \multirow{3}{*}{ Temporal Direito } & Grupo 1 & 20 & 1,79 & $\pm 0,16$ & \\
& Grupo 2 & 20 & 2,24 & $\pm 0,36$ & n.s. \\
& Grupo 3 & 40 & 1,55 & $\pm 0,19$ & \\
\hline \multirow{3}{*}{ Temporal Esquerdo } & Grupo 1 & 20 & 1,97 & $\pm 0,32$ & \\
& Grupo 2 & 20 & 1,85 & $\pm 0,19$ & n.s. \\
& Grupo 3 & 40 & 1,58 & $\pm 0,15$ & \\
\hline
\end{tabular}

*Significativo para $\mathrm{p}<0,05$

$* *$ Significativo para $\mathrm{p}<0,01$

n.s. = diferença entre grupos não significante 


\section{FORÇA DE MORDI DA}

A análise da força de mordida máxima revelou que o grupo controle apresenta maior força em KGF em relação aos grupos tratados. E, entre os grupos tratados, o grupo com transtornos do humor apresenta menor força que o grupo com esquizofrenia (Figura 15 e Tabela 14).

\section{Força de Mordida}

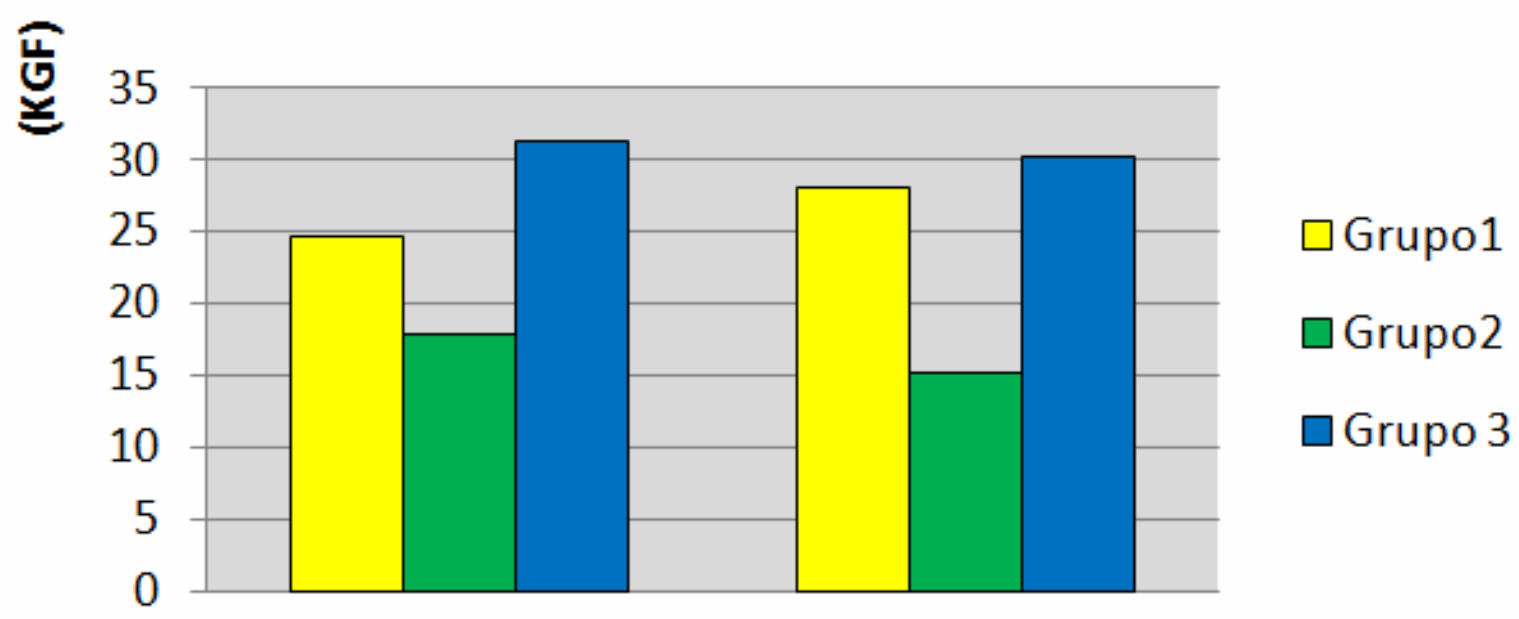

Molar D

Molar E

Figura 15. Força de mordida máxima em região de primeiros molares (valores em KGF).

Tabela 14. Médias das forças de mordida em região de primeiros molares.

\begin{tabular}{ccccc}
\hline Músculos & $\begin{array}{c}\text { Grupos de } \\
\text { Indivíduos }\end{array}$ & No & Média & Sig. \\
\hline \multirow{3}{*}{ Molar Direito } & Grupo 1 & 20 & 24,61 & $*$ \\
& Grupo 2 & 20 & 17,93 & $*$ \\
& Grupo 3 & 40 & 31,34 & $*$ \\
\hline \multirow{3}{*}{ Molar Esquerdo } & Grupo 1 & 20 & 28,01 & $*$ \\
& Grupo 2 & 20 & 15,21 & $*$ \\
& Grupo 3 & 40 & 30,27 & $*$ \\
\hline
\end{tabular}

*Significativo para $\mathrm{p}<0,05$ 
6. DiscusSÃo 


\section{DisCUSSÃo}

Milhões de pessoas sofrem com algum tipo de doença mental no mundo e este número está aumentando progressivamente, principalmente nos países em desenvolvimento, pelo acesso da população aos tratamentos psiquiátricos. Casos tais como ansiedade e depressão apresentam-se com taxas de elevada frequência na população adulta com mais de 65 anos, com prevalência de transtornos mentais comuns em torno de $24,95 \%$, no entanto, destacam-se indivíduos do sexo feminino que apresentam baixa escolaridade e renda per capita (Maragno et al., 2006).

Um dos estudos mais interessantes e completos realizados pela Organização Mundial de Saúde/OMS (Mental Illness in General Health Care) sobre a freqüência de doenças psicológicas evidencia que $34 \%$ de todas as consultas médicas em todo o mundo estão relacionadas a indivíduos portadores de problemas mentais, sendo os mais freqüentes a depressão, a ansiedade, desordens relacionadas ao álcool, sintomas inexplicáveis (desordens somatoformes) e neurastenia. As desabilidades (ou incapacidades, temporárias ou permanentes) para a vida normal são maiores neste grupo de indivíduos do que nos pacientes portadores de doenças crônicas ditas "clássicas", tais como a hipertensão arterial, o diabetes mellitus, a artrite e a lombalgia.

A maioria dos profissionais de saúde: médicos, psicólogos, fonoaudiólogos e dentistas, embora reconheçam a elevada prevalência dos distúrbios psiquiátricos não tem sido adequadamente preparada para os cuidados globais com indivíduos que apresentam desordens mentais. Neste aspecto, destaca-se a questão da falta de conhecimento por parte dos dentistas (e dos médicos) sobre os efeitos dos transtornos mentais e da medicação utilizada para controlar estas doenças na fisiologia do sistema estomatognático, seja nas condições posturais da mandíbula ou nos movimentos mastigatórios desenvolvidos e, conseqüentemente, de suas possíveis repercussões sistêmicas. Como conseqüência de 
alterações no sistema estomatognático, principalmente na cavidade bucal, há redução na quantidade dos alimentos ingeridos, assim como uma preferência por alimentos de textura macia, o que propicia a instalação do desequilíbrio nos fenômenos da nutrição (Galo et al., 2006).

Os portadores de transtornos mentais e comportamentais na sua grande maioria apresentam comprometimento intelectual e motor e requerem assistência temporária ou definitiva (Elias, 1995). As doenças bucais mais prevalentes nestes indivíduos são a cárie e prioritariamente a doença periodontal (Velasco et al., 1997; Whyma et al., 1995), sendo esta última decorrente de problemas de ordem local e/ou geral, podendo também estar modulada, pela utilização rotineira de medicamentos psicoativos, entre eles, os anticonvulsivantes.

Com o avanço da investigação científica na área da psiconeuroimunologia, foi constatada a influência da imunossupressão relacionada ao estresse e à ansiedade na vulnerabilidade orgânica do hospedeiro às doenças em geral, particularmente a periodontal (Monteiro da Silva et al., 1996; Linden et al., 1996; Moss et al., 1996). Destaque-se, ainda, em relação a esses indivíduos especiais, a utilização rotineira de medicamentos psicoativos, que não só provocam a redução no volume do fluxo salivar, fundamental na manutenção da homeostasia do meio bucal, fato este há muito já descrito na literatura (Campbell, 1945; O'Donnell; Cohen, 1984), como também afetam a sua coordenação motora, dificultando sobremaneira a higienização da cavidade bucal (Whyman et al., 1995).

A saúde bucal desses indivíduos, independente do modelo assistencial psiquiátrico ao qual estão submetidos, deve ser avaliada criteriosa e periodicamente, haja vista que a condição bucal interfere na saúde mental. As perspectivas futuras do programas de saúde bucal que estão sendo implementados apontam para a possibilidade e necessidade da atenção odontológica vir a ser rotina no contexto assistencial à saúde mental, considerandose não apenas as peculiaridades desta população especial, como uma opção de tratamento 
para indivíduos com patologias mentais específicas, sendo necessário cada vez mais conhecimentos específicos na área da saúde bucal e do sistema estomatognático como um todo.

Em meio à escassez de pesquisas na literatura referente ao tema estudado, e com o objetivo de melhor conhecer as características morfofuncionais da musculatura da mastigação analisou-se neste trabalho o comportamento funcional dos músculos masseter e temporal, por meio da eletromiografia, da força de mordida e da eficiência mastigatória em voluntários tratados com antipsicóticos e antidepressivos, mais precisamente, em voluntários com esquizofrina e transtornos do humor e, compararam-se os resultados obtidos com dados de voluntários não portadores destas patologias.

Todos os medicamentos produzem efeitos secundários e a medicação prescrita em casos de esquizofrenia não é exceção. Os efeitos secundários nem sempre são evidentes e são de menor gravidade que os próprios sintomas da esquizofrenia, devendo sempre ser avaliada a questão custo-benefício. Os efeitos colaterais mais comuns são a sonolência, movimentos ou posturas involuntárias (tremor das mãos, flexões ou fixações dos músculos), boca ou os músculos da face numa postura entranha (boca aberta ou semi-aberta), língua forçada para um lado (dificulta a fala ou faz com que a saliva escorra da boca), visão borrada, secura da boca, retenção urinária, hipotensão arterial, acatisia (inquietação constante, o indivíduo é incapaz de sentar-se no mesmo lugar durante muito tempo) (Kane, 1996; Akiskal, 2000a; Akiskal, 2000; Gotilib; Nolan, 2000; Coryell et al., 1992b; Rice et al., 1992; Sands; Harrow, 2000).

Tendo em vista os efeitos que podem acometer a musculatura da cabeça e pescoço em portadores de esquizofrenia, estudos tornam-se necessários para sua maior compreenção.

Sabe-se que a avaliação da atividade mioelétrica dos músculos da mastigação por meio da eletromiografia torna-se cada vez mais útil ao cirurgião-dentista, por contribuir para 
o conhecimento do desempenho destes músculos em situação de repouso mandibular, nos movimentos dos reflexos reguladores e nas mudanças do padrão muscular. Além disso, a análise eletromiográfica é um meio de avaliação, assim como de acompanhamento de tratamento (Regalo et al., 2003; Santos, 2005). A eletromiografia, como método de estudo tem sido bastante utilizada para elucidar o desempenho da musculatura mastigatória nos processos fisiológicos da mastigação, deglutição, oclusão e fonação, onde se destacam os trabalhos de Tulley (1953), Cadenat et al. (1972), Vitti et al. (1975); Lowe; Johnston (1979), Tosello et al. (1998), Silva (2000), Regalo et al. (2003), Santos (2005), Galo et al. (2006), Zuccolotto et al. (2007). No presente trabalho, utilizou-se a análise eletromiográfica como metodologia para a avaliação do desempenho da atividade muscular mastigatória em diferentes condições clínicas, frente às alterações musculares resultantes do tratamento com medicações antidepressivas e antipsicóticas.

Os músculos da mastigação estão diretamente relacionados às posições posturais e de movimentação da mandíbula. Na posição de repouso a mandíbula está suspensa involuntariamente por coordenação recíproca dos músculos da mastigação e por músculos abaixadores da mandíbula, posição essa considerada neutra da mandíbula (Zuccolotto et al., 2007). Nessa condição de repouso os músculos se apresentam com tônus neuromuscular, ou seja, apresentam um estado de resistência passiva ao estiramento das fibras, como conseqüência, os estímulos chegam às suas unidades motoras (fibra nervosa e fibra muscular) que se excita de forma alternada para evitar a fadiga. Isto ocorre por meio de reflexos miotáticos inconscientes e automáticos, mantendo a mandíbula em posição antigravitacional (Rancan et al., 2009). Não se pode afirmar que os músculos estejam inativos nessa posição já que o tônus neuromuscular é um dos principais modeladores de crescimento ósseo, atuando assim de maneira decisiva na modelação e remodelação óssea (Simões, 2003), porém o silêncio eletromiográfico apresenta-se característico nesta posição relaxada (Sgobbi de Faria; Bérzin, 1998; Voudouris; Kuftinic, 2000; Regalo et al., 2006b). 
Os fusos neuromusculares são proprioceptores com terminações sensitivas e motoras próprias, presentes em grande quantidade nos músculos elevadores da mandíbula (Houssay, 1966; Kawamura, 1974; Simões, 2003). Estes captam estímulos locais, do próprio músculo e do sistema nervoso central, controlando os baixos níveis de atividade dos músculos da mastigação durante o repouso e, qualquer alteração no equilíbrio facial, causa mudanças na tensão muscular (Harper et al., 1997).

Analisando os resultados desse trabalho observou-se que nos voluntários que faziam uso dos medicamentos (Grupos 1 e 2) a atividade eletromiográfica na condição clínica de repouso ficou bem mais elevada quando comparada com os voluntários do Grupo 3 (grupo controle), principalmente para os músculos temporais direito e esquerdo. Este dado evidencia que o uso da medicação, associada ao quadro clínico dos voluntários, interferiu no padrão de atuação e relaxamento da musculatura mastigatória. Sabe-se que indivíduos portadores de disfunções musculares (Santos et al., 2008) apresentam atividade eletromiográfica aumentada durante o repouso, o que foi evidenciado nos resultados obtidos com os voluntários usuários de medicamentos antidepressivos e antipsicótiocos, onde verificou-se maior instabilidade da atividade muscular evidenciando que eles têm uma grande tendência à contração muscular em posição estática de equilíbrio. De acordo com Liu et al. (1999) e Pinho et al. (2000), a atividade eletromiográfica dos músculos da mastigação em repouso é maior nos indivíduos com disfunções do sistema estomatognático quando comparada com indivíduos saudáveis, o que indica um aumento do tônus basal da musculatura.

Sgobbi de Faria e Bérzin (1998) consideraram a eletromiografia como um método adequado para avaliar a posição de repouso mandibular, observando sempre a necessidade de manter de forma correta o posicionamento da cabeça e do voluntário, assim como um ambiente calmo e silencioso durante o exame eletromiográfico, protocolo este que foi 
executado na coleta de dados dos exames eletromiográficos do repouso, e todas as demais condições, nesta pesquisa.

Durante a movimentação lateral da mandíbula sabe-se que ocorre um padrão de ativação muscular neuroanatômica em que deve ocorrer maior atividade eletromiográfica do músculo temporal do lado em que está ocorrendo à excursão da mandíbula (lado de trabalho), enquanto que para o músculo masseter, o lado mais ativado é o contra-lateral (Santos et al., 2008). Na manutenção do movimento de lateralidade direita os voluntários dos Grupos 1 e 2 apresentaram atividade eletromiográfica maior que o Grupo 3, sendo que os voluntários do Grupo 2 apresentaram valores maiores que os voluntários do Grupo 1. Com relação ao padrão de normalidade do movimento, somente o Grupo 2 e o controle (Grupo 3) mantiveram o músculo temporal direito mais ativo que o temporal esquerdo e o músculo masseter esquerdo mais ativo do que o direito. No Grupo 1, dos voluntários com esquizofrenia, os mesmos não conseguiram manter os padrões de normalidade para a execução deste movimento, o músculo temporal esquerdo foi o mais ativo e os masseteres apresentaram valores semelhantes de ativação. Já no movimento de lateralidade esquerda, apesar dos valores encontrados para os voluntários dos grupos tratados serem maiores que nos voluntários do Grupo 3 (controle), houve uma exceção com relação aos achados para o músculo masseter direito, ou seja, os voluntários do Grupo 1 apresentaram valores menores em relação aos voluntários do Grupo 3, e ainda, os voluntários do Grupo 2 apresentaram todos seus valores maiores quando comparados aos valores encontrados para os voluntários do Grupo 1. Com relação aos padrões de normalidade, verificou-se somente que os voluntários do Grupo 3, controle, mantiveram o músculo temporal esquerdo mais ativo que o direito, assim como o músculo masseter direito mais ativo que o esquerdo, o que era esperado neste movimento excursivo da mandíbula.

Para a condição clínica de protrusão, o padrão de contração eletromiográfica esperado para a manutenção desta postura consiste em maior ativação da musculatura 
massetérica quando comparada com a atividade da musculatura temporal (Santos et al., 2008). Observou-se que os indivíduos pertencentes aos grupos tratados (Grupo 1 e 2) apresentaram valores maiores para todos os músculos se comparados aos resultados encontrados nos indivíduos do Grupo 3, no entanto, entre os grupos tratados, os resultados encontrados nos indivíduos do Grupo 2 apresentaram valores menores que os encontrados nos indivíduos do Grupo 1 para a atividade do músculo temporal direito. Cumpre ressaltar que somente os Grupos 2 e 3 apresentaram o padrão de ativação muscular esperado para esta atividade de postura, com os masseteres mais ativos que os temporais. Nota-se, entretanto, que para o Grupo 2 não há um equilíbrio muscular entre os lados direito e esquerdo.

A máxima atividade eletromiográfica dos músculos masseter e temporal foi observada durante o apertamento dental em indivíduos portadores de dentição completa e sem disfunções (Gibbs et al., 1984; Blanksma; van Eijden, 1995), resultados concordes aos desta pesquisa. Durante a manutenção da posição de apertamento dental com parafilme todos os três grupos apresentaram os masseteres mais ativos que os temporais, o que era esperado para esta condição clínica (Santos et al., 2008). Não houve diferença estatisticamente significante entre os grupos analisados, no entanto, para os voluntários do Grupo 2 (transtornos do humor) a atividade muscular foi maior para todos os músculos estudados exceto temporal esquerdo e a atividade muscular para os voluntários do Grupo 1 (esquizofrênico) foi menor se comparado ao Grupo 2 exceto a atividade do músculo temporal esquerdo.

A mastigação é um mecanismo complexo que ocorre por integração da ação motora e neurofisiológica, com atuação da interação de receptores e nervos, que atuam sobre músculos e ossos de todo o sistema estomatognático. Os movimentos mastigatórios evoluem gradativamente com os estímulos recebidos pelos proprioceptores do periodonto e das articulações temporomandibulares, assim como o desenvolvimento do sentido de tato nas 
regiões de língua e mucosas (Galo et al.,2006). É considerada o primeiro passo do processo digestório (Karkazis; Kossioni, 1997). Durante o processo mastigatório observa-se uma atividade neuromuscular integrada, onde ocorrem contração e relaxamento dos músculos mastigadores de forma sincrônica, coordenando os movimentos de fechamento, abertura, lateralidade e protrusão mandibular (Rancan et al., 2009). Mesmo sendo um ato necessário para a sobrevivência, é executado diariamente de forma automática e inconsciente. Os estímulos gerados pela força da mastigação são suficientes para provocar assimetria da face, caso seja realizada mastigação viciosa unilateral (Mizumori et al., 2003).

Na análise dos dados das atividades mastigatórias habituais executadas neste estudo, observou-se que não houve diferenças estatisticamente significantes na comparação dos grupos estudados na mastigação de amendoim, um alimento considerado de textura consistente (duro), apesar dos valores relacionados à atividade muscular serem maiores nos indivíduos dos grupos tratados se comparados aos indivíduos do grupo controle. No entanto, mesmo sem significância estatística, observou-se aumento na atividade muscular de todos os músculos analisados para os voluntários dos grupos tratados comparados com o grupo controle (Grupo 3) e verificou-se maior ativação muscular mastigatória para o Grupo 2 se comparado com os voluntários do Grupo 1. Já para a mastigação de uvas passas, um alimento considerado de textura macia, os grupos tratados também apresentaram maior ativação eletromiográfica em todos os músculos para exercerem a atividade mastigatória, entretanto ocorreu diferença estatisticamente significante entre os grupos apenas para a atividade muscular do músculo masseter esquerdo.

A mastigação não-habitual de parafilme é um movimento padronizado em que se consegue eliminar alguns fatores de interferência que atuam durante a mastigação, tais como lado preferencial de mastigação, deglutição entre os ciclos mastigatórios, freqüência de mastigação, textura do alimento, o que permite a análise do movimento mastigatório de forma padronizada. Nesta pesquisa, na condição clínica de mastigação não-habitual com 
parafilme, verificou-se o aumento da atividade eletromiográfica de todos os músculos analisados, embora os valores não tenham sido estatisticamente significativos.

Tanto no apertamento de parafilme quanto na mastigação do mesmo, não houve diferença estatisticamente significante entre os grupos, no entanto, comparando os resultados entre os grupos tratados com os do grupo controle observou-se que os indivíduos dos grupos tratados durante a mastigação de parafilme, apresentaram maior atividade eletromiográfica em todos os músculos estudados e que houve maior atividade de todos os músculos analisados dos indivíduos do grupo com transtornos do humor exceto para o temporal esquerdo quando comparado aos indivíduos com esquizofrenia, exceto para o músculo temporal esquerdo que se apresentou maior e, para o músculo masseter direito que apresentou a mesma atividade para os dois grupos.

No que se refere à força de mordida, verificou-se que os indivíduos do grupo tratado apresentaram menor força de mordida quando comparado aos indivíduos do grupo controle, e tais resultados foram estatisticamente significantes. Assim, como foram estatísticamente significantes os resultados entre os grupos tratados, foi possível observar que a força de mordida foi maior nos indivíduos do Grupo 1 (esquizofrênicos) quando comparados ao Grupo 2 (transtornos do humor) ou seja, os indivíduos esquizofrênicos apresentam maior força de mordida na região dos primeiros molares que os, com transtornos do humor.

Apesar de poucos, os trabalhos encontrados na literatura relatam a relação entre disfunção temporomandibular (DTM), bruxismo e pacientes com doenças mentais (Selaimen et al., 2007; Gungormus; Erciyas, 2009; Rollman; Gillespie, 2000). Segundo Velasco-Ortega et al., 2005, 32\% dos indivíduos esquizofrênicos apresentam sintomas de disfunções temporomandibulares.

Ao longo das últimas décadas, está ocorrendo aumento gradual da expectativa de vida da população em geral. No Brasil, a expectativa de vida passou de 43,2 anos (em 1950), para 64 anos (na década de 1990), com estimativa de atingir os 70 anos por volta de 
2025 (Instituto Brasileiro de Geografia e Estatística. IBGE. Pesquisa Nacional por Amostragem Domiciliar. Brasília; 2001). Nas próximas décadas serão necessárias mudanças sérias na área de atendimento básico a saúde para suprir o atendimento desta gigantesca massa emergente de cidadãos portadores de problemas de ordem psicológica, com um enorme aumento de atenção e cuidados para a esfera de ação psiquiátrica. Os resultados dessas estimativas indicam que as doenças não contagiosas, dentre as quais, as doenças psiquiátricas, responderão por mais mortes precoces e incapacidades para o trabalho do que as doenças infecto-contagiosas e a subnutrição e desnutrição.

Em um futuro próximo, o atendimento odontológico em instituições psiquiátricas será desenvolvido rotineiramente, ressaltando que a equipe multiprofissional deverá contar com cirurgiões-dentistas capacitados, que conheçam as características e particularidades desses indivíduos, que requerem cuidados diferenciados e que constituem uma população de alto risco para disfunção do sistema mastigatório. Portanto torna-se imprescindível que a atenção à saúde mental nos seus diversos paradigmas deverá possibilitar a inserção do cirurgiãodentista na equipe multiprofissional que assiste estes indivíduos de modo a assegurar a integralidade não apenas da assistência como também do cuidado. A doença mental pode levar o cirurgião-dentista ao preconceito contra o paciente, proporcionando tratamento inadequado, principalmente por desconhecer os fatores que interferem direta e indiretamente na cavidade da boca e no sistema estomatognático destes pacientes. Assim, este trabalho abre perspectivas para outros projetos de investigação científica capazes de responder a todas as indagações e dúvidas daqueles que atendem esta população. 
"Um ditado chinês nos ensina que, quando duas pessoas negociam um cavalo, uma delas leva o animal. A outra, o dinheiro ou a mercadoria equivalente à troca. Quando trocam seus conhecimentos ou suas experiências, ambas ganham em dobro, pois cada uma delas leva para casa duas idéias."

\author{
Robert Wong \\ em O Sucesso está no Equilíbrio
}




\section{CONCLUSÕES}

De acordo com os resultados obtidos neste estudo é possível concluir:

1) Com relação a atividade eletromiográfica:

- observou-se aumento estatísticamente significante da atividade eletromiográfica dos músculos masseter e temporal (ambos os lados) nas condições de repouso, lateralidade direita e esquerda e protrusão dos grupos tratados quando comparado ao controle;

2) Com relação a força de mordida:

- a força de mordida molar máxima (direita e esquerda) manifestou-se maior no grupo controle quando comparado aos dois grupos tratados;

- a comparação entre os grupos tratados mostrou que a força de mordida molar máxima foi maior para o Grupo 1 (esquizofrênicos).

3) Com relação a eficiência mastigatória de amendoins, uva passa e parafilme

- não se encontrou significância estatística para esta análise, no entanto:

- a eficiência mastigatória, independente do alimento analisado, foi maior nos grupos tratados quando comparado ao grupo controle e

- maior para o Grupo 1 quando comparado ao Grupo 2

4) Os resultados eletromiográficos e de força de mordida sugerem que a combinação dos sinais e sintomas das doenças psiquiátricas - esquizofrenia e transtornos do humor - somado aos efeitos adversos provocados pelas medicações utilizadas em seus tratamentos possa resultar numa ativação de maior número de fibras musculares simultaneamente na tentativa de realizar os mesmos movimentos e posturas mandibulares que os voluntários sadios e sem medicação. 


\section{REFERÊNCIAS BI BLI OGRÁFICAS*}




\section{REFERÊNCI AS BI BLI OGRÁFI CAS}

1. Acierno SP, Baratta RV, Solomonow M. A pratical guide to eletromyography for biomechanists. Lousiana State University, 1995.

2. Addington DE, Addington JM. Attempted suicide and depression in schizophrenia. Acta Psychiatr Scand. 1992; 85:288.

3. Akiskal HS. In: Sadock BJ, Sadock VA, eds. Kaplan \& Sadock's Comprehensive Textbook of Psychiatry. $7^{\text {th }}$ ed. Vol I.Baltimore: Lippincott Williams \& Wilkins; 2000a:1284.

4. Akiskal HS. Dysthymia and cyclothymia in psychiatric practice a century after Kraepelin. J Affective Disorders. 2001; 62(1-2):17.

5. Akiskal HS. Mood disorder: clinical features. In: Sadock Bj, Sadock VA, eds. Kaplan \& Sadock's Comprehensive Textbook of Psychiatry. $7^{\text {th }}$ ed. Vol 1. Baltimore: Lippincott Williams \& Wilkins; 2000:1338.

6. Alajbeg IZ, Valentic-Peruzovic M, Alajbeg I, Illes D. Influence of occlusal stabilization splint on the asymmetric activity of masticatory muscles in patients with temporomandibular dysfunction. Coll Antropol. 2003 Jun;27(1):361-71.

7. Altmann EBC. Deglutição atípica. In: Fisioterapia, fonoaudiologia e terapia ocupacional em pediatria. São Paulo: Savier, 1990. p. 116-131.

8. American Psychiatric Association. Practice guidelines for the treatment of patients with schizophrenia. In: Practice Guidelines for the Treatment of Psychiatric Disorders: Compendium 2000. Washington, DC: American Psychiatric Association; 2000.

9. Ap Biasotto-Gonzalez D, Berzin F, Da Costa JM, De Gonzalez TO. Electromyographic study of stomatognathic system muscles during chewing of different materials. Electromyogr Clin Neurophysiol. Mar;50(2):121-7,2010.

10. Baldessarini RJ, Tondo L. Does lithium treatment still work? Evidence of stable responses over three decades. Arch Gen Psychiatry. 2000; 57:187.

11. Baldwin DS. Dysthymia: options in pharmacotherapy. In: Palmer KJ, ed.Managing Depressive Disorders. Kwai Chung, Hong Kong: Adis International Publications; 2000:157. 
12. Bates JF, Stafford GD, Harrison A. Masticatory function - a review of the literature. III. Masticatory performance and efficiency. J Oral Rehabil, v.3, n.1, p.57-67, 1976.

13. Bazzotti L. Electromyography tension and frequency spectrum analysis of some masticatory muscles at rest, isotonic and isometric contractions. Electromyogr Clin Neurophysiol., v.39, n.7, p.421-34, 1999.

14. Beasley CM Jr et al, J Clin Psychopharmacol. 2007 Dec;27(6):682-6

15. BECHELLI LPC. Impacto e evoluçäo do emprego dos neuropépticos no tratamento da esquizofrenia / Impact and evolution of the use of antipsychotic agents the tratment of schizophrenia. J. bras. psiquiatr;49(5):131-47, maio 2000.

16. Blanksma NG, van Eijden TM. Electromyographic heterogeneity in the human temporalis and masseter muscles during static biting, open/close excursions, and chewing. J Dent Res., v.74, p.1318-27, 1995.

17. Bogerst $B$, Lieberman JA, Ashtari $M$, et al. Hippocampus-amygdala volumes and psychopathology schizophrenia. Biol Psychiatry. 1993; 33:236.

18. Bonjardim LR, Gaviao MB, Pereira LJ, Castelo PM. Bite force determination in adolescents with and without temporomandibular dysfunction. J Oral Rehabil. 2005;32:577-83.

19. Breier A, Schreiber JL, Dyer J, Pickar D. National Institute of Mental Health longitudinal study of chronic schizophrenia: prognosis and predictors of outcome. Arch Gen Psychiatry. 1991; 48:239.

20. Brown T. Mandibular movements. Monogr Oral Sci., v.4, p.126-50, 1975.

21. Brunello N, Akiskal H, Boyer P, et al. Dysthymia: clinical picture, extent of overlap with chronic fatigue syndrome, neuropharmacological considerations, and new therapeutic vistas. J Affective Disorders. 1999;52(1-3):275.

22. Buzinelli RV, Berzin F. Electromyographic analysis of fatigue in temporalis and masseter muscles during continuous chewing. J Oral Rehabil.; v.28;n.12;p.1165-7;2001.

23. Cadenat H, Barthelemy R, Combelles R, Fabie M, Vincent JF. Electromyographic study of the orbicularis oris muscle in prognathism of the upper jaw. Rev Stomatol Chir Maxillofac; 73(2): 93-9, 1972 Mar.

24. Campbell DG. Psychosomatic mechanisms in oral disease. Am J Orthodontic Oral Surg, v. 31, n. 5, p. 440-446, May, 1945. 
25. Cancro R, Lehman HE. Schizophrenia: clinical features. In: Sadock BJ, Sadock VA, eds. Comprehensive Textbook of Psychiatry. $7^{\text {th }}$ ed. Baltimore: Lippincott Williams \& Wilkins; 2000.

26. Carapito SMM. Força de mordida no lado de preferência .2004. Dissertação de Mestrado apresentada à Universidade Federal de São Paulo - Escola Paulista de Medicina.

27. Carlsson GE. Masticatory efficiency: the effect of age, the loss of teeth and prosthetic rehabilitation. Int Dent J. 1984 Jun; 34(2):93-7.

28. Carney RM, Hong BA, O'Connell MF, Amado $\mathrm{H}$. Facial electromyography as a predictor of treatment outcome in depression. Br J Psychiatry; 138: 485-9, 1981 Jun.

29. Carone BJ, Harrow M, Westermeyer JF. Posthospital course and outcome in schizophrenia. Arch Gen Psychiatry. 1991; 48:247.

30. Coryell W, Endicott J, Keller M. Major depression in a nonclinical sample: demographic and clinical risk factors for first onset. Arch Gen Psychiatry. 1992a; 49:117.

31. Coryell W, Endicott J, Keller M. Rapid cycling affective disorder: demographics, diagnosis, family history, and course. Arch Gen Psychiatry. 1992b; 49:126.

32. Cram JR, Kasman GS, Holtz J. Introduction to Surface Electromyography. Ed. Gaithersburg, p. 257-258. Maryland: Aspen Publication @.1998.

33. Crocker AD, Hemsley KM. An animal model of extrapyramidal side effects induced by antipsychotic drugs: relationship with D2 dopamine receptor occupancy. Prog Neuropsychopharmacol Biol Psychiatry, 25 (3): 573-90, 2001.

34. Cunningham SL, Winkelman JW, Dorsey CM, Lukas SE, Richardson GS, Sholar MB, Hunt A. An electromyographic marker for neuroleptic-induced akathisia: preliminary measures of sensitivity and specificity. Clin Neuropharmacol, 19(4): 321-32, 1996.

35. Davey NJ, Puri BK, Lewis HS, Lewis SW, Ellaway PH. Effects of antipsychotic medication on electromyographic responses to transcranial magnetic stimulation of the motor cortex in schizophrenia. Journal of Neurology, Neurosurgery and Psychiatry, 63 (4): $468-73,1997$.

36. De Lima MS, Hotoph M, Wessely S. The efficacy of drug treatments for dysthymia: a systematic review and meta-analysis. Psychol Med. 1999;29(6):1273. 
37. De Luca C. The use of surface electromyography in biomechanics. J Appl. Biomech. 1997; 13: 135-163.

38. Elias R. Odontologia de alto risco: pacientes especiais. Rio de Janeiro: Revinter, 1995. 171p.

39. Elter JR, White BA, Gaynes BN, Bader JD. Relationship of clinical depression to periodontal treatment outcome. J. Periodontol, 73(4): 441-9, 2002.

40. Enlow DH. Crescimento facial. 3.ed. São Paulo: Artes Médicas, 1993.

41. Felício CM. Fonoaudiologia nas desordens temporomandibulares - uma ação educativa-terapeutica. São Paulo: Pancast, 1994. 179p.

42. Ferrario VF, et al. Relationship between the number of occlusal contacts and masticatory muscle activity in healthy young adults. J. Craniomand. Pract 2002; 20(2):91-98.

43. Flyckt L, Borg J, Borg K, Ansved T, Edman G, Bjerkenstedt L, Wiesel FA. Muscle biopsy, macro EMG, and clinical characteristics in patients with schizophrenia. Biological Psychiatry, 47 (11): $991-9,2000 b$.

44. Flyckt L, Wiesel FA, Borg J, Edman G, Ansved T, Sydow O, Borg K. Neuromuscular and psychomotor abnormalities in patients with schizophrenia and their first-degree relatives. Journal of Psychiatry Research, 34 (4-5): 355 - 64, 2000a.

45. Friedlander AH, Birch NJ. Dental conditions in patients with bipolar disorders on longterm lithium maintenance therapy. Spec Care Dentist, 10(5): 148-51, 1990.

46. Gabbard GO. Psychodynamic Psychiatry in Clinical Practice; The DSM-IV Edition. Washington, DC: American Psychiatric Press; 1994.

47. Gaertner I, Gaertner HJ, Vonthein R, Dietz K. Therapeutic drug monitoring of clozapine in retapse prevention. J Clin Pharmacol. 2001; 305:21.

48. Galo $R$, et al. The effect of age on the function of the masticatory system--an electromyographical analysis. Gerodontology, v. 23, n. 3, p. 177-182, sep. 2006.

49. George TP, Potenza MN, Degan K. Acute tryptophan depletion in schizophrenic patients treated with clozapine. Arch Gen Psychiatry. 2002; 291:59.

50. Gibbs $\mathrm{CH}$, Mahan PE, Wilkinson TM, Mauderli A. EMG activity of the superior belly of the lateral pterygoid muscle in relation to other jaw muscles. J Prosthet Dent. 1984 May;51(5):691-702. 
51. Gibbs $\mathrm{CH}$, Wickwire NA, Jacobson AP, Lundeen HC, Mahan PE, Lupkiewicz SM. Comparison of typical chewing patterns in normal children and adults. J Am Dent Assoc., v.105, n.1, p.33-42, 1982.

52. Gibbs $\mathrm{CH}$, Mahan PE, Wilkinson TM, Mauderli A. EMG activity of the superior belly of the lateral pterygoid muscle in relation to other jaw muscles. J. Prosthet. Dent., v.51, n.5, p.691-702, may. 1984.

53. Goff DC, Henderson DC, Amico E. Cigarette smoking in schizophrenia: relationships to psychopathology and medication side effects. Am J Psychiatry. 1992; 149:1189.

54. González R, Sifre S, Benedito J, Nogués V. Comparison of electromyographic pattern of sensory experts and untrained subjects during chewing of Mahon cheese. J Dairy Res., v.69, n.1, p.151-61, 2002.

55. Gotlib IH, Nolan SA. Depressive disorders. In: Hersen M, Bellack AS, ed. Psychopathology in Adulthood. $2^{\text {nd }}$ ed. Needham Heights, MA: Allyn \& Bacon; 2000:252.

56. Greden JF, Price HL, Genero N, Feinberg M, Levine S. Facial EMG activity levels predict treatment outcome in depression. Psychiatry Res; 13(4): 345-52, 1984 Dec.

57. Gungormus Z, Erciyas K. Evaluation of the relationship between anxiety and depression and bruxism. J Int Med Res; 37(2): 547-50, 2009.

58. Harper RP, Bruin $\mathrm{H}$, Burcea I. Muscle activity during mandibular movements in normal and mandibular retrognathic subjects. J. Oral Maxillofac. Surg., v. 55, n. 3, p. 225-233, 1997.

59. Harrison PJ. On the neuropathology of schizophrenia and its dementia: neurodevelopmental, neurodegenerative, or both? Neurodegeneration. 1995;4:1.

60. Hatch JP, Shinkai RSA, Sakai S, Rugh JD, Paunovich ED. Determinants of masticatory performance in dentate adults. Arch Oral Biol 2001; 46:641-648.

61. Helkimo E, Carlsson GE, Carmeli Y. Bite force in patients with functional disturbance of the masticatory system. J Oral Rehabil. 2:397-406, 1975.

62. Helkimo E, Carlsson GE, Helkimo M. Bite force and state of dentition. Acta Odontol Scand., v.35, n.6, p.297-303, 1977.

63. Hemsley KM, Crocker AD. Raclopride and chlorpromazine, but not clozapine, increase muscle rigid in the rat: relationship with D2 dopamine receptor occupancy. Neuropsychopharmacology, 21(1): 101-9, 1999. 
64. Henrikson T, Ekberg EC, Nilner M. Masticatory efficiency and ability in relation to occlusion and mandibular dysfunction in girls. Int J Prosthodont., v.11, n.2, p.125-32, 1998.

65. Hermens $H J$, Freriks $B$, Merletti R. European recommendations for surface electromyography - results of the SENIAM project. v. 8, 1999. p. 13-58.

66. Houssay AB. Nervous and hormonal control of the structure and I-131 uptake by the submaxillaries. Ala J Med Sci; 3(3): 312-24, 1966 Jul.

67. Jankelson RR. Scientific rationale for surface electromyography to measure postural tonicity in dental patients. Cranio 1990; 8:207-9.

68. Jofré J, Hamada $T$, Nishimura $M$, Klattenhoff $C$. The effect of maximum bite force on marginal bone loss of mini-implants supporting a mandibular overdenture: a randomized controlled trial. Clin Oral Implants Res. 2010 Feb;21(2):243-9.

69. Johnson SL, Hayes AM, et al., eds. Stress, Coping and Depression. Mahwah, NJ: Lawrence Erlbaum Associates; 2000:35.

70. Kane JM. Schizophrenia. N Engl J Med. 1996; 334:34.

71. Kaplan HI, Grebb JA, Sadock BJ, Sadock VA. Compêndio de Psiquiatria. Artmed. 9a ed., p.507- 541, 2007a

72. Kaplan HI, Grebb JA, Sadock BJ, Sadock VA. Compêndio de Psiquiatria. Artmed. 9a ed., p.572:629, 2007b

73. Kapur S, Remington G. Serotonin-dopamine interaction and its relevance to schizophrenia. Am J Psychiatry. 1996; 153:466.

74. Karkazis HC, Kossioni AE. Re-examination of the surface EMG activity of the masseter muscle in young adults during chewing of two test foods. J Oral Rehabil.v.24(3),p.216-23,1997.

75. Kashiwagi K, Tanaka M, Kawazoe T, Furuichi K, Takada H. Effect of amplitude normalization on surface EMG linear envelopes of masticatory muscles during gum chewing. J Osaka Dent Univ., v.29, n.1, p.19-28, 1995.

76. Kawamura Y. Neurogenesis of mastication. In:_., Physiology of mastication. Front. Oral Physiol. Basel: S Karger, 1974, v.1, p.77-120. 
77. Keck PE Jr, Nabulsi AA, Taylor JL, et al. A pharmacoeconomic model of divalproex vs. lithium in the acute and prophylactic treatment of bipolar I disorder. J Clin Psychiatry. 1996; 57:213.

78. Kendler KS, Diehl SR. The genetics of schizophrenia: a current, genetic-epidemiologic perspective. Schizophr Bull. 1993; 19:261.

79. Kiliaridis S. Effects of fatigue and chewing training on maximal bite force end endurance. Am J Orthod Dentofac Orthop., v.107, n.4, p. 372-378, 1995.

80. Kinon BJ, Lieberman JA. Mechanisms of action of atypical antipsychotic drugs: a critical analysis. Psychopharmacology. 1996:124:2.

81. Klasser GD, Okeson JP. The clinical usefulness of surface electromyography in the diagnosis and treatment of temporomandibular disorders. J Am Dent Assoc. 2006 Jun;137(6):763-71.

82. Koc D, Dogan A, Bek B. Bite force and influential factors on bite force measurements: a literature review. Eur J Dent. 2010 Apr;4(2):223-32.

83. Kogawa EM, Calderon PS, Lauris JRP, Araujo CRP, Conti PCR. Evaluation of maximal bite force in mandibular disorders patients. J Oral Rehabil. 2006; 33:559-565.

84. Kurth LE. Mandibular movements in mastication. J Am Dent Assoc., v.29, p.17-69, 1942.

85. Kurumaji A, Okubo Y. D1 dopamine receptors, schizophrenia, and antipsychotic medications. In: Lidow MS, ed. Neurotransmitter Receptors in Actions of Antipsychotic Medications. Pharmacology and Toxicology. Boca Raton, FL: CRC Press; 2000:65.

86. Leitão RJ, Ferraz MB, Chaves AC, Mari JJ. Cost of schizophrenia: direct costs and use of resources in the State of São Paulo. Rev Saude Publica 40(2): 304-309, 2006; epub, Mar 29th 2006.

87. Limpert C, Amador XF. Negative symptoms and the experience of emotion. In: Keefe RSE, McEvoy JP, eds. Negative Symptom and Cognitive Deficit Treatment Response in Schizophrenia. Washington, DC: American Psychiatric Press; 2001:111.

88. Linden $\mathrm{GL}$, Mullally BH, Freeman R. Stress and the progression of periodontal disease. J Clin Periodontol, Copenhagen, v. 23, n. 7, p. 675-680, Jul. 1996.

89. Linderholm $\mathrm{H}$, Wennström $\mathrm{A}$. Isometric bite force and its relation to general muscle force and body build. Acta Odontol Scand., v.28, n.5, p.678-689, nov.1970. 
90. Liu ZJ, Yamagata K, Kasahara Y, Ito G. Electromyographic examination of jaw muscles in relation to symptoms and occlusion of patients with temporomandibular joint disorders. J. Oral Rehab., v.26, n.1, p.33-47, 1999.

91. Lorenc-Koci E, Wolfarth S, Ossowska K. HALOPERIDOL - Increased muscle tone in rats as a model of parkinsonian rigidity. Exp Brain Res, 109(2): 268-76, 2003.

92. Lous I, Sheikholeslam A, Moller E. Postural activity in subjects with functional disorders of the chewing apparatus. Scan J Dent Res. 1970; 78 (4): 404-9.

93. Lowe $A A$, Johston WD. Tongue and jaw muscle activity in response to mandibular rotations in a sample of normal and anterior open bite subjects. Am J Orthod., St. Louis, v. 76, p. $565-76,1979$.

94. Lysaker PH, Bryson GJ, Bell MD. Insight and work performance in schizophrenia. J Nerv Ment Dis. 2002; 190:142.

95. MacKinnon DF, Zandi PP, Cooper J, et al. Comorbid bipolar disorder and panic disorder in families with a high prevalence of bipolar disorder. Am J Psychiatry. 2002; 159:30.

96. Maragno L, Goldbaum M, Gianini RJ, Novaes HMD, César CLG. Prevalência de transtornos mentais comuns em populações atendidas pelo Programa Saúde da Família (QUALIS) no Município de São Paulo, Brasil. Cad. Saúde Pública [online]. 2006, vol.22, n.8, pp. 1639-1648.

97. Marchese G, Casu MA, Bartholini F, Roiu S, Saba P, Gessa GL, Pani L. Sub-chronic treatment with classical but not atypical antiphsychotics produces morphological changes in rat nigro-striatel dopaminergic neurons directlyrelated to "early onset" vacuous chewing. Eur J Neurosc, 15(7): 1187-96, 2002.

98. Mari JJ, Leitão RJ. A epidemiologia da esquizofrenia. Rev. Bras. Psiquiatr. vol.22 s.1 São Paulo Maio. 2000.

99. Mattes RM, Schneider F, Heimann H, Birbaumer N. Reduced emotional response of schizophrenic patients in remission during social interaction. Schizophrenia Research, 17 (3): $249-55,1995$.

100. McNeill C. Ciência e prática da oclusão. Trad. AJG Perrotti. São Paulo: Quintessence; 2000.

101. Merletti R. The standards for reporting EMG data. J. Electromyogr. Kinesiol 1999; 9(1). 
102. Micheli F, Fernandez Pardal M, Gatto M, Asconape J, Giannaula R, Parera IC. Bruxism secondary to chronic antidopaminergic drug exposure. Clin Neuropharmacol, 16(4): 31523, 1993.

103. Michelotti A, Farella M, Vollaro S, Martina R. Mandibular rest position and electrical activity of the masticatory muscles. J Prosthet Dent; 78(1): 48-53, 1997 Jul.

104. Mioche L, Bourdiol P, Martin JF, Noel Y. Variations in human masseter and temporalis muscle activity related to food texture during free and side-imposed mastication. Arch Oral Biol. 1999;44:1005-12.

105. Mishellany-Dutour A, Renaud J, Peyron MA, Rimek F, Woda A. Is the goal of mastication reached in young dentates, aged dentates and aged denture wearers? $\mathrm{Br}$ J Nutr., v.99, n.1, p.121-8, 2008.

106. Mizumori T, Tsubakimoto T, Iwasaki M, Nakamura T. Masticatory laterality--evaluation and influence of food texture. J. Oral Rehabil., v.30, n.10, p.995-999, oct. 2003.

107. Mohamed SE, Christensen LV, Penchas J. A randomized double-blind clinical trial of the effect of amitriptyline on nocturnal masseteric motor activity (sleep bruxism). Cranio, 15 (4): $326-32,1997$.

108. Moldin SO. Gender and schizophrenia: an overview. In: Frank E, ed. Gender and its Effects on Psychopathology. Washington. DC: American Psychiatric Press; 2000:169.

109. Monteiro da Silva AM, et al. Psychossocial factors and adult onset rapidly progressive periodontitis. J Clin Periodontol, Copenhagen, v. 23, n. 9, p. 789-794, Aug. 1996.

110. Moss $\mathrm{ME}$, et al. Exploratory case control analysis of psychosocial factors and adult periodontitis. J Periodontol, Indianapolis, v. 67, n. 10 (Suppl.), p. 1060-1063, Oct. 1996.

111. Moyers RE. Temporomandibular muscle contraction patterns in angle class II, division I malocclusions: an electromyographic analysis. Am. J. Orthodont. 1949; 35: 837-857.

112. O'Donnell JP, Cohen MM. Dental care for institutionalized retarded individual. J Pedodon, Boston, v. 9, n. 1, p. 3-38, Jan. 1984.

113. Okiyama S, Ikebe K, Nokubi T. Association between masticatory performance and maximal occlusal force in young men. J Oral Rehabil. Mar;30(3):278-82, 2003.

114. Oliveira AS, Vitti M, Chaves TO, Teixeira VR, Grossi DB, Regalo SCH. Electromyographic amplitude variability of chewing cycles in deaf individuals. Electromyogr Clin Neurophysiol., v.46, n.5, p.269-73, 2006. 
115. Ono $Y$, Lin YF, Iijima $H$, Miwa Z, Shibata M. Masticatory training with chewinggum on young children. Kokubyo Gakkai Zashi., v.59, p.512-517, 1992.

116. Ow RK, Carlsson GE, Jemt T. Biting forces in patients with craniomandibular disorders. Cranio., v.7, n.2, p.119-125, apr.1989.

117. Palinkas M. Influência da idade e do gênero na força de mordida molar máxima e espessura dos músculos mastigatórios. 2010. Dissertação de Mestrado apresentada à Faculdade de Odontologia de Ribeirão Preto - Universidade Federal de São Paulo.

118. Papargyriou G, Kjellberg $\mathrm{H}$, Kiliaridis $\mathrm{S}$. Changes in masticatory mandibular movements in growing individuals: a six-year follow-up. Acta Odontol Scand., v.58, n.3, p.129-34, 2000.

119. Pedroni CR, De Oliveira AS, Guaratini MI. Prevalence study of signs and symptoms of temporomandibular disorders in university students. J Oral Rehabil. 2003 Mar;30(3):283-9.

120. Penn DL, Ritchie MF, Francis JC, Martin J. Social perception in schizophrenia: the role of context. Psychiatry Res. 2002; 109:149.

121. Pereira LJ, Steenks MH, de Wijer A, Speksnijder CM, van der Bilt A. Masticatory function in subacute TMD patients before and after treatment. J Oral Rehabil. 2009 Jun;36(6):391-402. Epub 2009 Feb 6.

122. Pereira LJ, Duarte Gaviao MB, van der Bilt A. Influence of oral characteristics and food products on masticatory function. Acta Odont Scand., v.64, n.4, p.193-201, aug.2006.

123. Peyron MA, Blanc O, Lund JP, Woda A. Influence of age on adaptability of human mastication. J Neurophysiol., v.92, n.2, p.773-9, 2004

124. Peyron MA, Woda A. Adaptation of mastication in response to the characteristics of the individual or the food. Orthod Fr., v.77, n.4, p.417-30, 2006.

125. Piancino MG, Farina D, Talpone F, Castroflorio T, Gassino G, Margarino V, Bracco P. Surface EMG of jaw-elevator muscles and chewing pattern incomplete denture wearers. J Oral Rehabil., v.32, n.12, p.863-870, dec.2005.

126. Piancino MG, Talpone F, Bole $T$, Castroflorio $T$, Torsello F, Debernardi C, Bracco P. Electromyographic evaluation of neuromuscular co-ordination during chewing in a subject with organic occlusion. Minerva Stomatol., v.54, n.6, p.379-87, 2005a. 
127. Pinho JC, Caldas FM, Mora MJ, Santana-Penin U. Electromyographic activity in patients with temporomandibular disorders. J. Oral Rehabil., v.27, n.11, p.985-990, 2000.

128. Prikhojan A, Davis KL. Dementia in Schizophrenia. In: Breier A, Tran PV, eds. Current Issues in the Psychopharmacology of Schizophrenia. Philadelphia: Lippincott Williams \& Wilkins; 2001:513.

129. Pröschel PA, Raum J. Preconditions for estimation of masticatory forces from dynamic EMG and isometric bite force-activity relations of elevator muscles. Int J Prosthodont. V.14(6),p.563-9,2001.

130. Raigrodski AJ, Christensen LV, Mohamed SE, Gardiner DM. The effect of four-week administration of amitriptyline on sleep bruxism. A double-blind crossover clinical study. Cranio, 19 (1): 21-5, 2001.

131. Ramfjord SP, Ash MM. Oclusão. 3.ed. Trad. DF Vieira. Rio de Janeiro: Interamericana Ltda, 1984.

132. Rancan SV, Bataglion C, Bataglion SA, Bechara OM, Semprini M, Siéssere S, Sousa JP, Crippa JA, Hallak JE, Regalo SC. Acupuncture and temporomandibular disorders: a 3month follow-up EMG study. J Altern Complement Med. 2009 Dec;15(12):1307-10.

133. Regalo SC, Santos CM, Vitti M, Regalo CA, de Vasconcelos PB, Mestriner W Jr, Semprini M, Dias FJ, Hallak JE, Siéssere S. Evaluation of molar and incisor bite force in indigenous compared with white population in Brazil. Arch Oral Biol. 2008 Mar;53(3):282-6.

134. Regalo SC, Vitti M, Hallak JE, Siéssere S, Pagnano VO, Semprini M. Electromyographic analysis of upper and lower fascicles of the orbicularis oris muscle in deaf individuals, in mandibular rest position, compared to hearers. Electromyogr Clin Neurophysiol. 2006a Jul-Aug;46(4):211-5.

135. Regalo SC, Vitti M, Semprini M, Rosa LB, Martinez FH, Santos CM, Hallak JE. Electromyographic analysis of the masseter and temporal muscles in oralized deaf individuals. Electromyog Clin Neurophysiol 2006b; 46(4):217-222.

136. Regalo SCH, Vitti M, Hallak JEC, Semprini M, Mattos MG, Tosello DO, Constancio RF, Pegoraro ME, Lopes RA. EMG analysis of the upper and lower fascicles of the orbicularis oris muscle in deaf individuals. Electromyogr Clin Neurophysiol. 43(6):367-72, 2003.

137. Rentes AM, Gaviao MB, Amaral JR. Bite force determination in children with primary dentition. J Oral Rehabil. $2002 ; 29: 1174-80$. 
138. Rice JP, Rochberg N, Endicott J, Lavori PW, Miller C. Stability of psychiatric diagnoses: an application to the affective disorder. Arch Gen Psychiatry. 1992;49:824.

139. Rilo B, Santana U, Mora MJ, Cadarso CM. Myoelectrical activity of clinical rest position and jaw muscle activity in young adults. J Oral Rehabil., v.24, n.10, p.735-40,1997.

140. Roldán S, Buschang PH, Isaza Saldarriaga JF, Throckmorton G. Reliability of maximum bite force measurements in age-varying populations. J Oral Rehabil. 2009 Nov;36(11):801-7. Epub 2009 Sep 15.

141. Rollman GB, Gillespie JM. The role of psychosocial factors in temporomandibular disorders. Curr Rev Pain; 4(1): 71-81,2000.

142. Ruf S, Cecere F, Kupfer J, Pancherz H. Stress-induced changes in the functional electromyographic activity of the masticatory muscles. Acta Odontol Scand 1997;55(1):44-8.

143. Sachs GS, Thase ME. Bipolar disorder therapeutics maintenance treatment. Biol Psychiatry. 2000; 48:573.

144. Sands JR, Harrow M. Bipolar disorder: psychopathology, biology, and diagnosis. In: Hersen M, Bellack AS, ed. Psychopatlhology in Adulthood. $2^{\text {nd }}$ ed. Needham Heights, MA: Allyn \& Bacon; 2000:326.

145. Santos CM, Vitti M, de Mattos Mda G, Semprini M, Paranhos H de F, Regalo SC. Electromyographic analysis of the upper and lower fascicles of the orbicular oris muscle, in edentulous patients, before and after complete denture implantation. Electromyogr Clin Neurophysiol. 2003 Jul-Aug;43(5):315-20.

146. Santos CM, Vitti M, Matsumoto W, Berro RJ, Semprini M, Hallak JEC, Galo R, Regalo SCH. Using overdenture on implants and complete dentures: Effects on postural maintenance of masticatory musculature. Brazilian Journal of Oral Science 7 (25) PP. 1550-1554, 2008.

147. Santos CM. O efeito dos hábitos de vida dos indígenas (aldeias do xingu) na atividade da musculatura do sistema estomatognático - análise eletromiográfica.2009. Tese de Doutorado apresentada à Faculdade de Odontologia de Ribeirão Preto - Universidade Federal de São Paulo.

148. Santos CM. Efeitos do uso de overdenture sobre implantes e de próteses totais na atividade eletromiográfica da musculatura da mastigação. 2005. Dissertação (Mestrado) Faculdade de Odontologia de Ribeirão Preto, Universidade de São Paulo, Ribeirão Preto. 
149. Selaimen C, Brilhante DP, Grossi, ML, Grossi, PK. Avaliação da depressão e de testes neuropsicológicos em pacientes com desordens temporomandibulares. Ciênc. Saúde Coletiva; 12(6): 1629-39. 2007.

150. Scelsa SN, Simpson DM, McQuistion HL, Fineman A, Ault K, Reichler B. Clozapine induced myotoxicity in patients with chronic psychotic disorders. Neurology, 47 (6): 1518-23, 1996.

151. Schimidt RF. Neurofisiologia. São Paulo: Editora Pedagógica e Universitária; 1979.

152. Sgobbi de Faria CRS, Bérzin F. Electromyographic study of the temporal, masseter and suprahyoid muscle in mandibular rest position. J Oral Rehabil., v.25, n.10, p.776780, 1998.

153. Sheikholeslam A, Møller E, Lous I. Pain, tenderness and strength of human mandibular elevators. Scand J Dent Res., v.88, n.1, p.60-66, feb.1980.

154. Sheldon HP, Christina YS, Ruth R. "Selective serotonin reuptake inhibitor": 242. in Sheldon H. Preskorn; Christina Y. Stanga, John P. Feighner, Ruth Ross (2004). "Antidepressants: Past, Present, and Future". Springer.

155. Shiau YY, Wang JS. The effects of dental condition on hand strength and maximum bite force. Cranio., v.11, n.1, p.48-54, jan.1993.

156. Silva AMT. Eletromiografia: avaliação dos músculos orbiculares da boca em crianças respiradoras bucais, pré e pós mioterapia. 2000. 133f. Tese (Doutorado em Distúrbios da Comunicação Humana) - Universidade de São Paulo, São Paulo.

157. Simões WA. Ortopedia funcional dos maxilares. 3 ed., São Paulo: Artes Médicas, 2003. 1024p.

158. Sjogren R, Nordstrom G. Oral health status of psychiatric patients. J Clin Nurs; 9(4): 632-8, 2000 Jul.

159. Sonnesen L, Bakke M, Solow B. Temporomandibular disorders in relation to craniofacial dimensions, head posture and bite force in children selected for orthodontic treatment. Eur J Orthod. 2001;23:179-92.

160. Sonnesen $L$, Bakke M. Bite force in children with unilateral crossbite before and after orthodontic treatment. A prospective longitudinal study. Eur J Orthod., v.29, n.3, p. 310313 , jun.2007. 
161. Stone MH. A cura da mente: a história da psiquiatria da Antiguidade até o presente. Porto Alegre: Artmed, 1999. 480 p.

162. Sullivan SOB, Schmitz TJ. Reabilitação Física - Avaliação e Tratamento. $2^{\text {a }}$ ed., Editora Marola, p. 183 -223, 1993.

163. Sweeney JA, Haas G, Nimgaonkar V. Schizophrenia: etiology. In: Hersen M, Bellack AS. Psychopathology in Adulthood. Needham Heights. MA: Allyn \& Bacon; 2000;278.

164. Thomas A, Lavrentzon E, Karouses C, Kontis C. Factors which influence the oral condition of chronic schizophrenia patients. Spec Care Dentist. 16(2): 84-6, 1996.

165. Thongudomporn U, Chongsuvivatwong V, Geater AF. The effect of maximum bite force on alveolar bone morphology. Orthod Craniofac Res. 2009 Feb;12(1):1-8.

166. Tomiyama N, Ichida T, Yamaguchi K. Electromyographic activity of lower lip muscles when chewing with the lips in contact and apart. Angle Orthod., v.74, n.1, p.31-6, 2004.

167. Tosello DO, Vitti M, Berzin F. EMG activity of the orbicularis oris and mentalis muscles in children with malocclusion, incompetent lips and atypical swallowing - part I. J Oral Rehabil. 1998; 25(11): 838-46.

168. Tsuga K, Carlsson GE, Osterberg T, Karlsson S. Self-assessed masticatory ability in relation to maximal bite force and dental state in 80 -year-old subjects. J Oral Rehabil., v.25, n.2, p.117-124, feb.1998.

169. Tulley WJ. Methods of recording patterns of behaviour of the orofacial muscles using the electromyography. Dent. Rec., 73: 741-748, 1953.

170. van der Bilt A. Human oral function: a review. Braz J Oral Sci April/June 2002. $1(1): 7-18$.

171. van der Bilt A, Olthoff LW, Bosman F, Oosterhaven SP. The effect of missing postcanine teeth on chewing performance in man. Arch Oral Biol., v.38, n.5, p.423-9, 1993.

172. Velasco $E$, et al. Dental health among institutionalized psychiatric patients in Spain. Spec Care Dentist, Chicago, v.17, n. 6, p. 203-206, June, 1997.

173. Velasco-Orterga E, Monsalve-Guil L, Velasco-Ponferrada C, Medel-Soteras R, SeguraEgea JJ. Temporomandibular disorder among schizophrenic patients. A case-control study. Med Oral Patol Oral Cir Bucal; 10(4): 315-22, 2005. 
174. Vianna-Lara MS, Caria PH, Tosello Dde O, Lara F, Amorim MM. Electromyographic activity of masseter and temporal muscles with different facial types. Angle Orthod. 2009 May;79(3):515-20.

175. Vitti M. Estudo eletromiográfico das ações conjugadas dos músculos mastigadores.[tese]. Piracicaba: UNICAMP/FOP; 1975.

176. Voudouris J C, Kuftinic MM. Improved clinical use of twin-block and herbst as a result of radiating viscoelastic tissue forces on the condyle and fossa in treatment and long term retention: growth relativity. Am. J. Orthod. Dentofacial Orthop., v. 117. n. 3, p. 247-266, 2000.

177. Watt DM. A preliminary investigation of the support of partial dentures and its relationship to vertical loads. Dent Prac Dent Record., v.9, p.2-15,1958.

178. Whyman RA, et al. The oral health of long-term residents of a hospital for the intellectually handicapped and psychiatrically ill. New Z Dent J, v. 91, n. 6, p. 49-56, June, 1995.

179. Wickwire NA, Gibbs $\mathrm{CH}$, Jacobson AP, Lundeen $\mathrm{HC}$. Chewing patterns in normal children. Angle Orthod., v.51, n.1, p.48-60 1981.

180. Yamashita S, Hatch JP, Rugh JD. Does chewing performance depend upon a specific masticatory pattern? J Oral Rehabil., v.26, n.7, p.547-53, 1999.

181. Yousefzadeh F, Shcherbatyy V, King GJ, Huang GJ, Liu ZJ. Cephalometric and electromyographic study of patients of East African ethnicity with and without anterior open bite. Am J Orthod Dentofacial Orthop. 2010 Feb;137(2):236-46.

182. Youssef RE, Throckmorton GS, Ellis E $3^{\text {rd }}$, Sinn DP. Comparison of habitual masticatory patterns in men and women using a custom computer program. J Prosthet Dent., v.78, n.2, p.179-86, 1997.

183. Zivko-Babic J, Panduric J, Jerolimov V, Mioc M, Pizeta L, Jakovac M. Bite force in subjects with complete dentition. Coll Antropol., v.26, p.293-302, 2002.

184. Zuccolotto MC, et al. Electromyographic evaluation of masseter and anterior temporalis muscles in rest position of edentulous patients with temporomandibular disorders, before and after using complete dentures with sliding plates. Gerodontology, v. 24, n. 2, p. 105-110, 2007. 